\title{
分子碘催化氧化 $\mathrm{C}\left(\mathrm{sp}^{3}\right)-\mathrm{H}$ 功能化反应的研究进展
}

\author{
张露文 何 炜* \\ (第四军医大学药学院 化学教研室 西安 710032)
}

\begin{abstract}
摘要 现代有机合成中, $\mathrm{C}-\mathrm{H}$ 功能化反应可以用于直接构建各种生物活性骨架以及增加目标分子结构的复杂性, 是对 传统合成方法的有效补充, 其中惰性 $\mathrm{C}\left(\mathrm{sp}^{3}\right)-\mathrm{H}$ 功能化长期以来是该领域的难点. 目前, 碘试剂已被确定为经济和生态 上无害的过渡金属替代品，在具有挑战性的 $\mathrm{C}\left(\mathrm{sp}^{3}\right)-\mathrm{H}$ 功能化反应中已经取得了卓有成效的进展. 分子碘与高价芳基 碘试剂、二甲基亚砜(DMSO)、过氧化物以及氧气等组合, 能够高效地催化不同反应类型的 $\mathrm{C}\left(\mathrm{sp}^{3}\right)-\mathrm{H}$ 功能化反应, 在 不同氧化体系下具有不同的反应特点和机制. 另外, 近年来, 过渡金属/分子碘协同催化以及含碘电化学催化等新型碘 催化体系在 $\mathrm{C}\left(\mathrm{sp}^{3}\right)-\mathrm{H}$ 功能化反应中也得到了前所未有的发展. 综述了 2015 年至今分子碘在不同氧化体系下催化的 $\mathrm{C}\left(\mathrm{sp}^{3}\right)$ - $\mathrm{H}$ 功能化反应, 希望能进一步了解分子碘的绿色催化体系, 为深入研究 $\mathrm{C}\left(\mathrm{sp}^{3}\right)$ - $\mathrm{H}$ 功能化反应提供帮助.

关键词 分子碘; $\mathrm{C}\left(\mathrm{sp}^{3}\right)$ - $\mathrm{H}$ 功能化; 氧化体系; 绿色化学; 电化学
\end{abstract}

\section{Research Progress in $\mathrm{C}\left(\mathrm{sp}^{3}\right)-\mathrm{H}$ Functionalization Reaction via Molecular lodine-Catalyzed Oxidation}

\author{
Zhang, Luwen He, Wei* \\ (Department of Chemistry, School of Pharmacy, The Fourth Military Medical University, Xi'an 710032)
}

\begin{abstract}
In modern organic synthesis, $\mathrm{C}-\mathrm{H}$ functionalization can be used to construct various bioactive skeletons quickly and directly, and increase the complexity of the target molecular structure, which becomes an effective supplement to the traditional methods. Among them, $\mathrm{C}\left(\mathrm{sp}^{3}\right)-\mathrm{H}$ functionalization has long been a big challenge in this field. Molecular iodine has been identified as an economically and ecologically harmless transition metal substitute, and tremendous progress has been made in the challenging $\mathrm{C}\left(\mathrm{sp}^{3}\right)-\mathrm{H}$ functionalization reaction recently. The molecular iodine-catalyzed $\mathrm{C}\left(\mathrm{sp}^{3}\right)-\mathrm{H}$ functionalization reactions under different oxidation systems have different reaction characteristics and mechanisms. The combination of molecular iodine and hypervalent aryl iodanes, dimethyl sulfoxide (DMSO), peroxide and oxygen can efficiently catalyze the functionalization of $\mathrm{C}\left(\mathrm{sp}^{3}\right)-\mathrm{H}$ with different mechanisms. Recently, transition-metal/iodine co-catalysis and iodine-containing electrochemical catalysis have also made unprecedented progress in $\mathrm{C}\left(\mathrm{sp}^{3}\right)-\mathrm{H}$ functionalization reaction. Herein, the progress of $\mathrm{C}\left(\mathrm{sp}^{3}\right)-\mathrm{H}$ functionalization catalyzed by iodine under different oxidation systems from 2015 to now is summarized. The research on the green catalytic system of molecular iodine in the $\mathrm{C}\left(\mathrm{sp}^{3}\right)-\mathrm{H}$ functionalization reaction is summarized and prospected.
\end{abstract}

Keywords molecular iodine; $\mathrm{C}\left(\mathrm{sp}^{3}\right)-\mathrm{H}$ functionalization; oxidation system; green chemistry; electrochemistry

分子碘是一种常见的环境友好试剂，在有机合成中 占据着不可替代的位置. 分子碘作为一种温和的亲电试 剂、氧化剂和催化剂, 能够参与各种有机反应 ${ }^{[1]}$, 包括多 组分串联反应 ${ }^{[2] 、}$ 串联环化反应、迈克尔反应 ${ }^{[3-5]}$ 、交叉 脱氢偶联反应 ${ }^{[6]}$ 、芳构化反应 ${ }^{[7-9]}$ 和霍夫曼 - 勒夫勒-弗赖 伊塔格反应 (Hofmann-Löfler-Freytag reaction, HLF ${ }^{[10]}$ 等. 近年来, 分子碘在具有挑战性的 $\mathrm{C}\left(\mathrm{sp}^{3}\right)-\mathrm{H}$ 功能化
反应中取得了一些可喜的进展 ${ }^{[11-15]}$.

惰性 $\mathrm{C}-\mathrm{H}$ 键选择性活化是化学领域中最基本和最 具挑战性的问题之一. $\mathrm{C}-\mathrm{H}$ 键具有较高的键能 ${ }^{[16-18]}$, 稳 定坚固且极性很小，在没有官能团导向的情况下，活化 和选择性是反应中两个最大的问题. 与传统有机反应相 比, 直接的 $\mathrm{C}-\mathrm{H}$ 功能化不仅消除了底物中功能团预先 存在的需要 ${ }^{[19-23]}$, 并且优化和补充了传统合成方法无法

\footnotetext{
* Corresponding author. E-mail: weihechem@fmmu.edu.cn

Received August 15, 2020; revised October 22, 2020; published online November 18, 2020.

Project supported by the National Science and Technology Major Project of China on "Key New Drug Creation and Development Program" (No. 2018ZX09J18108-004-001) and the Shaanxi Province Key Research and Development Program (No. 2019ZDLSF03-03).

中国科技部 “重大新药创制课题” (No. 2018ZX09J18108-004-001)和陕西省重点研发计划(No. 2019ZDLSF03-03).
} 
实现的选择性分子位点活化的方式. $\mathrm{C}-\mathrm{H}$ 功能化按化 学键类型可分为 $\mathrm{C}(\mathrm{sp})-\mathrm{H}$ 键、 $\mathrm{C}\left(\mathrm{sp}^{2}\right)-\mathrm{H}$ 键和 $\mathrm{C}\left(\mathrm{sp}^{3}\right)-$ $\mathrm{H}$ 键. $\mathrm{C}\left(\mathrm{sp}^{3}\right)-\mathrm{H}$ 键依据活化位点可分为脂肪族碳氢键 (一级、二级、三级)、烯丙基碳氢键、茮基碳氢键、羰 基 $\alpha$-碳氢键和羰基 $\beta$-碳氢键等, 它们在键能 ${ }^{[24-25]}$ 上存在 着一定的差别(图 1a). 通常 $\mathrm{C}\left(\mathrm{sp}^{3}\right)-\mathrm{H}$ 键的选择性活化 较难以实现, 当分子中含有多个化学性质相似的 $\mathrm{C}\left(\mathrm{sp}^{3}\right)-\mathrm{H}$ 键, 如何选择性地活化一个或者多个 $\mathrm{C}\left(\mathrm{sp}^{3}\right)-\mathrm{H}$ 键是难点问题. 近年来在这一领域出现了许 多成功的选择性地活化 $\mathrm{C}\left(\mathrm{sp}^{3}\right)-\mathrm{H}$ 键的例子 ${ }^{[26-30]}$, 从而 发展成为一类在有机合成领域中非常有价值的化学转 变.

近年来, 化学工作者陆续发展了基于分子碘的无金 属、无溶剂甚至无氧化剂的绿色催化体系 ${ }^{[31-32]}$, 在 $\mathrm{C}\left(\mathrm{sp}^{3}\right)-\mathrm{H}$ 功能化反应中得到了前所未有的应用和发展. 在这些转化中无论是碘催化反应还是碘介导的反应往 往都需要加入氧化剂, 用以实现催化循环. 不同氧化剂 与分子碘构成了不同类型的催化体系, 可产生高活性物 种(如自由基等)或形成弱化学键从而实现 $\mathrm{C}\left(\mathrm{sp}^{3}\right)-\mathrm{H}$ 功 能化反应(图 1b). 例如在 $\mathrm{I}_{2} / \mathrm{ArI}(\mathrm{III})$ 体系下的 HLF 反应, 通常经历自由基生成/氢原子转移/自由基捕获/取代这 一反应过程 ${ }^{[10]}$. 相比较, $\mathrm{I}_{2} /$ 二甲基亚砜(DMSO)体系中 使用芳基酮构建杂环分子, 通常需要经历碘化/Kornblum 氧化/取代的顺序反应过程 ${ }^{[33]}$. 而 $\mathrm{I}_{2} /$ 过氧化物体系 中, 加热条件下过氧化物较容易生成自由基来促进反应 完成 ${ }^{[14]}$. $\mathrm{I}_{2}$ 还可以在 $\mathrm{O}_{2}$ 下、碱性条件下、光照下、加热 下以及与其他催化剂联合构成不同体系催化 $\mathrm{C}\left(\mathrm{sp}^{3}\right)-\mathrm{H}$ 功能化反应 ${ }^{[34-36]}$. 此外, 在分子碘催化的 $\mathrm{C}\left(\mathrm{sp}^{3}\right)-\mathrm{H}$ 功 能化反应中, 过渡金属可作为氧化剂或添加剂联合高效 地催化反应转化. 含碘试剂可在氧化剂或电解池 ${ }^{[37]}$ 中 原位生成分子碘从而催化反应, 此类反应为分子碘催化
$\mathrm{C}\left(\mathrm{sp}^{3}\right)-\mathrm{H}$ 功能化反应的新型绿色方法. 由此分子碘催 化 $\mathrm{C}\left(\mathrm{sp}^{3}\right)-\mathrm{H}$ 键的功能化反应能够使用更绿色的催化体 系，采用简单的化学分子和合成路线来简化化学合成. 对分子碘在不同氧化体系下的研究工作进行总结与分 析，对深入理解其反应历程和反应性质具有重大意义. 本文对 2015 年至今分子碘在不同氧化体系下催化的 $\mathrm{C}\left(\mathrm{sp}^{3}\right)-\mathrm{H}$ 功能化反应的研究进行综述.

\section{2 分子磑在不同氧化体系下催化 $\mathrm{C}\left(\mathrm{sp}^{3}\right)$ - $\mathrm{H}$ 功 能化反应}

\section{$2.1 \mathrm{I}_{2} / \mathrm{Arl}(\mathrm{III})$ 体系催化的 $\mathrm{C}\left(\mathrm{sp}^{3}\right)-\mathrm{H}$ 功能化反应}

高价芳基碘试剂也称为超价碘试剂，本身具有独特 的氧化性质，在有机合成中可作为亲电芳烃、氧化剂和 催化剂. 其氧化性能与二价录 $[\mathrm{Hg}(\mathrm{II})]$ 、四价铅 $[\mathrm{Pb}(\mathrm{IV})]$ 、 六价铬 $[\mathrm{Cr}(\mathrm{VI})]$ 和八价锇 $[\mathrm{Os}(\mathrm{VIII})]$ 等金属氧化剂相近, 但其具有低毒性、性能温和等优点，被认为是过渡金属 的 “绿色替代品” [38]. 高价芳基碘试剂与分子碘能够进 行原位配体(Ligand)交换生成活性化合物 I(L) 2 , 该化合 物是促进有机转化的重要分子.

自由基的氢原子转移(Hydrogen atom transfer, HAT) 策略是实现碳氢键官能团化的一种有效途径. 最近基于 HAT 策略的 $\mathrm{I}_{2} / \mathrm{ArI}(\mathrm{III})$ 体系在 $\mathrm{C}\left(\mathrm{sp}^{3}\right)$ - $\mathrm{H}$ 功能化反应中得 到了前所未有的发展 ${ }^{[10]}$. 早在 1883 年, Hofmann ${ }^{[39]}$ 报道 了通过 HAT 策略实现选择性 $\mathrm{C}-\mathrm{H}$ 功能化的例子 (Scheme 1, a). 基于这种策略, Suárez 课题组 ${ }^{[40-42]}$ 创新地 使用 $\mathrm{I}_{2} /$ 碘苯二乙酸(PIDA), 在光照诱导下, 通过 1,5-HAT 实现分子内 $\mathrm{C}\left(\mathrm{sp}^{3}\right)-\mathrm{H}$ 胺化反应(Scheme $\left.1, \mathrm{~b}\right)$. $\mathrm{I}_{2} /$ 碘苯二乙酸(PIDA)的成功应用凸显了 $\mathrm{I}_{2} / \mathrm{ArI}(\mathrm{III})$ 体系 在 $\mathrm{C}\left(\mathrm{sp}^{3}\right)-\mathrm{H}$ 功能化反应中的价值.

(a) Different $\mathrm{C}\left(\mathrm{sp}^{3}\right)-\mathrm{H}$ bonds energy

\begin{tabular}{|c|c|c|c|c|}
\hline 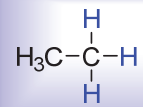 & $\begin{array}{c}\mathrm{C}_{3} \mathrm{H}_{3} \\
\mathrm{H}_{3} \mathrm{C}-\stackrel{\mathrm{C}}{\mathrm{I}}-\mathrm{H} \\
\stackrel{\mathrm{H}}{\mathrm{H}}\end{array}$ & $\begin{array}{r}\mathrm{CH}_{3} \\
\mathrm{H}_{3} \mathrm{C}-\stackrel{\mathrm{\perp}}{\mathrm{L}}-\mathrm{H} \\
\stackrel{\mathrm{C}}{\mathrm{C}} \mathrm{H}_{3}\end{array}$ & & \\
\hline $423 \mathrm{~kJ} / \mathrm{mol}$ & $414 \mathrm{~kJ} / \mathrm{mol}$ & $406 \mathrm{~kJ} / \mathrm{mol}$ & $347 \mathrm{~kJ} / \mathrm{mol}$ & $356 \mathrm{~kJ} / \mathrm{mol}$ \\
\hline
\end{tabular}

(b) Different oxidation systems

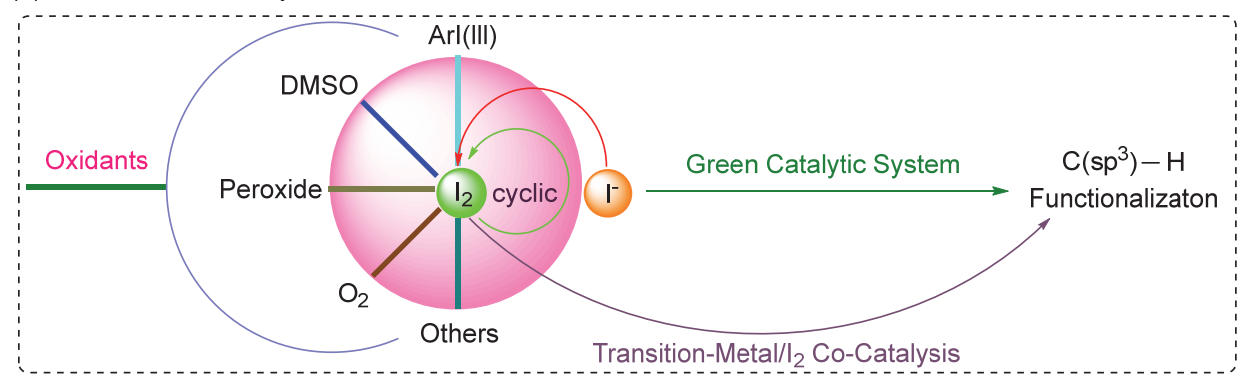

图 1 不同的 $\mathrm{C}\left(\mathrm{sp}^{3}\right)-\mathrm{H}$ 键键能和不同氧化体系

Figure 1 Different $\mathrm{C}\left(\mathrm{sp}^{3}\right)-\mathrm{H}$ bonds energy and different oxidation systems 
(a) Hofmann-Löffler-Freytag reaction (HLF)

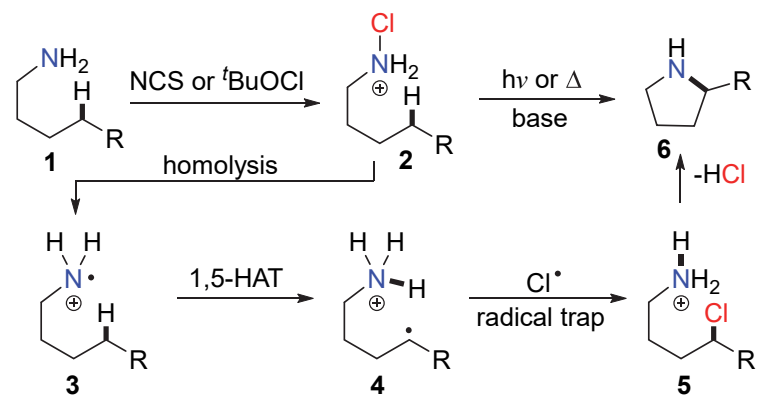

(b) Suárez modification: $\delta-\mathrm{C}-\mathrm{H}$ amination via $\mathrm{N}$-centered radicals by $\mathrm{N}-\mathrm{X}$ homolysis

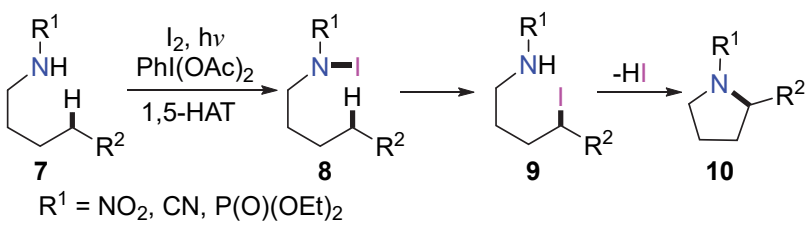

图式 1 分子碘在霍夫曼一勒夫勒一弗赖伊塔格反应中的应用 Scheme 1 Application of molecular iodine in Hofmann-LöflerFreytag reaction

在 2015 年, Herrera 课题组 ${ }^{[43]}$ 和 Muñiz 课题组 ${ }^{[44]}$ 分 别报道了不同底物类型的 $\mathrm{I}_{2} / \mathrm{ArI}(\mathrm{III})$ 体系催化的分子内 $\mathrm{C}\left(\mathrm{sp}^{3}\right)-\mathrm{H}$ 胺化反应(Scheme 2). Herrera 课题组 ${ }^{[43]}$ 在 $\mathrm{I}_{2} / \mathrm{PIDA} /$ 光体系下, 对脂肪族初级 $\mathrm{C}\left(\mathrm{sp}^{3}\right)-\mathrm{H}$ 键进行选 择性功能化合成了五元环胺或酰胺. Muñiz 课题组 ${ }^{[44]}$ 则 采用 $\mathrm{I}_{2} / \mathrm{Ph}(m \mathrm{CBA})_{2}$ 催化体系, 对苄基位或脂肪族三级 $\mathrm{C}\left(\mathrm{sp}^{3}\right)-\mathrm{H}$ 键进行选择性功能化, 实现了分子内的 $\mathrm{C}\left(\mathrm{sp}^{3}\right)-\mathrm{H}$ 胺化. 该方法使用 $\mathrm{I}_{2}$ 作为催化剂将 $\mathrm{C}-\mathrm{H}$ 键选 择性地转化为 $\mathrm{C}-\mathrm{N}$ 键, 为四氢吡咯化合物的合成提供 了一种新途径. Muñiz 课题组由此开展了更深入的反应 机理和应用研究, 报道了一系列 $\mathrm{I}_{2} / \mathrm{ArI}(\mathrm{III})_{2}$ 体系下 $\mathrm{C}\left(\mathrm{sp}^{3}\right)-\mathrm{H}$ 功能化反应, 提高了 HLF 反应在含氮化合物 合成中的应用价值.

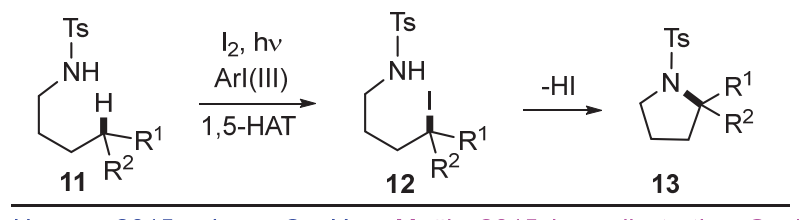

Herrera, 2015, primary C-H Muñiz, 2015, benzylic, tertiary C-H

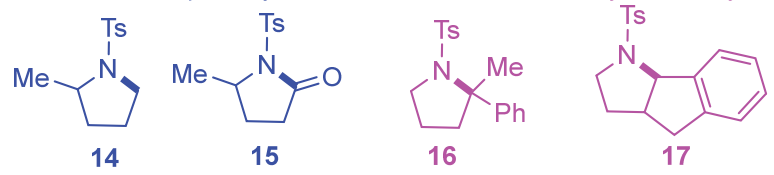

$\mathrm{I}_{2}, \mathrm{Phl}(\mathrm{OAc})_{2}$ (slow addition) catalytic : $10 \mathrm{~mol} \% \mathrm{I}_{2}, \mathrm{Phl}(m \mathrm{CBA})_{2}$

图式 2 碘催化的霍夫曼-勒夫勒反应

Scheme 2 Iodine-catalyzed Hofmann-Löffler reaction

Muñiz 课题组 ${ }^{[44]}$ 对该反应的催化循环机制提出了 合理的反应路径(Scheme 3). 该反应有两个连续的催化 循环过程. 在反应最初, $\mathrm{I}_{2}$ 和 $\mathrm{PhI}(m \mathrm{CBA})_{2}$ 反应生成了 2 equiv. 的活性催化剂 $\mathrm{I}(m \mathrm{CBA}), \mathrm{I}(\mathrm{mCBA})$ 促进了 $\mathrm{N}-\mathrm{I}$ 键 的形成, 使底物 18 转化为关键中间体 19 . 随后经过可 见光引导, $\mathrm{N}-\mathrm{I}$ 键发生裂解产生了氮自由基中间体 $\mathbf{2 0}$, 再从芳基位提取转移氢原子(1,5-HAT), 生成碳自由基 中间体 21. 中间体 21 通过自由基捕获得到 $\alpha$-碘代中间 体 22, 之后在氧化剂作用下氧化为中间体 23. 最后, 中 间体 23 进行分子内亲核取代得到目标产物 24.

对给定的目标化合物进行逆合成分析(Scheme 4,a), 有两种可选的 $\mathrm{C}-\mathrm{N}$ 键断裂方式 ${ }^{[45]}$. 后者 3 位取代基的 末端为甲基的吡咯烷类化合物需要在不利的甲基位置 进行选择性 $\mathrm{C}-\mathrm{H}$ 功能化, 但它具有提高反应对映选择 性的优点, 因为该类型底物没有固定的立体基团中心. 受此启发, 2018 年 Muñiz 课题组 ${ }^{[45]}$ 首次探索了碘催化霍 夫曼一洛弗勒变体反应，成功对映选择性地合成了一系 列尼古丁衍生物 28 (Scheme 4, b). 反应最初由吡啶-3醛化合物得到 3-吡啶- $N$-甲苯磺酰亚胺 25, 再通过格式 试剂发生 1,2-烷基化得到反应底物 26. 再在反应中

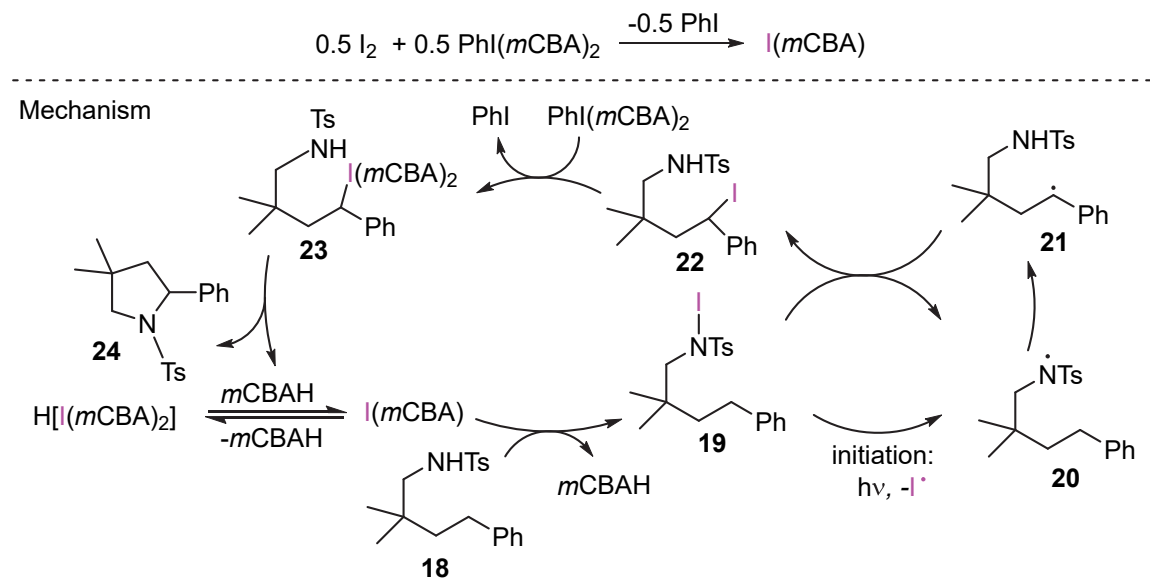

图式 3 碘催化霍夫曼-勒夫勒反应机理

Scheme 3 Mechanism of iodine-catalyzed Hofmann-Löffler reaction 


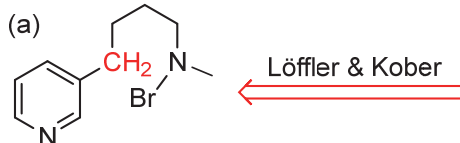

benzylic $\mathrm{C}-\mathrm{H}$ amination (racemic)<smiles>CN1CCCC1c1cccnc1</smiles>

retrosynthetic analysis<smiles>C=C=CCC(c1cccnc1)N(C)C</smiles>

aliphatic $\mathrm{C}-\mathrm{H}$ amination ( potentially enatioselective )

Retrosynthetic $\mathrm{C}-\mathrm{N}$ bond disconnection for the pyrrolidine core of nicotine $(X=\mathrm{Br}, \mathrm{I})$

(b)<smiles>C=CC=N[As-]</smiles>

25

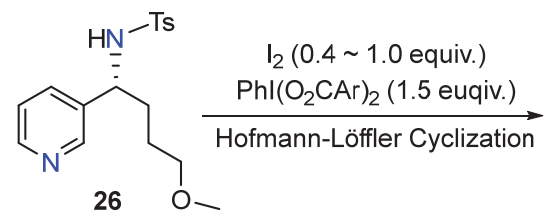

26<smiles>[3H]N1[C@@H](OC)CC[C@H]1c1cccnc1</smiles>

27
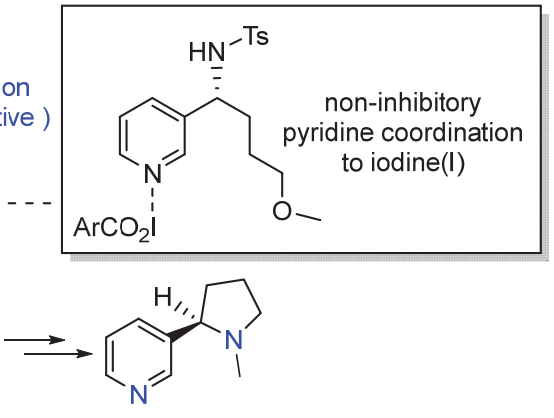

28

图式 4 碘催化对映选择性地合成尼古丁衍生物

Scheme 4 Enantioselective synthesis of nicotine via iodine-catalyzed

加入 $\mathrm{I}_{2} / \mathrm{PhI}\left(\mathrm{O}_{2} \mathrm{CAr}\right)_{2}$, 以 $\mathrm{CH}_{2} \mathrm{Cl}_{2}$ 为溶剂, 常温下实现了 选择性分子内 $\mathrm{C}\left(\mathrm{sp}^{3}\right)-\mathrm{H}$ 功能化, 得到环化产物 27. 最 后通过简单的还原反应, 得到一系列具有对映选择性的 尼古丁衍生物 28. 该反应条件温和, 具有潜在应用价 值. 据以往文献报道, 在 $\mathrm{N}-\mathrm{H}$ 键碘化之前, 亲电碘试 剂容易与吡啶发生竞争性配位 ${ }^{[46-48]}$, 从而无法形成目标 $\mathrm{N}$ - I 键. 而该方法的优势在于亲电碘试剂对吡咯结构 的耐受性, 从而能够选择性形成 $\mathrm{N}-\mathrm{I}$ 键, 成功实现非活 化脂肪族 $\mathrm{C}-\mathrm{N}$ 键的构建.

此后, 该课题组 ${ }^{[49]}$ 提出了一种碘催化的非活化 $\mathrm{C}\left(\mathrm{sp}^{3}\right)-\mathrm{H}$ 键的 Ritter 型胺化反应, 高效地合成了 1,3- $\alpha-$ 三级二胺化合物 32. 磺胺基自由基作为自由基启动位 点引导三级 $\mathrm{C}-\mathrm{H}$ 键通过独特的 1,6-HAT 过程得到碘化 中间体 31 (Scheme 5). 随后, 通过 Ritter 反应构建了 $\mathrm{C}-\mathrm{N}$ 键. 该反应通过 1,6-HAT 进行选择性卤化, 反应底 物仅限制于含三级 $\mathrm{C}-\mathrm{H}$ 键的化合物. 反应中胺基磺酸 酯基团具有独特的作用, 使得它本身很难进行胺化. 通 过对霍夫曼-洛弗勒反应中的氮自由基进行电子顺磁共

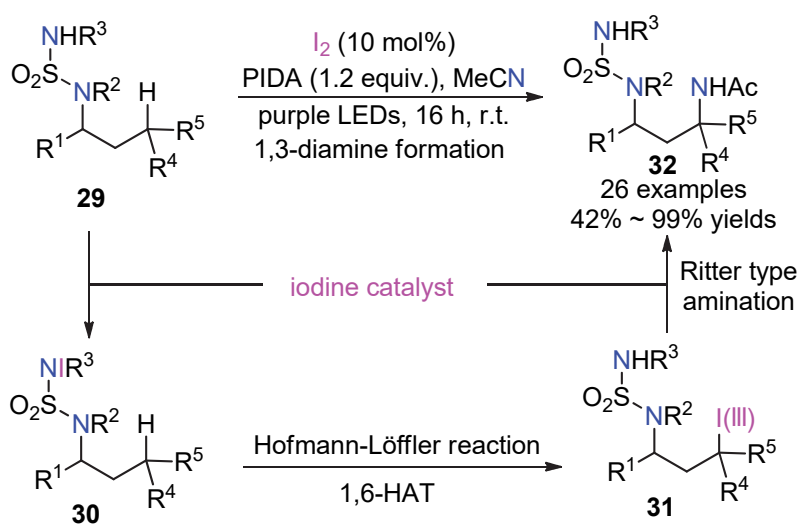

图式 5 通过碘催化 Ritter 型胺化反应合成 1,3-二胺化合物 Scheme 5 Synthesis of 1,3-diamine by iodine catalyzed Rittertype amination
振(EPR)检测 [50], 发现该类反应的活性基于磺酰胺自由 基，磺酰胺自由基是 $\mathrm{C}-\mathrm{H}$ 胺化反应中的决定性中间体.

Muñiz 课题组 ${ }^{[51]}$ 在 2019 年使用 $\mathrm{I}_{2} / \mathrm{PhI}\left(\mathrm{O}_{2} \mathrm{CAr}\right)_{2}$ 体系, 外加磺酰胺, 在蓝色 LED 光诱导下, 实现了脂肪族的分 子间 $\mathrm{C}\left(\mathrm{sp}^{3}\right)-\mathrm{H}$ 胺化反应. 该方法提供了一种获得胺类 化合物 34 的直接高效的策略, 并且创新地实现了多重 $\mathrm{C}-\mathrm{H}$ 胺化(Scheme 6). 该方法在四种相关药物合成中 的应用也证明了该合成方法的实用性. 相关机理证明, 该反应存在三个反应过程: $\mathrm{C}-\mathrm{H}$ 碘化、碘化烷烃氧化和 胺源亲核取代. 该方法有望应用于生物活性分子、天然 产物和药物等化合物的后期修饰，直接构建胺类化合物 侯选库.

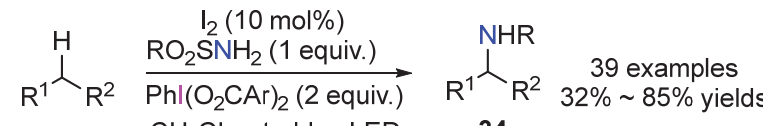

$$
\begin{aligned}
& 33 \quad \mathrm{CH}_{2} \mathrm{Cl}_{2} \text {, r.t., blue LED } \quad 34 \\
& \mathrm{C}-\mathrm{H} \text { iodination phase } \quad \text { alkyl iodide } \quad \text { amination phase }
\end{aligned}
$$

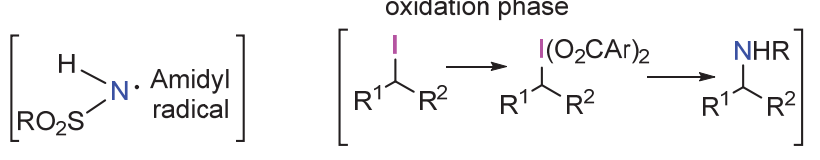

图式 6 碘催化下分子间自由基 $\mathrm{C}\left(\mathrm{sp}^{3}\right)-\mathrm{H}$ 胺化反应 Scheme 6 Intermolecular radical $\mathrm{C}\left(\mathrm{sp}^{3}\right)-\mathrm{H}$ amination under iodine catalysis

2017 年, Bolm 课题组 ${ }^{[52]}$ 报道了一种由分子碘介导 的 $S$-芳基- $S$-苯基丙基亚砜亚胺的环化反应(Scheme 7). 通过选择性活化 $\mathrm{C}\left(\mathrm{sp}^{3}\right)-\mathrm{H}$ 键, 提供了一种直接合成二 氢异噻唑氧化物 36 和苯并 $[d]$ 异噻唑-1-氧化物 37 的新 方法. 反应中加入等物质的量的 $\mathrm{I}_{2}$, 以 PIDA 作为氧化 剂, 可见光诱导, 通过 1,5-HAT 策略构建五元杂环. 值 得注意的是，对具有取代基团的苯类底物通过竞争性的 选择 1,5-HAT 过程, 合成了苯并 $[d]$ 异噻唑-1-氧化物 37. 


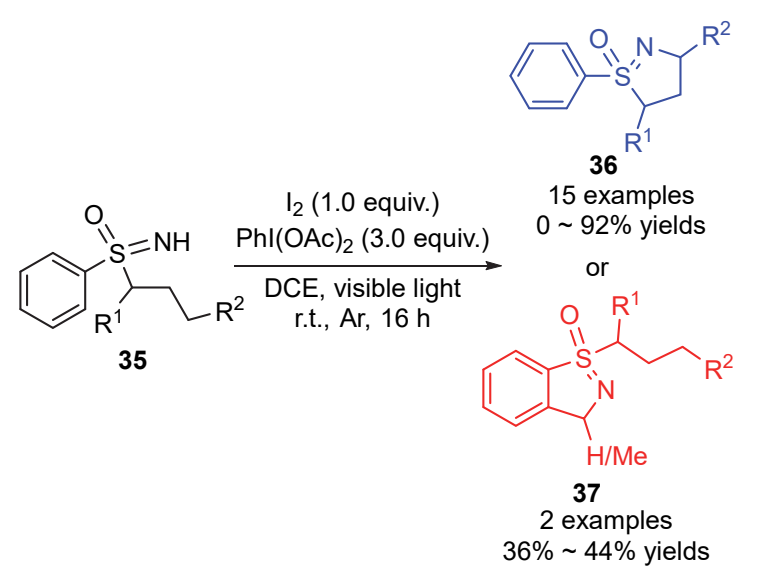

图式 7 碘介导 HLF 环化反应

Scheme 7 Iodine-mediated HLF-type cyclization reactions

目前, 有关叔胺 $\alpha$-和 $\beta$-双 $\mathrm{C}\left(\mathrm{sp}^{3}\right)-\mathrm{H}$ 功能化反应功 能化反应, 主要使用过渡金属催化 ${ }^{[53-55]}$, 但是此类催化 方法, 产率低, 且存在竞争性副产物. 相比较, 梁永民 课题组 ${ }^{[56]}$ 使用 PIDA 介导, 有效地实现了 $\alpha$-和 $\beta$-双 $\mathrm{C}\left(\mathrm{sp}^{3}\right)-\mathrm{H}$ 氧化乙酰化. 受此启发, 赵勤实课题组 ${ }^{[57]}$ 创 新地开发了一种由 $\mathrm{I}_{2} / \mathrm{PIDA}$ 介导的直接、温和、无金属 和位点特异性的方法, 用于叔胺 $\alpha$-和 $\beta$-双 $\mathrm{C}\left(\mathrm{sp}^{3}\right)-\mathrm{H}$ 键 双重功能化, 高效地构建了叔胺 $\alpha$-和 $\beta$-双羰基化合物 39 (Scheme 8), 该方法成为促进药物发现与开发的强有 力工具.

作者提出了可能的反应机理. 关于氧的来源, 通过 ${ }^{18} \mathrm{O}$ 标记进行了确认, 结果表明 $\mathrm{C}(2)$ 上的氧可能来自 $\mathrm{H}_{2} \mathrm{O}$, 而 $\mathrm{C}(3)$ 上的氧可能来自 HOAc. 反应最初由 $\mathrm{I}_{2} / \mathrm{PIDA}$ 原位生成 IOAc 促进底物 38a 通过脱氢转化为亚 胺中间体 40. 亚胺中间体 40 被 $\mathrm{H}_{2} \mathrm{O}$ 进攻, 亲核加成转 化为 $\alpha$-着基中间体 41. IOAc 重复活化中间体 41 得到内 酰胺中间体 43. 中间体 $\mathbf{4 3}$ 与 IOAc 反应生成 $\alpha$-碘代内 酰胺 44. 中间体 44 与 $\mathrm{AcOH}$ 反应, 得到 $\alpha$-乙酰氧基酮 内酰胺 $\mathbf{4 5}$, 再与 IOAc 反应转化为中间体 $\mathbf{4 6}$, 最后脱去 一分子 $\mathrm{Ac}_{2} \mathrm{O}$ (同时脱磑)得到产物 39a (path a). 中间体 44 也可能与 IOAC 反应直接生成产物 39b (path b). 这种 选择性的转变有着非常明显的溶剂效应 [四氢呋喃 (THF) vs 1,2-二氯乙烷(DCE), 导致 39a vs 39b], 这可能 是因为中间体 $\mathbf{4 4}$ 在 THF 和 DCE 中的溶解度不同所致. 作者认为这种转变不仅与溶剂相关, 还受其他综合因素 的影响, 如底物结构的影响等.

2019 年, Shibata 课题组 ${ }^{[58]}$ 通过 $\mathrm{N}-\mathrm{H} / \mathrm{C}\left(\mathrm{sp}^{3}\right)-\mathrm{H}$ 脱 氢偶联策略, 使用碘催化 $\alpha$-氨基酸衍生物合成了手性 4咪唑烷酮衍生物 48 (Scheme 9). 该反应条件温和, 无需 金属试剂, 底物范围广, 产率中等至优良, 并且二级和 三级 $\mathrm{C}\left(\mathrm{sp}^{3}\right)-\mathrm{H}$ 键都能被胺化, 各种官能团耐受性也很 好. 4-咪唑烷酮衍生物是一种重要的有机分子, 具有多
Metal-free apporach: by Liang

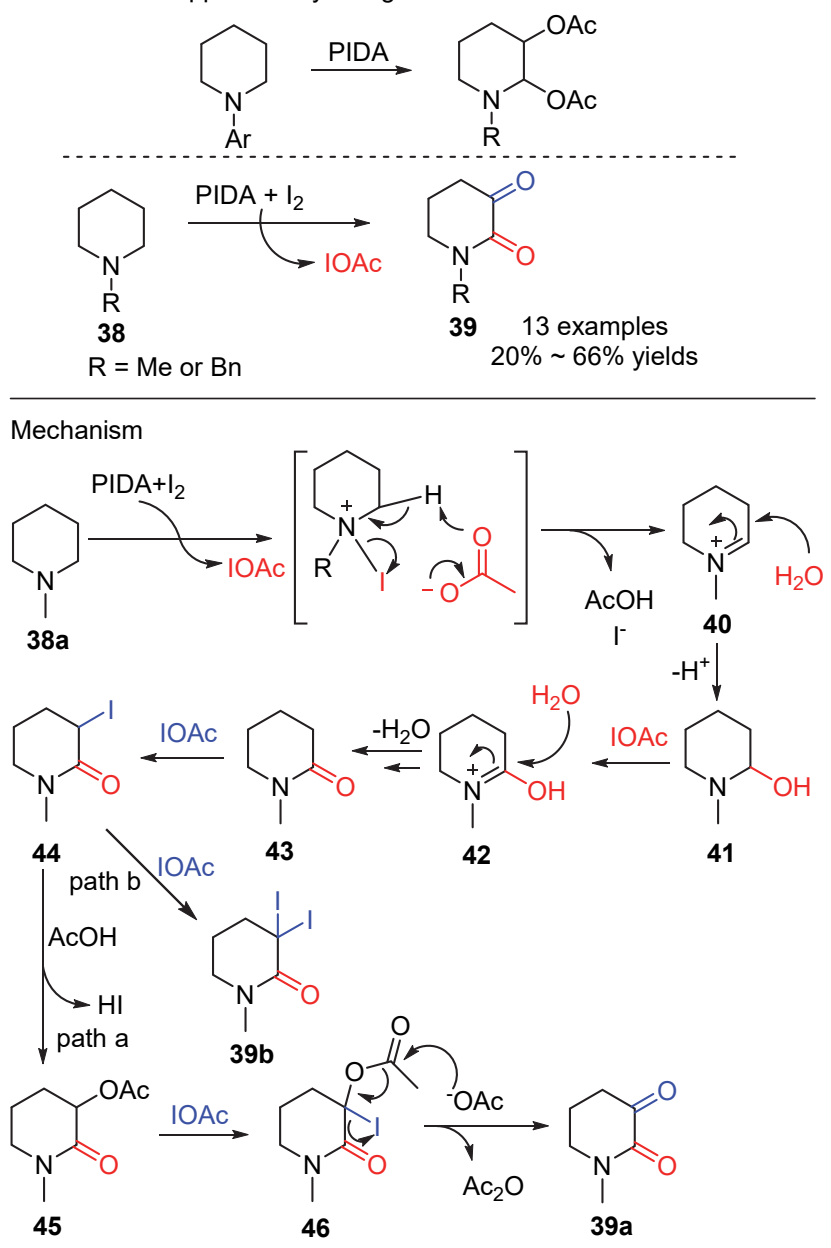

图式 $8 \mathrm{PIDA} / \mathrm{I}_{2}$ 介导的三级胺 $\alpha$-和 $\beta$-双 $\mathrm{C}\left(\mathrm{sp}^{3}\right)-\mathrm{H}$ 键功能化 反应

Scheme 8 PIDA//2-mediated $\alpha$ - and $\beta-\mathrm{C}\left(\mathrm{sp}^{3}\right)-\mathrm{H}$ bond dual functionalization of tertiary amines

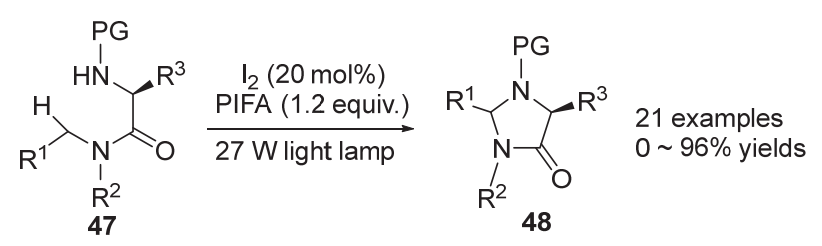

图式 9 碘催化手性 4-咪唑啉酮的合成

Scheme 9 Iodine-catalyzed synthesis of chiral 4-imidazolidinones

种有用的生物活性，包括抗肿瘤、抗惊厥、抗炎和抗病 毒活性等. 该反应能简单、高效地合成结构多样的手性 4-咪唑烷酮衍生物. 机理研究表明, 该反应通过光引导 1,5-HAT 过程实现.

同年, Nagib 课题组 ${ }^{[27]}$ 报道了一种新型亚胺自由基 传递的 $\beta-\mathrm{C}-\mathrm{H}$ 胺化反应(Scheme 10). 醇类化合物 49 与 腈类化合物很容易反应生成亚胺化合物. 亚胺化合物在 $\mathrm{I}_{2} / \mathrm{PhI}(\mathrm{OAc})_{2}$ 体系下，通过热裂解生成亚胺自由基中间 
体 50, 再通过选择性 1,5-HAT 得到碳自由基中间体 51 . 随后，中间体 51 发生自由基捕获，再通过分子内亲核取 代得到噁唑啉类化合物. 最后酸解得到 $\beta$-胺基醇类化合 物 52. 该反应首次将亚胺自由基应用于 $\mathrm{C}-\mathrm{H}$ 功能化. 相比较第一代的催化方法 ${ }^{[59]}$, 该方法更快速且反应活 性更高. 该课题组还通过控制实验对该反应化学选择 性、区域选择性、立体选择性进行了探究.

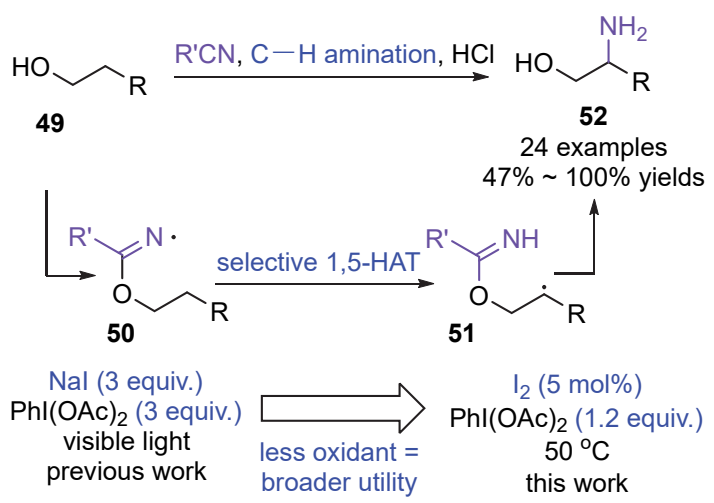

图式 10 亚胺自由基传递的 $\beta-\mathrm{C}-\mathrm{H}$ 胺化催化反应 Scheme 10 Catalytic $\beta-\mathrm{C}-\mathrm{H}$ amination via an imidate radical relay

2020 年, Nagib 课题组 ${ }^{[60]}$ 开发了一种使用碘试剂介 导醇类化合物通过亚胺自由基极性交叉串联实现邻近 双 C-H 功能化的方法(Scheme 11). 这种自由基极性交 叉串联反应首先需要通过 $\mathrm{I}_{2}$ 配位去饱和原位生成烯丙 基酰亚胺，再通过邻氨基碘化实现双取代. 该反应将脂
肪族醇类转化为多种 $\alpha, \beta, \gamma$-三取代含杂原子化合物 56 (三个相邻碳)，证明了该方法合成的高效性. 作者从机 理角度对实验的可行性进行分析，在相同的条件下得到 了 $\beta$-碘取代的中间体，而该中间体在不同的条件下有三 种不同的反应途径: (1)单 $\mathrm{C}-\mathrm{H}$ 胺化, (2)偕 $\mathrm{C}-\mathrm{H}$ 双卤化 和(3)邻 $\mathrm{C}-\mathrm{H}$ 氨基碘化. 机理研究表明, 该邻 $\mathrm{C}-\mathrm{H}$ 双 功能化反应的机理与自由基极性交叉串联反应一致.

2019 年, 吴安心课题组 ${ }^{[61]}$ 报道了 $\mathrm{I}_{2} / \mathrm{PhI}(\mathrm{OAc})_{2}$ 共同 促进的甲基酮、碳酸氢铵和二甲基亚砜的胺化反应，高 效合成了 $\alpha$-二羰基亚砜亚胺衍生物 58 (Scheme 12). 反 应通过氧化偶联形成 $\mathrm{C}-\mathrm{N}$ 键, 亲电胺化形成 $\mathrm{N}=\mathrm{S}$ 键. 在反应中, DMSO 作为溶剂、氧化剂和底物参与反应, 丰 富了 DMSO 的用途，同时提供“ $\mathrm{S} / \mathrm{C}_{2} / \mathrm{O}$ ”的来源.

同时，作者提出了合理的机理推测. $\mathrm{NH}_{4} \mathrm{HCO}_{3}$ 作为 氨源, 通过分解反应得到 $\mathrm{NH}_{3}$. 随后, $\mathrm{NH}_{3}$ 与 $\mathrm{PhI}(\mathrm{OAc})_{2}$ 反应，消除 $\mathrm{AcOH}$ 形成中间体 $\mathbf{A}$. 二甲基亚砜的胺化可 以通过两条途径来构建 $\mathrm{N}=\mathrm{S}$ 键. 中间体 $\mathbf{A}$ 被二甲基亚 砜分子捕获，生成二甲基亚砜亚胺 61 (path a). 中间体 $\mathbf{A}$ 也可与碘苯 $(\mathrm{PhI}=\mathrm{O})$ 结合生成中间体 $\mathbf{B}$. 中间体 $\mathbf{B}$ 经过 亲电胺化得到中间体 $\mathbf{C}$, 再转化为 $\mathbf{6 1}$ (path b). 同时, 底 物 57a 通过碘化/Kornblum 氧化释放 HI 和二甲基硫化物 (DMS), 转化为苯乙二醛 60 . 在 $\mathrm{I}_{2}$ 存在下, 二甲基亚砜 亚胺 61 与苯乙二醛 60 的醛基反应，中间体 62 通过原位 交叉捕获，随后再快速氧化得到目标产物 58a.
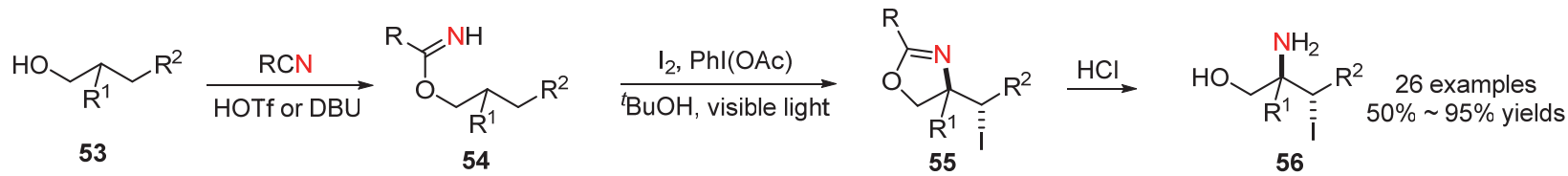

Several single and double $\mathrm{C}-\mathrm{H}$ functionalization mechanisms enabled by an imidate radical chaperone strategy
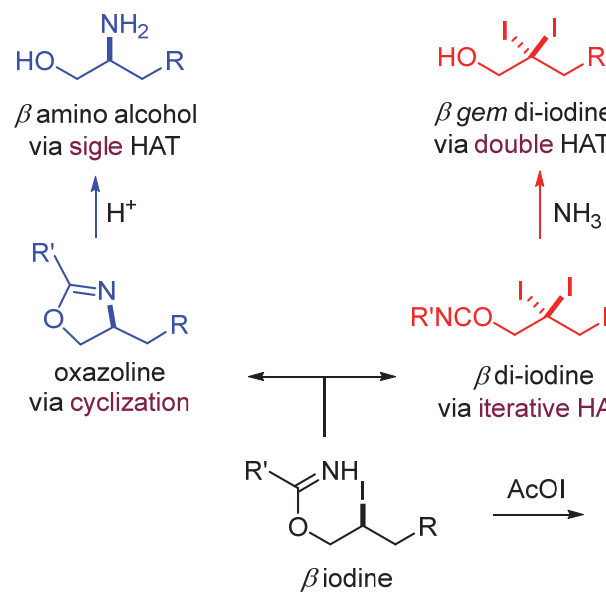

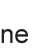

$$
\text { HAT }
$$$$
\mathrm{NH}_{3}
$$ 


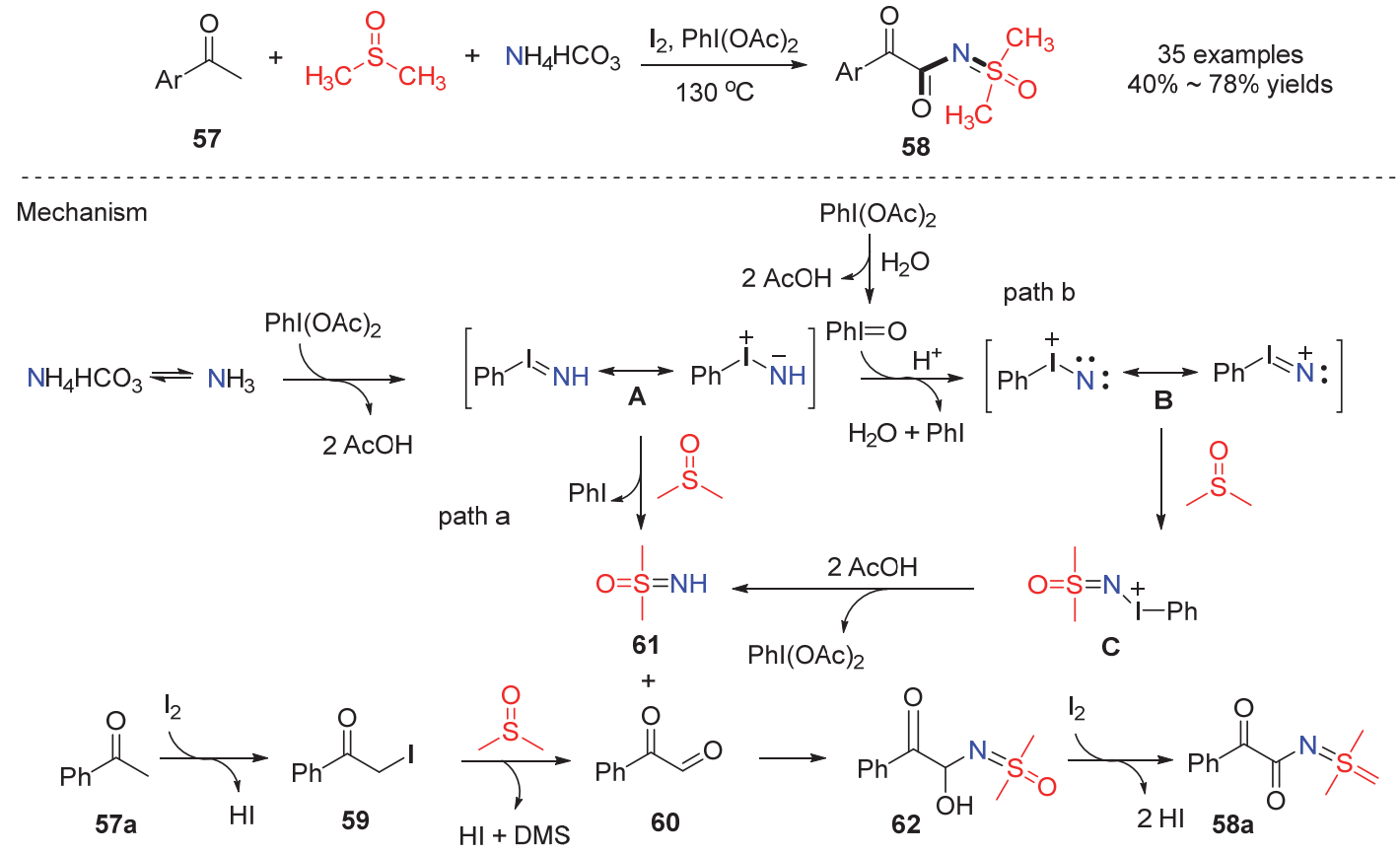

图式 $12 \alpha$-二羰基亚砜亚胺衍生物的合成

Scheme 12 Synthesis of $\alpha$-dicarbonylsulfoximine derivatives

通过以上研究实例分析, 可以得知分子碘和高价碘 (Ш)的有效组合, 通过自由基的氢原子转移(HAT)策略 实现 $\mathrm{C}\left(\mathrm{sp}^{3}\right)-\mathrm{H}$ 键功能化, 已经得到了较为广泛的研究. 然而, 为了实现有机分子的精准 $\mathrm{C}\left(\mathrm{sp}^{3}\right)-\mathrm{H}$ 功能化, 有 两个非常关键的问题仍然亟待解决 ${ }^{[25]}$ : (1)如何实现有机 分子中 $\mathrm{C}\left(\mathrm{sp}^{3}\right)-\mathrm{H}$ 键的自由基选择性㩲氢? 以往研究是 基于有机分子中具有显著差异的 $\mathrm{C}\left(\mathrm{sp}^{3}\right)-\mathrm{H}$ 键来进行的, 而结构相似的 $\mathrm{C}\left(\mathrm{sp}^{3}\right)$ - $\mathrm{H}$ 键很难实现选择性盿氢; (2)实 现 $\mathrm{I} / \mathrm{ArI}(\mathrm{H})$ 体系下的不对称 $\mathrm{C}\left(\mathrm{sp}^{3}\right)-\mathrm{H}$ 功能化关键在于, 如何控制箱氢后的碳自由基的不对称转化? 由于自由 基的高活性，其不对称转化的控制目前是该研究领域的 一大挑战.

\section{$2.2 \mathrm{I}_{2} / \mathrm{DMSO}$ 体系催化的 $\mathrm{C}\left(\mathrm{sp}^{3}\right)-\mathrm{H}$ 功能化反应}

DMSO 是一种极性有机硫试剂, 可以作为溶剂、氧 化剂、配体、DNA 引物酶抑制剂及冷冻保护剂等. 在有 机合成中作为溶剂、氧化剂、氧源和硫源等发挥着多重 作用，尤其是在 Kornblum 反应中作为氧源而被熟知. 由于其低成本和环境友好性, DMSO 已被广泛应用于各 种绿色有机转化. $\mathrm{I}_{2} / \mathrm{DMSO}$ 组合已被证明是一个绿色、 原子经济的催化体系 ${ }^{[31-32]}$, 被广泛应用于 $\mathrm{C}\left(\mathrm{sp}^{3}\right)-\mathrm{H}$ 功 能化反应，高效构建各种有机生物骨架分子.

一般而言, $\mathrm{I}_{2} / \mathrm{DMSO}$ 体系以两种方式作用 ${ }^{[62]}$ : (1) DMSO 介质中 $\mathrm{I}_{2}$ 催化的反应; (2) $\mathrm{I}_{2} / \mathrm{DMSO}$ 介导的氧 化转化反应. $\mathrm{I}_{2} / \mathrm{DMSO}$ 体系中通常通过亲电碘化后氧化 亲核取代或消除实现转化, 氧化过程通常为 Kornblum
氧化[指卤化物在 DMSO 中加热转化为醛或酮的反应, 同时产生二甲基硫梄(DMS)]. 羰基 $\alpha-\mathrm{C}\left(\mathrm{sp}^{3}\right)-\mathrm{H}$ 键功能 化，通常在 $\mathrm{I}_{2} / \mathrm{DMSO}$ 体系下 $\alpha$-羰基化合物发生亲电碘化 /Kornblum氧化/亲核取代或亲电碘化后直接被亲核试剂 取代(Scheme 13,a). 这类底物若有特殊结构, 同样可以 发生 $\alpha$-碘消除, 或者进一步亲电碘化. 另外一类 $\alpha-\mathrm{C}\left(\mathrm{sp}^{3}\right)-\mathrm{H}$ 键功能化，底物一般通过亲电碘化/消除/取 代实现转化(Scheme 13，b). I 2 /DMSO 体系中，一分子 DMSO 将两分子 HI 氧化生成 $\mathrm{I}_{2}$ 和 DMS (Scheme 13, c).

吴安心课题组 ${ }^{[63-74]}$ 一直致力于 $\mathrm{I}_{2} / \mathrm{DMSO}$ 催化体系 研究, 2015 年至今围绕该类体系通过活化 $\mathrm{C}\left(\mathrm{sp}^{3}\right)-\mathrm{H}$ 键, 构建了各种复杂的含杂原子分子. 他们采用甲基酮类化 合物为原料, 构建了吡啶、喹啉、噁唑、吲哚嗪、吡唑 酮、吡咯、香豆素、 $\alpha$-酮酰胺和邻二酮等化合物及其衍 生物.甲基酮类化合物在 $\mathrm{I}_{2} / \mathrm{DMSO}$ 体系下，通过不同构 环形式构建杂环骨架，包括[3+2+1]、[3+2]、[4+2]、 $[3+1+1] 、[3+1+3]$ 以及 $[2+2+1+1]^{[63-69]}$ 等形式，极 大丰富了甲基酮类化合物在杂环骨架构建中的应用，拓 展了 $\mathrm{I}_{2} / \mathrm{DMSO}$ 体系在有机合成的发展前景(Scheme 14).

2015 年, 吴安心课题组 ${ }^{[63]}$ 报道了 $\mathrm{I}_{2}$ 催化芳胺与两 种不同类型酮的 Povarov 型反应(波瓦罗夫反应)，以副 产物 HI 促进 Povarov 反应合成了喹啉化合物 66 (Scheme 14 ，a). 相较于以往甲基酮的氧化 $\mathrm{C}\left(\mathrm{sp}^{3}\right)-\mathrm{H}$ 键的 $[3+2$ +1 ]环加成反应的方法 ${ }^{[64]}$, 该方法简单高效，有着良好 的官能团耐受性. 之后，该课题组 ${ }^{[65]}$ 通过碘催化了甲 
(a) General strategy A

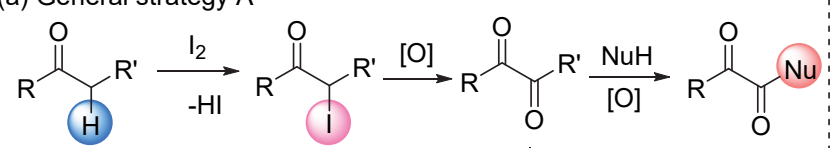
$\mathrm{R}^{\prime}=\mathrm{H}$, alkyl, etc

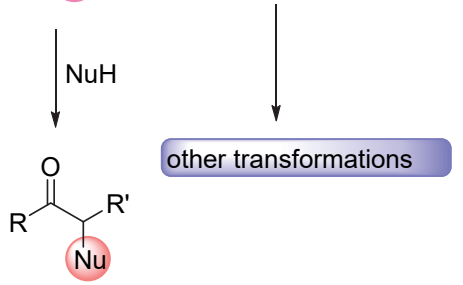

(b) General strategy B

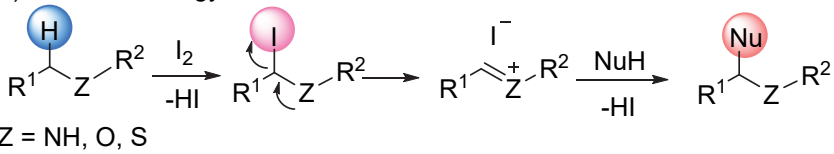

(c) $\mathrm{I}_{2} / \mathrm{DMSO}$ catalytic cycle

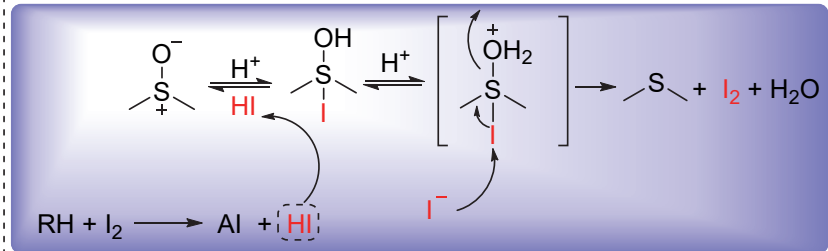

图式 $13 \mathrm{I}_{2} / \mathrm{DMSO}$ 的一般催化策略

Scheme 13 General catalytic strategies of $\mathrm{I}_{2} / \mathrm{DMSO}$

(a) Formal $[3+2+1]$

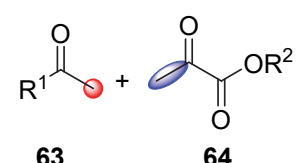

$$
63
$$

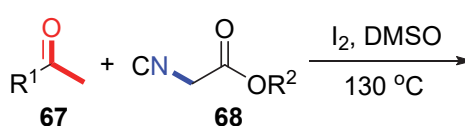<smiles>[R]OC(=O)c1c2cc[R1]ccc-2nc1C([R])=O</smiles>

26 examples $0 \sim 94 \%$ yields

(b) Formal [3+2]
65
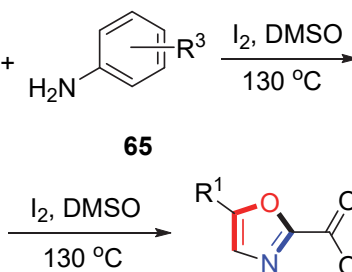<smiles></smiles>

23 examples $62 \% \sim 83 \%$ yields (c) Formal [4+2]<smiles>[R11]c1ccc(C(=O)O[R]2ccc(N)cc2)cc1</smiles><smiles>OC1CSCCS1</smiles>

72<smiles></smiles>

24 examples $60 \% \sim 83 \%$ yields<smiles></smiles>

24 examples $60 \% \sim 88 \%$ yields

(d) Formal $[3+1+1]$<smiles>O=C(O)c1cc[R1]cc1</smiles><smiles>[R]COC=NCC</smiles><smiles>CO[AsH3-]O[Na]</smiles><smiles>[R]N1N=C(C)CC1=O</smiles>

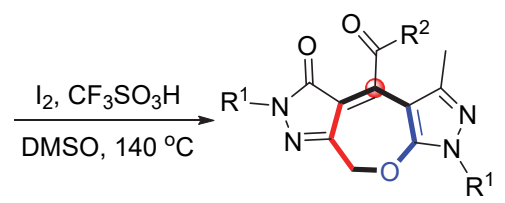

35 examples $15 \% \sim 88 \%$ yields

(f) Formal $[2+2+1+1]$

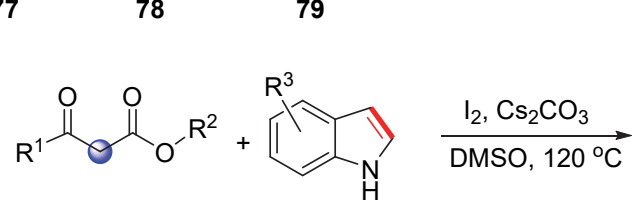

81
82

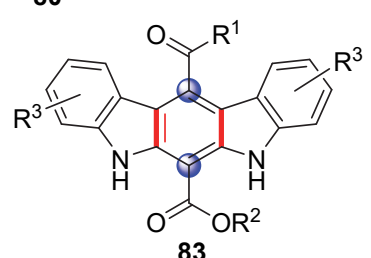

14 examples $0 \sim 55 \%$ yields

图式 14 不同环加成形式构建杂环分子

Scheme 14 Construction of heterocyclic molecules via different cycloaddition formals

基异氧酸酯与甲基酮类化合物的 $[3+2]$ 环加成反应，产 物为 2,5-二取代噁唑类化合物 69, 而不是传统的 4,5-二 取代噁坐类化合物(Scheme 14, b). 该反应首次使用路 易斯酸促进异氧酸酯与甲基酮的 $[3+2]$ 环加成反应，反
应过程涉及异氧酸酯的 $\mathrm{C}-\mathrm{N}$ 键裂解. 2017 年, 该课题 组 ${ }^{[66]}$ 开发了一种高效的 $\mathrm{I}_{2}$ 促进[4+2]环加成反应, 使用 1,4-二硫-2,5-二醇化合物作为乙烯替代物，由甲基酮化 合物和芳胺合成 2-酰基喹啉化合物 73 (Scheme 14，c). 
该反应的机理研究表明, 反应是通过碘化/Kornblum 氧 化/Pova- rov 反应/芳构化的顺序进行的, 并且芳胺底物 在反应中也起着重要促进作用. 同年该课题组 ${ }^{[67]}$ 还报 道了由 2-(吡啶-2-) 乙酸衍生物直接氧化裂解多个 $\mathrm{C}\left(\mathrm{sp}^{3}\right)-\mathrm{H}$ 键和一个 $\mathrm{C}-\mathrm{C}$ 键, 通过 $[3+1+1]$ 形式环加 成反应, 构建 3-(吡啶-2-)吲哚嗪骨架 76 (Scheme 14, d). 值得注意的是, 吡啶衍生物发挥了两个关键作用, 提供 了两个片段来构建 3-(吡啶-2-)吲哚嗪骨架, 而不是在构 建普通吲哚中的单一作用. 相同的催化体系下, 在反应 中加入 3-甲基-5-吡唑酮化合物, 通过碘催化氧化偶联 构建 $\mathrm{C}\left(\mathrm{sp}^{3}\right)-\mathrm{O}$ 键, 以 $[3+1+3]$ 环加成形式 ${ }^{[68]}$, 形成七 元氧杂环骨架 80 (Scheme 14, e). 该方法直接有效地合 成氧杂环, 通过碘化/氧化偶联/ $\mathrm{C}-\mathrm{O}$ 键构建的顺序步 骤. 吴安心课题组 ${ }^{[69]}$ 还通过分子碘介导了 $\beta$-酮酯化合物 $\mathrm{C}\left(\mathrm{sp}^{3}\right)-\mathrm{H}$ 键与吲哚 $\mathrm{C}\left(\mathrm{sp}^{2}\right)-\mathrm{H}$ 键的氧化交叉偶联反应, 通过 $[2+2+1+1]$ 形式环化构建了取代吲哚 $[2,3-b]$ 咔唑 化合物 83 (Scheme 14, f). 该反应通过碘化/Kornblum 氧 化/水解/脱碳氧化/脱酰化/芳构化的顺序步骤实现反应. $\beta$-酮酯化合物 $\mathrm{C}\left(\mathrm{sp}^{3}\right)-\mathrm{H}$ 键在碱性条件更容易活化, 该 反应中使用 $\mathrm{Cs}_{2} \mathrm{CO}_{3}$ 作为碱性添加剂.

2015 年, 吴安心课题组 ${ }^{[70]}$ 首次在 $\mathrm{I}_{2} / \mathrm{DMSO}$ 体系下, 由芳香甲基酮和 2-氨基吡啶通过 C-3 甲基硫化和 C-6 碘 化直接构建了 6-碘-3-甲基硫咪唑[1,2- $a$ ]吡啶化合物 86
(Scheme 15). 基于前期工作, 作者设想在分子碘存在 下，甲基酮可以原位转化为相应的 $\alpha$-碘代羰基化合物， 而 2-氨基吡啶则原位生成了 5-碘-2-氨基吡啶, 由两种 中间体交叉串联得到 2-氨基吡啶盐. 随后, 通过分子内 环化、芳构化、C-3 甲基硫化合成目标产物 86. 反应中 DMSO 原位生成 DMS, 参与 C-3 甲基硫化.

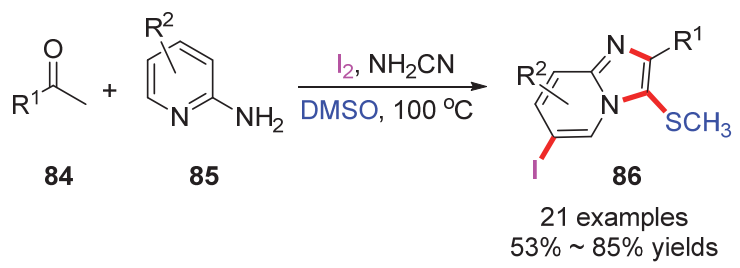

图式 15 6-碘-3-甲基硫咪唑[1,2- $a$ ] 吡啶化合物的直接合成 Scheme 15 Direct synthesis of 6-iodo-3-methylthioimidazo[1,2-a]pyridines

2016 年，一种无保护的苯胺和甲基酮直接双 $\mathrm{C}-\mathrm{H}$ 键功能化被证明能够高效地实现苯胺的 C(4)-二羰基 化 ${ }^{[71]}$ (Scheme 16). 化学和区域选择性地氧化苯胺 $\mathrm{C}\left(\mathrm{sp}^{2}\right)-\mathrm{H}$ 键/甲基酮 $\mathrm{C}\left(\mathrm{sp}^{3}\right)-\mathrm{H}$ 键进行交叉偶联. 这种 直接氧化偶联避免了底物的预功能化, 由副产物 HI 促 进反应进行. 该反应最突出的创新点是通过 $\mathrm{C}-\mathrm{H}$ 功能 化而不是没有保护的 $\mathrm{N}-\mathrm{H}$ 的功能化.

作者提出了可能的反应机理. 苯乙酮通过碘化/ Kornblum 氧化得到双羰基中间体 87c, 之后醛基被 $\mathrm{HI}$

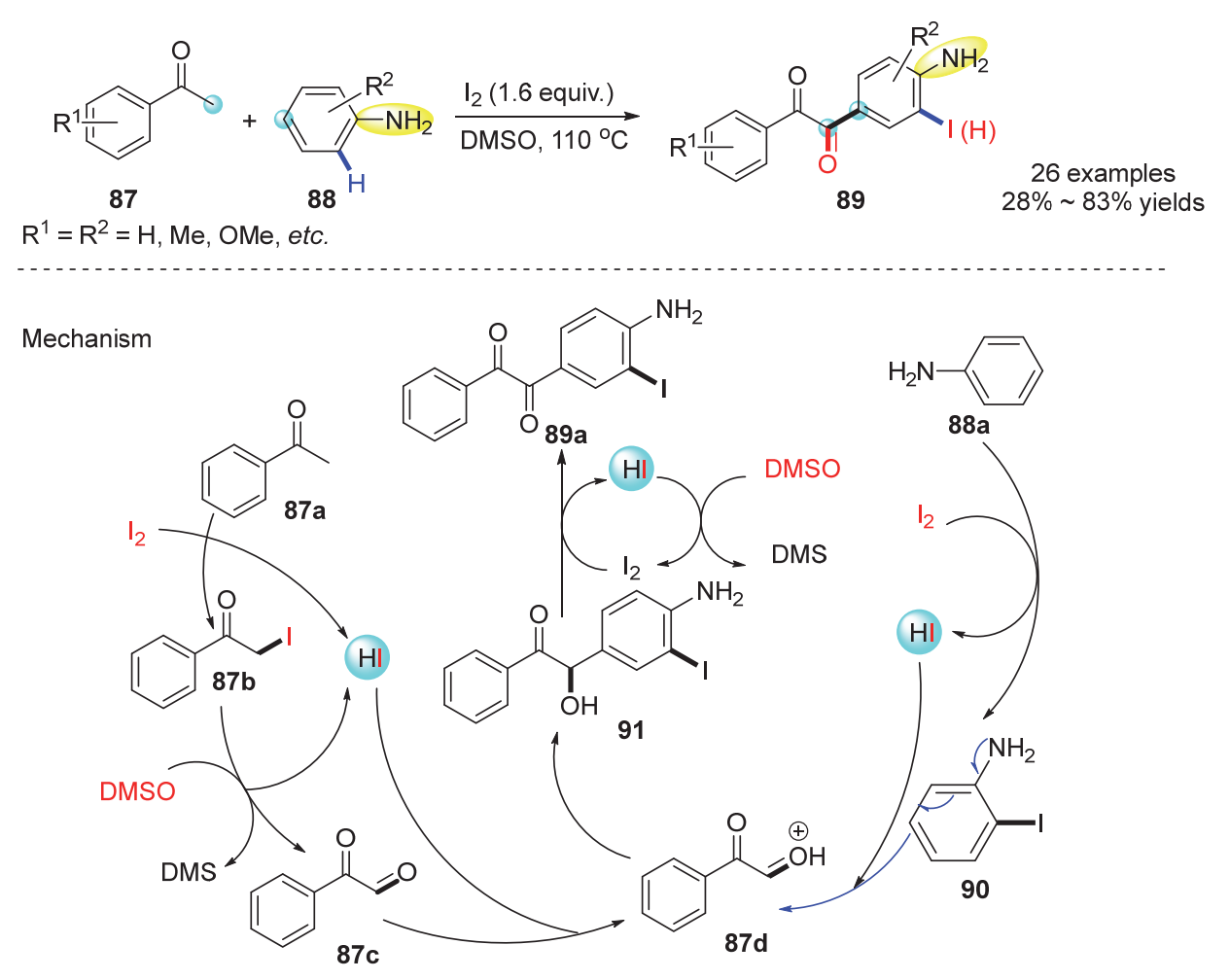

图式 16 碘促进无保护的苯胺与甲基酮的氧化交叉偶联反应

Scheme 16 Iodine-promoted oxidative cross-coupling of unprotected anilines with methyl ketones 
激活得到带正电荷化合物 87d. 底物 88a 与碘发生亲电 取代得到 2-碘苯胺中间体 90, 再与中间体 87d 通过 Friedel-Crafts 型反应(傅克反应)原位生成中间体 91. 最 后，中间体 91 快速被碘氧化得到目标产物 89a.

2019 年, 吴安心课题组 ${ }^{[72]}$ 报道了碘介导的芳基甲 基酮和 4-羟基香豆素的氧化串联反应，高效地合成多取 代吡喃[3,2-c]苯并吡喃-2,5-二酮化合物 94 (Scheme 17, a). 该方法通过碘化/Kornblum 氧化/环化的反应顺序步 骤进行. 同年, 该课题组报道了 ${ }^{[73]}$ 由芳基甲基酮和硫氰 酸盐作为底物, 通过调节添加剂选择性地合成 $\alpha$-酮酰胺 化合物 97 和 2-酰基啞唑化合物 96 的方法(Scheme 17, b). 首次使用硫氰酸盐用作氨基替代物通过 $\mathrm{C}-\mathrm{N}$ 键裂解提 供胺源. 该方法丰富了硫氰酸盐的应用, 不局限于作为 “SCN"、“CN”或“S”源.

(a)

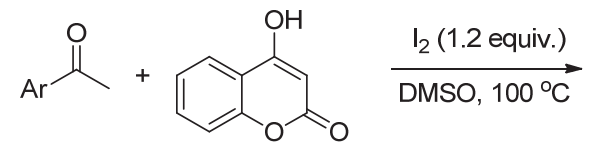

92

93

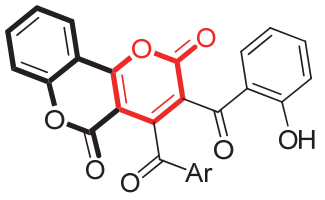

94

25 examples $55 \% \sim 89 \%$ yields

(b)

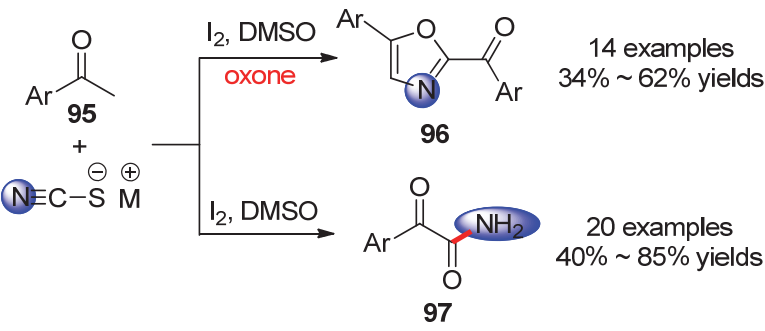

图式 $17 \mathrm{I}_{2} / \mathrm{DMSO}$ 介导多取代吡喃[3,2-c]苯并吡喃-2,5-二酮、 $\alpha$-酮酰胺和 2-酰基噁唑的合成

Scheme 17 Synthesis of polysubstituted pyrano[3,2c]chromene-2,5-diones, $\alpha$-ketoamides and 2-acyl-oxazoles via $\mathrm{I}_{2}$ /DMSO-mediated

三唑吡啶是一类重要的杂环化合物, 广泛存在于天 然产物、合成药物和材料中, 并且具有显著的生物和药 物活性, 例如抗真菌、抗惊厥和抗菌活性等. 传统的合 成方法需要苛刻的反应条件, 且通常需要使用强酸和过 渡金属. 2019 年, 吴安心课题组 ${ }^{[74]}$ 使用 $\mathrm{I}_{2} / \mathrm{DMSO}$ 体系直 接对 2-甲基喹啉进行氧化 $\mathrm{C}\left(\mathrm{sp}^{3}\right)-\mathrm{H}$ 功能化, 通过[4+ 1]氧化环化策略简单高效地构建了 $1,2,4$-三唑并 [4,3- $a$ ] 吡啶化合物 100 (Scheme 18). 在温和的条件下, 通过连 续的碘化、Kornblum 氧化、缩合、氧化和芳构化反应 顺序步骤成功构建了 1,2,4-三唑并[4,3- $a$ ]吡啶化合物,
该方法具有较广的底物范围和较好的功能基团耐受性.

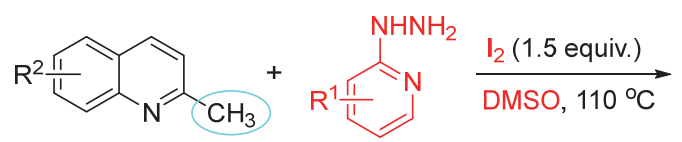

98

99

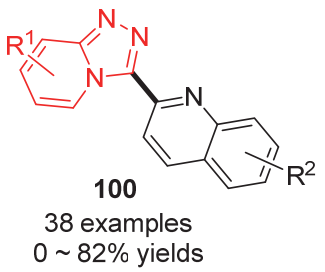

图式 $18 \mathrm{I}_{2} / \mathrm{DMSO}$ 介导 1,2,4-三唑并[4,3- $a$ ] 吡啶化合物的合成 Scheme 18 Synthesis of 1,2,4-triazolo[4,3-a]pyridines via $\mathrm{I}_{2} / \mathrm{DMSO}-$ mediated

除了以上吴安心课题组报道的一系列出色的研究 成果外, 其他课题组在此领域同样有着重要贡献. 2015 年, 马晨课题组 ${ }^{[75]}$ 提出了一种碘催化串联偶联方法, 通 过 $\mathrm{C}\left(\mathrm{sp}^{3}\right)-\mathrm{H}$ 键和 $\mathrm{C}\left(\mathrm{sp}^{2}\right)-\mathrm{H}$ 键交叉脱氢偶联策略合成 吡咯 [1,2- $a$ ] 喹喔啉和咪唑 [1,5- $a$ ] 喹喔啉衍生物 103 (Scheme 19, a). 随后, 该课题组 ${ }^{[76]}$ 提出了一种直接、有 效的一锅两步法合成喹喔啉衍生物 105 (Scheme 19, b). 以碘为催化剂, DMSO 为溶剂和氧化剂, 由 2-差基-2-苯 乙酮和邻二氨基苯合成了多种喹喔啉衍生物 105.

(a)

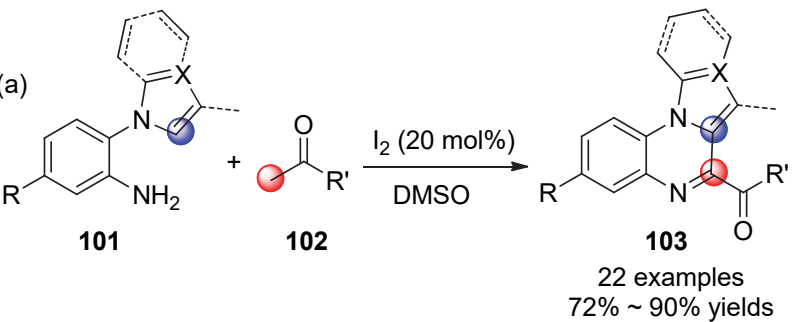

(b)

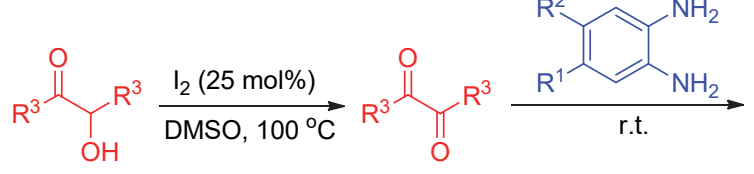

104

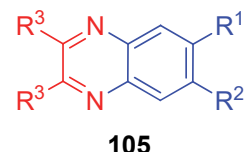

23 examples

$78 \% \sim 99 \%$ yields

图式 19 碘催化一锅法合成喹喔啉衍生物

Scheme 19 Iodine-catalyzed synthesis of quinoxaline derivatives via one-pot method

2015 年, Ilangovan 课题组 ${ }^{[77]}$ 通过对 $\mathrm{C}(\mathrm{sp})-\mathrm{H}$ 、 $\mathrm{C}\left(\mathrm{sp}^{2}\right)-\mathrm{H}$ 和 $\mathrm{C}\left(\mathrm{sp}^{3}\right)-\mathrm{H}$ 键进行氧化形成酰胺, 由 $2^{\prime}$-氨基 苯基乙炔、 $2^{\prime}$-氨基苯乙烯和 $2^{\prime}$-氨基- $\beta$-酮酯构建了吲哚 二酩化合物 107 (Scheme 20). 就 $2^{\prime}$-氨基- $\beta$-酮酯类底物 
而言, 在分子碘的作用下, 对 $\alpha$-羰基 $\mathrm{C}-\mathrm{H}$ 键进行活化, 再通过分子内亲核取代, 直接得到目标产物. 该方法可 应用于吲哚醌(Isatins)类生物活性化合物的合成.

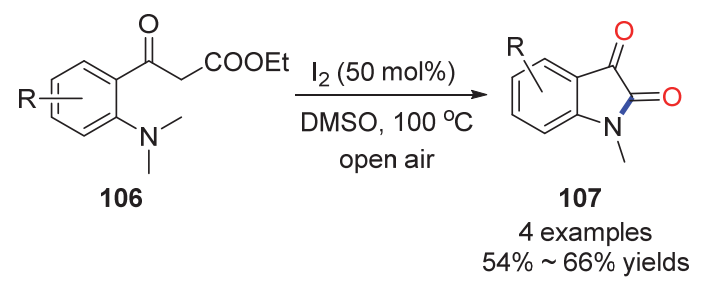

图式 20 分子碘促进由 $2^{\prime}$-氨基- $\beta$-酮酯高效合成吲哚醌 Scheme 20 Molecular iodine promoted efficient construction of isatins 2 '-amino- $\beta$-ketoesters

2015 年, 焦宁课题组 ${ }^{[78]}$ 开发了一种 $\mathrm{I}_{2}$ 催化酮与二 甲基亚砜的 $\alpha$-羟基化反应(Scheme 21, a). 以廉价易得的 $\mathrm{I}_{2}$ 作为催化剂, DMSO 作为氧化剂、氧源和溶剂, 对脂肪 族二级或者三级的 $\mathrm{C}\left(\mathrm{sp}^{3}\right)-\mathrm{H}$ 键进行活化, 构建 $\mathrm{C}-\mathrm{O}$ 键. 随后, 该课题组 ${ }^{[79]}$ 开发了一种新型的 $\mathrm{I}_{2} / \mathrm{DMSO}$ 催化 环已酮在加热条件下通过选择性多步氧化和脱氢芳构 化构建高价值的取代邻苯二酚化合物 111 的方法 (Scheme 21, b). 并且通过改变底物, 开发了另外一种多 取代的环已烯酮在相同体系下通过脱氢芳构化合成多 取代苯酚化合物 113 的方法 ${ }^{[80]}$ (Scheme 21, c). 作者通过 密度泛函理论(DFT) 计算, 合理地解释了反应途径 (Scheme 21, d). 单取代的环己酮在 $I_{2}$ 催化下得到 $\alpha$-碘代 化合物后，通过 $\mathrm{S}_{\mathrm{N}} 2$ 亲核取代得到邻酮中间体，再转化 为邻苯二酚. 而多取代环己酮在得到 $\alpha$-碘代化合物后, 通过 E2 消除, 得到环己烯酮, 最后转化为多取代苯酚. 前者使用 DMSO 作为氧化剂、氧源和溶剂; 而后者则使 用 $\mathrm{CH}_{3} \mathrm{NO}_{2}$ 作为溶剂. 此类反应操作方便、环境友好并 且高效实用, 为有价值的芳香化合物提供了一种直接的 合成方法.

2015 年, Ahmed 课题组 ${ }^{[81]}$ 提出了一种在无金属条件 下 $\alpha$-酮酰胺化合物的简便合成途径(Scheme 22). 该方 法采用 $\mathrm{I}_{2} / \mathrm{DMSO}$ 体系促进芳基甲基酮与胺之间的氧化 偶联反应. 机理研究表明, $\alpha$-酩酰胺化合物 $\mathbf{1 1 6}$ 的 C(1)氧原子来源于 DMSO.

2016 年, 杨罗课题组和王立霞课题组 ${ }^{[82]}$ 开发了一 种高效、实用的碘催化 $\mathrm{C}\left(\mathrm{sp}^{3}\right)-\mathrm{H}$ 键的功能化反应, 构 建了喹唑啉- 4(3H)-酮化合物 119 (Scheme 23, a). 该方 法以烷基氮杂芳烃 118 为起始原料, 以 $\mathrm{O}_{2}$ 为末端氧化 剂，该方法较之前的报道更为“绿色”. 机理研究表明， 活化 $\mathrm{C}\left(\mathrm{sp}^{3}\right)-\mathrm{H}$ 键转化为碘代中间体后, 通过 Kornblum 氧化得到醛基中间体或烷基氮杂芳烃的亲核胺化得到 亚胺中间体. 王桦课题组 ${ }^{[83}$ ]报道了碘催化的环缩合反 应和 $\mathrm{C}-\mathrm{H}$ 键的磺化反应, 有效合成了 $\mathrm{C}-4$ 磺化吡唑类化 (a)

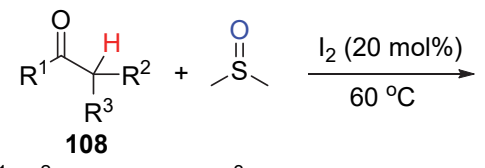

$\mathrm{R}^{1}, \mathrm{R}^{2}=$ Aryl, alkyl; $\mathrm{R}^{3}=\mathrm{H}$, alkyl

(b)

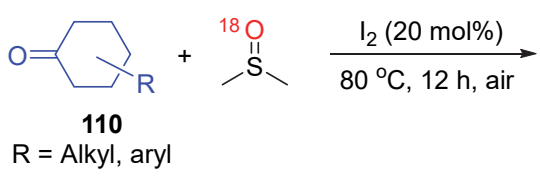<smiles>[R]C(=O)C([R])([R])O</smiles>
$37 \% \sim 82 \%$ yields $\mathrm{HO}^{18}$

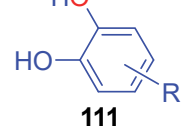

22 examples $16 \% \sim 91 \%$ yields

(c)<smiles>[R]C1=C([R])C([R])C([R])C(=O)C1[R]</smiles>

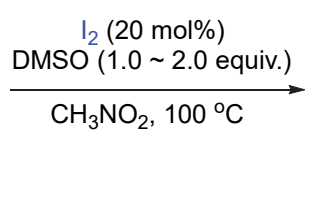<smiles>[R]c1c([R])c([R])c(O)c([R])c1[R]</smiles>

113

20 examples $26 \% \sim 95 \%$ yields

(d) DFT calculation

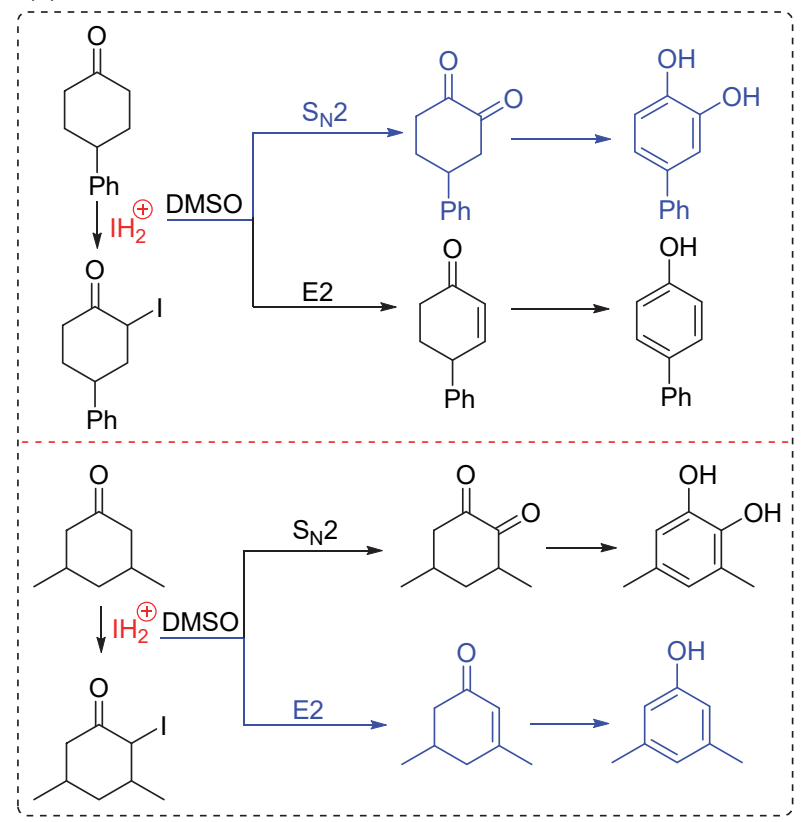

图式 21 碘催化酮的 $\alpha$-差基化和环己酮的多次氧合和脱氢芳 构化

Scheme $21 \quad \mathrm{I}_{2}$-catalyzed $\alpha$-hydroxylation of ketones and multiple oxygenation and dehydrogenative aromatization of cyclohexanone

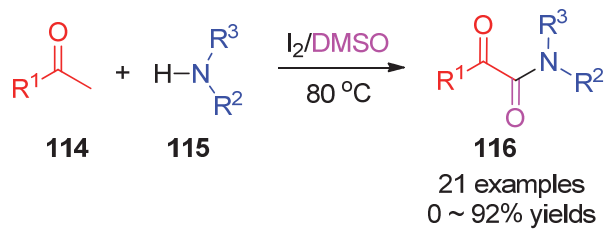

图式 $22 \mathrm{I}_{2} / \mathrm{DMSO}$ 促进 $\mathrm{C}\left(\mathrm{sp}^{3}\right)-\mathrm{H}$ 功能化合成 $\alpha$-酮酰胺 Scheme $22 \mathrm{I}_{2} / \mathrm{DMSO}$-promoted $\mathrm{C}\left(\mathrm{sp}^{3}\right)-\mathrm{H}$ functionalization to synthesize $\alpha$-ketoamides

合物 123 (Scheme 23, b). 该反应为分子碘催化 1,3-二 
(a)

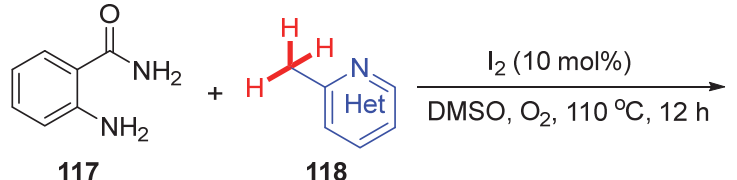<smiles>O=c1[nH]c(-c2ccccn2)nc2ccccc12</smiles>

5 examples $60 \% \sim 95 \%$ yields

(b) $\mathrm{R}^{1} \stackrel{\mathrm{O}}{\mathrm{O}}+\mathrm{R}^{2} \mathrm{NHNH}_{2}+\mathrm{R}^{3} \mathrm{SH} \frac{\mathrm{I}_{2}(5 \mathrm{~mol} \%)}{\mathrm{DMSO}(3 \text { equiv. }), 70^{\circ} \mathrm{C}}$

120 $121 \quad 122$<smiles>[R]Sc1c([R])nn([R2])c1O</smiles>

30 examples $60 \% \sim 88 \%$ yields

图式 23 I $2 / \mathrm{DMSO}$ 催化喹唑啉和 C-4 磺化吡唑类化合物的合 成

Scheme $23 \mathrm{I}_{2} / \mathrm{DMSO}$-catalyzed synthesis of quinazolinones and $\mathrm{C}-4$ sulfenylated pyrazoles

酮、肼和硫醇的多组分反应，一锅法构建了两个 $\mathrm{C}-\mathrm{N}$ 键和一个 $\mathrm{C}-\mathrm{S}$ 键.

2016 年, Prabhu 课题组 ${ }^{[84]}$ 在 $\alpha-\mathrm{CH}_{2}$ 或 $\alpha-\mathrm{CH}$ 存在下, 采用交叉脱氢串联策略(CDC), 实现了 $\alpha$-甲基酮区域选 择性磺酰化(Scheme 24, a). 醛也表现出良好的选择性, 形成相应的 $\alpha$-磺化产物. 首次报道了在 $\alpha-\mathrm{CH}_{2}$ 或 $\alpha-\mathrm{CH}$ 存在下甲基酮区域选择性磺酰化以及醛区域选择性磺 酰化. 该方法使用廉价的碘作为催化剂, 易得的 DMSO 作为氧化剂, 对环境友好, 有着广泛的底物范围, 得到 良好到优异的产率. 2017 年, Prabhu 课题组 ${ }^{[85]}$ 探索了一 种简单高效的吡唑酮与多种杂环硫醇、杂环硫酮和二硫 化物的磺化反应(Scheme $24, b)$. 该方法具有广泛的底 物范围，在无金属条件下短时间内获得了良好到优异的 产率.

2016 年，邱仁华课题组和许新华课题组 ${ }^{[86]}$ 报道了 碘催化的 1,2-二苄基硫烷和二糠基二硫化合物合成硫代 酰胺化合物 132 的反应(Scheme 25). 以 DMSO 作为氧化 剂和溶剂, 通过氧化得到了一系列的硫代酰胺化合物. 该方法可实现克级放大实验，是对 1,2-二苄基硫烷化合 物在 $\mathrm{C}-\mathrm{S}$ 键和 $\mathrm{C}-\mathrm{N}$ 键构建方面的有效补充.

2016 年, 余孝其课题组 ${ }^{[87]}$ 开发了一种合成 3-酰基 苯并噻二嗪 1,1-二氧化物 135 的新方法(Scheme 26). 在 $\mathrm{I}_{2} / \mathrm{DMSO}$ 体系下, 一系列电子结构多样化的苯乙酮与 2氨基苯磺酰胺反应，得到了中等到良好的产率.
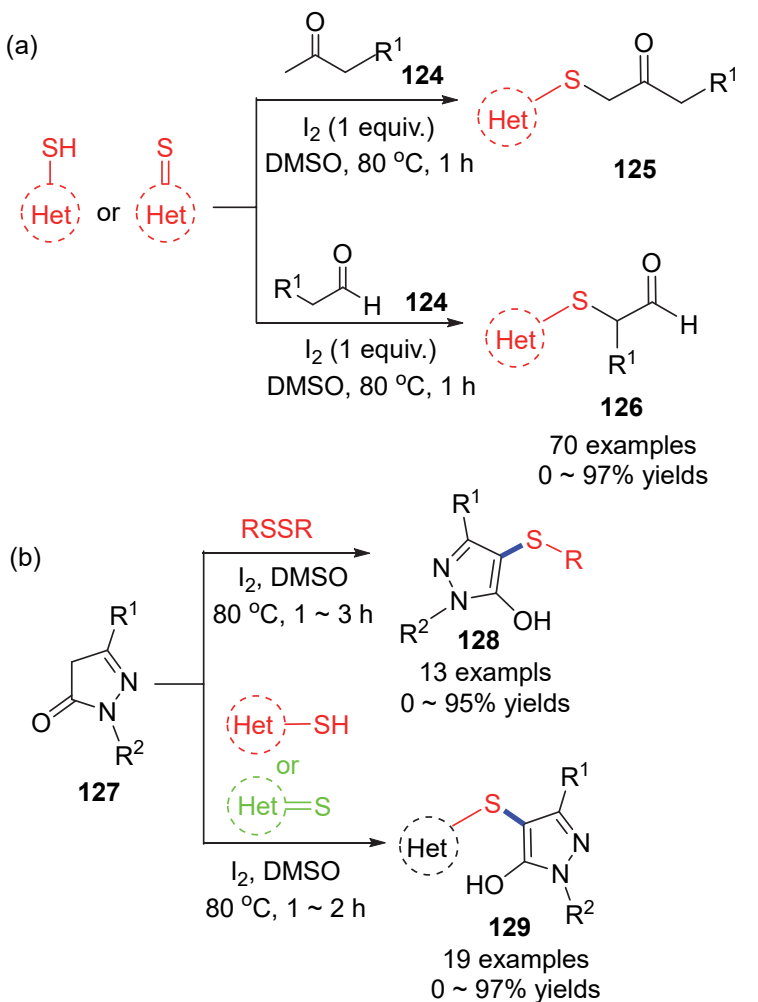

图式 24 碘介导羰基化合物和吡唑酮的区域选择性 $\mathrm{C}-\mathrm{H}$ 磺 酰化反应

Scheme 24 Iodine-mediated regioselective $\mathrm{C}-\mathrm{H}$ sulfenylation of carbonyl compounds and pyrazolones

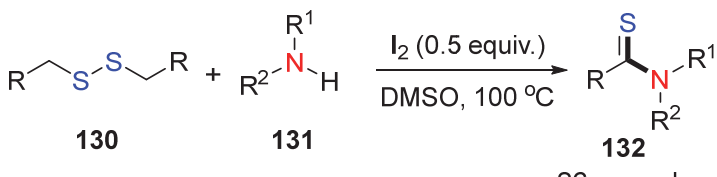

$$
\begin{aligned}
& 26 \text { examples } \\
& 17 \% \text { 95\% yields }
\end{aligned}
$$

图式 25 碘促进由 1,2-二苄基砜和二糠基二硫合成硫代酰胺 Scheme 25 Iodine-promoted synthesis of thioamides from 1,2-dibenzyl-sulfane and difurfuryl disulfide
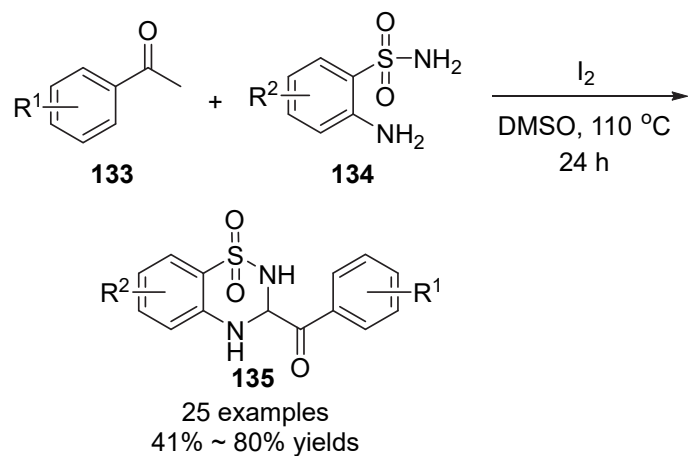

图式 26 碘介导 3-酰基苯并噻二嗪 1,1-二氧化物的合成 Scheme 26 Iodine-mediated synthesis of 3-acylbenzothiadiazine 1,1-dioxides 
2018 年, 潘远江课题组 ${ }^{[88]}$ 通过 $\mathrm{I}_{2}$ 催化环己酮和苯 胺的交叉脱氢芳构化合成了 $N, N^{\prime}$-二芳基邻苯二胺化合 物 138 (Scheme 27). 2016 年, 焦宁课题组 ${ }^{[79]}$ 首次报道了 以 DMSO 为溶剂和氧化剂, $\mathrm{I}_{2}$ 催化环己酮转化为邻苯二 酚的方法. 受此启发, 作者推测, $N, N^{\prime}$-二芳基邻苯二胺 衍生物可以通过 $\mathrm{I}_{2}$ 催化的交叉脱氢芳基化从环己酮和 苯胺中获得. 该方法使用 $\mathrm{I}_{2} / \mathrm{DMSO}$ 作为催化体系, 六甲 基磷酰三胺(HMPA)和甲磺酸 $(\mathrm{MsOH})$ 作为溶剂, $120{ }^{\circ} \mathrm{C}$ 下反应 $12 \mathrm{~h}$ 得到交叉脱氢芳构化产物. 因其具有无需金 属体系、操作方便及反应条件简便等优点, 在许多研究 领域特别是生物医学领域具有合成应用的潜力. 作者提 出了可能的反应机制, 环己酮通过碘代/Kornblum 氧化 得到关键邻崖基中间体 $\mathbf{B}$. 之后, 中间体 $\mathbf{B}$ 与两分子苯
胺反应得到活性中间体 $\mathbf{D}$. 最后，通过碘化脱氢实现芳 构化.

2018 年, Batra 课题组 ${ }^{[89]}$ 报道了在有氧条件下碘催 化的盐酸芳基肼与活性亚甲基化合物或 $N$-杂环化合物 的重氮化反应(Scheme 28). 该反应在加热或蓝色 LED 灯下进行，在碘催化下，由盐酸芳基肼氧化制得的芳基 二氮用作活性亚甲基化合物生成的自由基中间体的氮 清除剂，从而生成重氮化合物. 然而，该方法底物仅限 于含有至少一个腈基团的活性亚甲基化合物. 商业上可 用的廉价原料和开放的简单反应条件使该方法具有合 成重氮化合物的应用价值.

2018 年, Kamal 课题组 ${ }^{[00]}$ 采用 $\mathrm{I}_{2} / \mathrm{DMSO}$ 体系催化苯 胺或苯并噻唑与 2-甲基喹啉的氧化 $\mathrm{C}-\mathrm{H} / \mathrm{C}-\mathrm{H}$ 交叉偶

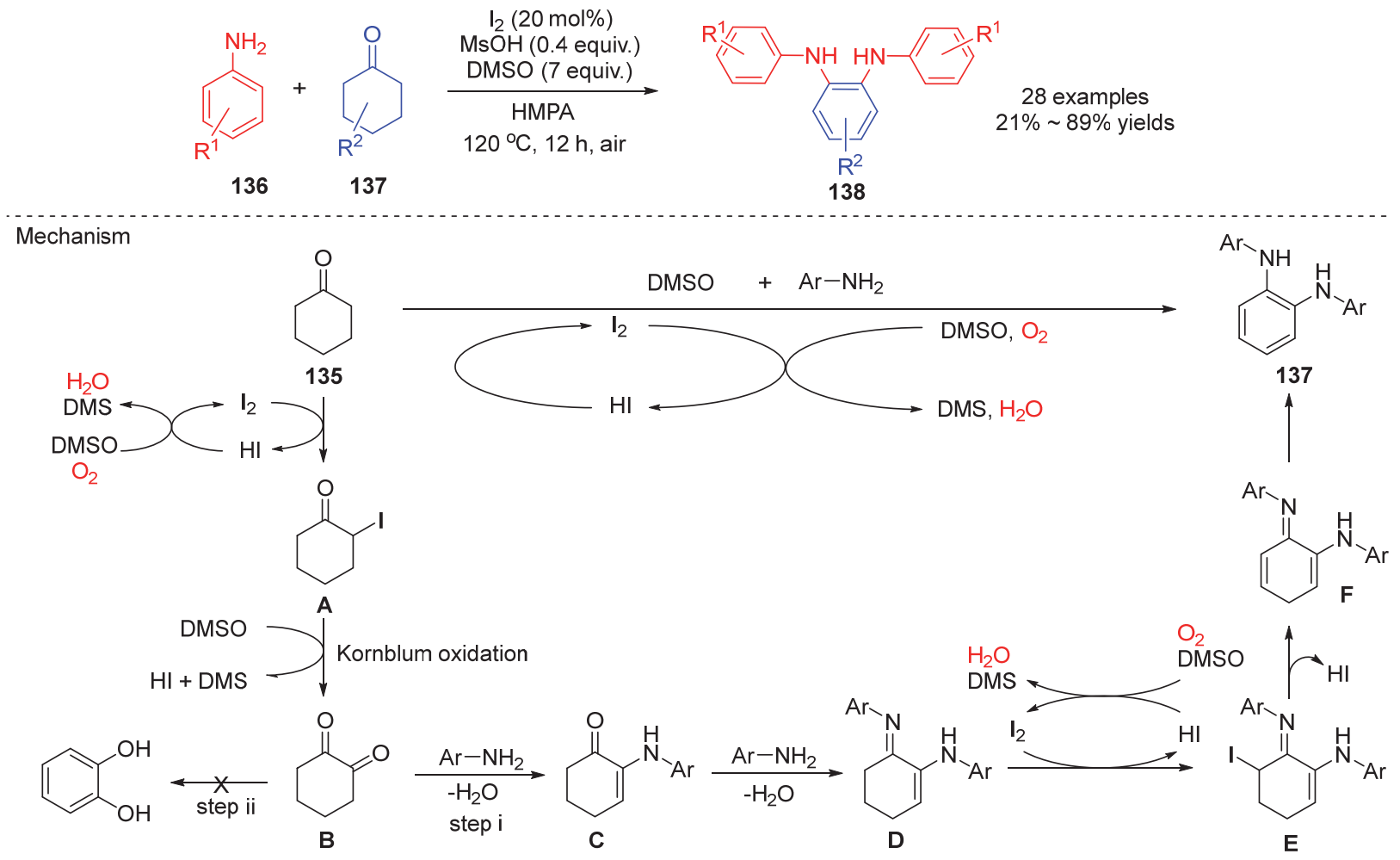

图式 $27 \mathrm{I}_{2} / \mathrm{DMSO}$ 催化 $N, N^{\prime}$-二芳基邻苯二胺化合物的合成

Scheme $27 \mathrm{I}_{2} / \mathrm{DMSO}$-catalyzed synthesis of $N, N^{\prime}$-diaryl-o-phenylenediamines
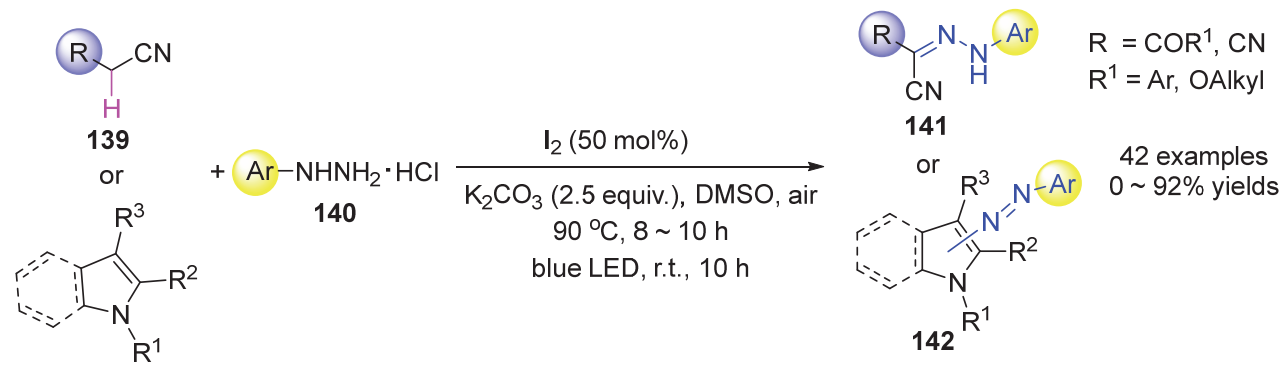

图式 28 在空气中碘催化芳基肼氢氯化物的重氮化反应

Scheme 28 Iodine-catalyzed diazenylation with arylhydrazine hydrochlorides in air 
联反应，以中等至良好的产率合成了 C(4)-羰基苯胺甲 基酮化合物 146 和 2-杂芳基苯并噻唑化合物 147 (Scheme 29, a). 该方法通过对 2-甲基喹啉的 $\mathrm{C}\left(\mathrm{sp}^{3}\right)-\mathrm{H}$ 键功能化/Kornblum 氧化/苯胺 $\mathrm{N}-\mathrm{H}$ 功能化(亲核取代) 的顺序反应得到 $\mathrm{C}(4)$-羰基苯胺甲基酮类化合物 146. 另 外, 额外加入 $\mathrm{KOH}$ 可以催化 2-甲基喹啉和苯并噻唑得 到 2-杂芳基苯并噻唑化合物 147. 作者推测 $\mathrm{KOH}$ 的作用 为促进苯并噻唑去质子化开环. 2019 年, 该课题组 ${ }^{[91]}$ 同 样通过 $\mathrm{C}\left(\mathrm{sp}^{3}\right)-\mathrm{H}$ 键功能化, 建立了一种 $\mathrm{I}_{2} / \mathrm{DMSO}$ 介导 的一锅法合成了 1,3,4-噁二唑化合物 150/153 (Scheme 29 , b). 该方法使用 $I_{2}$ 作为催化剂催化氧化胺化, 以 $\mathrm{Cs}_{2} \mathrm{CO}_{3}$ 作为有效的添加碱促进环化反应.

2019 年, Barrero 课题组 ${ }^{[92]}$ 利用 $\mathrm{I}_{2} / \mathrm{DMSO}$ 体系介导 $\alpha$-异丙烯基丙酮化合物一步合成了呋喃环化合物 155 (Scheme 30). 该方法已被用于合成具有重要生物活性 的六种萜烯呋喃衍生物, 如薄荷呋喃、莪术烯、苍术酮
和异苍术酮等. 同时，作者还通过串联反应直接由 4,5环氧吉马酮合成了 Linderazulene(钓樟), 显示了该方法 的合成潜力.

陈铁桥课题组 ${ }^{[93]}$ 通过 $\mathrm{I}_{2} / \mathrm{DMSO}$ 体系直接脱氢合成 了一系列 $\alpha, \beta$-不饱和键羰基化合物，拓展了 $\mathrm{I}_{2} / \mathrm{DMSO}$ 体 系在酮类和醛类化合物中的应用. 2016 年，该课题组 ${ }^{[94]}$ 采用 $\mathrm{I}_{2} / \mathrm{DMSO} / \mathrm{O}_{2}$ 催化体系, 通过 $\mathrm{C}\left(\mathrm{sp}^{3}\right)-\mathrm{H}$ 和 $\mathrm{C}\left(\mathrm{sp}^{2}\right)-$ $\mathrm{H}$ 双重活化实现酚类与 $N$-杂芳基甲烷直接氧化酰化，区 域选择性地构建了 2 -羟苯基芳基甲酮化合物 159 (Scheme 31, a). 采用同样体系, 他们 ${ }^{[95]}$ 还实现了苯胺与 $N$-异芳基甲烷的氧化对酰基化反应(Scheme 31, b). 该 方法通过原位生成的亚胺的 Friedel-Crafts 型转化实现 了氧化对酰化，位阻是该反应区域选择性高的关键. 在 $\mathrm{I}_{2} / \mathrm{DMSO} / \mathrm{O}_{2}$ 催化体系下, 对甲基进行氧化, 还实现了杂 芳醛化合物 164 的有效合成 ${ }^{[96]}($ Scheme 31, c). 在此反应 条件下，甲氧基、羰基、酯、硝基、酰胺和卤素等官 (a)<smiles>[H][R]1ccc2nc(C)ccc2c1</smiles><smiles>[R]c1cccc(N)c1CCc1ccccc1</smiles><smiles>[R17]c1ccc(C(=O)NN)cc1</smiles><smiles>Cc1ccc2ccccc2n1</smiles>

(b)

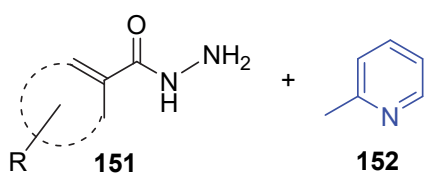

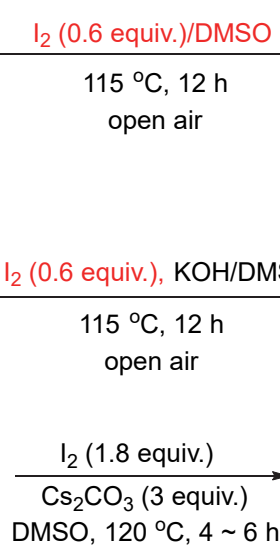<smiles>[R]c1cc(C(=O)c2ccc3cc[R](C)cc3n2)ccc1N</smiles>

14 examples $0 \sim 85 \%$ yields

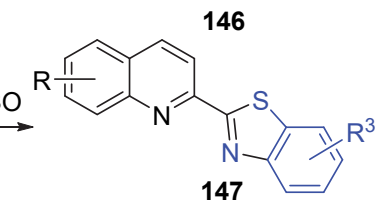

13 examples $0 \sim 90 \%$ yields 147<smiles></smiles>

10 examples $73 \% \sim 94 \%$ yields 150

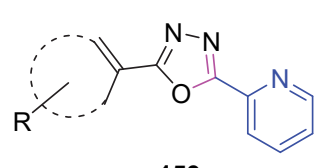

153
14 examples $18 \% \sim 89 \%$ yields

图式 $29 \mathrm{I}_{2} / \mathrm{DMSO}$ 促进 2-杂芳基苯并噻唑、甲基酮和 1,3,4-啞二唑化合物的合成

Scheme 29 I2/DMSO-promoted synthesis of 2-heteroaryl-benzothiazole, methanones and 1,3,4-oxadiazole scaffolds

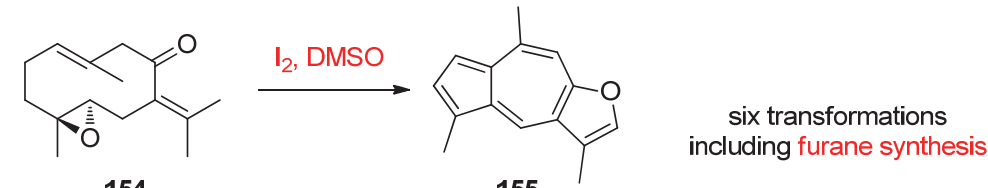

154

155

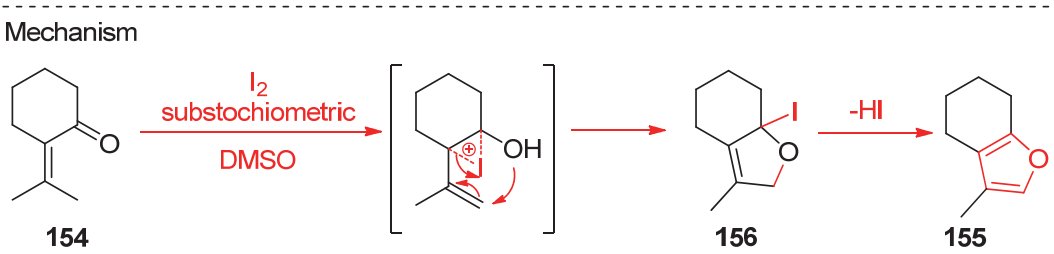

图式 $30 \quad \mathrm{I}_{2} / \mathrm{DMSO}$ 介导 $\alpha$-异丙烯基丙酮一步合成呋喃环

Scheme 30 One-step synthesis of furan rings from $\alpha$-isopropylidene ketones mediated by $\mathrm{I}_{2} / \mathrm{DMSO}$ 
(a)<smiles>Cc1ccccn1</smiles>

157

158

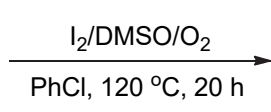<smiles>O=C(c1ccccn1)c1ccccc1O</smiles>

159 (b)

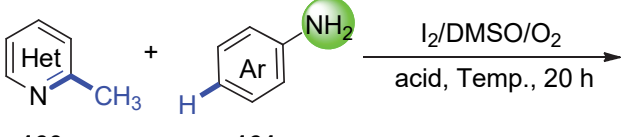

161

(c)<smiles>[R][C]1C=CC=c2cccnc2=C1</smiles>

163

(d)<smiles>O=C(Br)CCBr</smiles>

165
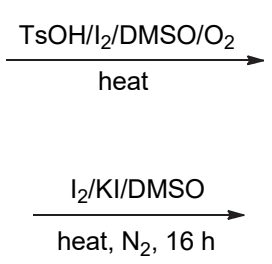

heat, $\mathrm{N}_{2}, 16 \mathrm{~h}$<smiles>O=C(c1ccc([N+](=O)[O-])cc1)c1ccccn1</smiles>

162
26 examples

$8 \% \sim 85 \%$ yields

32 examples $0 \sim 93 \%$ yields

23 examples $56 \% \sim 93 \%$ yields

图式 31 分子碘促进直接脱氢合成 $\alpha, \beta$-不饱和键羰基化合物

Scheme 31 Direct dehydrogenation for the synthesis of $\alpha, \beta$-unsaturated carbonyl compounds via iodine-promoted

能团均有良好的耐受性. 该方法通过碘代/Kornblum 氧 化实现转化. 对于氯霉素衍生物、罂粟碱等生物活性化 合物也能被氧化成相应的醛类和酮类. 2020 年, 陈铁桥 课题组 ${ }^{[97]}$ 又报道了 $\mathrm{I}_{2} / \mathrm{KI} / \mathrm{DMSO}$ 催化酮和醛的 $\alpha, \beta$ 脱氢 反应，生成共轭烯酮化合物 166 (Scheme 31d). 作者进 行了克级放大实验, 证明了反应的应用价值. DMSO 在 该反应中即作为溶剂, 也是弱氧化剂.

2019 年, Jeena 课题组 ${ }^{[98]}$ 报道了苯酮的苄基 $\mathrm{C}\left(\mathrm{sp}^{3}\right)$ $-\mathrm{H}$ 键在 $\mathrm{I}_{2} / \mathrm{DMSO}$ 体系下的功能化反应, 得到了相应的 二酮化合物 168, 分离产率为 $96 \%$ (Scheme 32). 该反应 为 $\mathrm{C}\left(\mathrm{sp}^{3}\right)-\mathrm{H}$ 键直接功能化提供了一种新思路, 并避免 了使用昂贵的过渡金属催化剂而导致官能团不相容和 底物范围有限制的缺点. 通过 EPR 光谱和控制实验, 表 明该反应中产生了碘自由基和芐基自由基 $169 . \mathrm{I}_{2} /$ DMSO 催化得到二酮化合物反应的机理是从热均裂分 子碘产生碘自由基开始. 在碘自由基存在下, 产生了芐 基自由基 169, 进而生成 $\alpha$-碘代酮中间体 170. 后续经过 Kornblum 氧化得到二酮化合物 $\mathbf{1 6 0}$.

2020 年, 祝艳平课题组 ${ }^{[99}$ ]报道了酰肼和甲基-杂环 芳烃的 $[4+1]$ 氧化环化反应, 通过直接的 $\mathrm{C}\left(\mathrm{sp}^{3}\right)-\mathrm{H}$ 键 功能化构建了多种 1,3,4-噁二唑化合物 174 (Scheme 33). $\mathrm{K}_{2} \mathrm{CO}_{3}$ 作为最佳的碱性添加剂可促进环化去质子.

至今 $\mathrm{I}_{2} / \mathrm{DMSO}$ 体系运用于 $\mathrm{C}\left(\mathrm{sp}^{3}\right)-\mathrm{H}$ 功能化反应已 经得到巨大的发展与应用. 采用不同的环化形式, 能够 有效地合成各种复杂杂环分子; 多对个 $\mathrm{C}\left(\mathrm{sp}^{3}\right)-\mathrm{H}$ 键功 能化, 通过氧化和脱氢芳构化, 能够构建芳烃类化合物; 通过脱氢交叉偶联策略(CDC), 实现区域选择性磺酰化; 以及和金属试剂联合促进反应等. 总之, $\mathrm{I}_{2} / \mathrm{DMSO}$ 体系 已经成功地开辟了不同的 $\mathrm{C}\left(\mathrm{sp}^{3}\right)-\mathrm{H}$ 功能化反应,

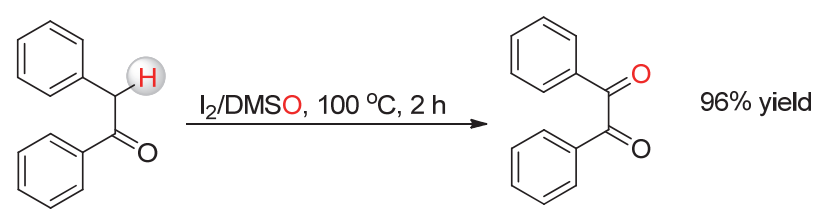

167

168

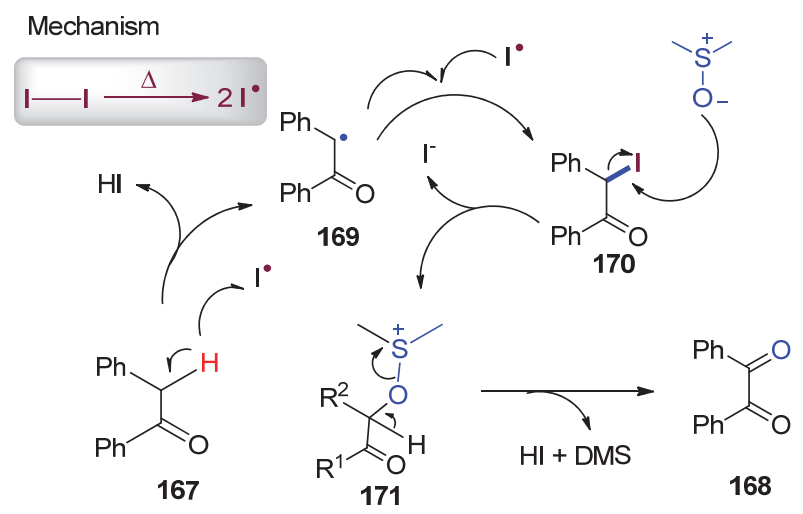

图式 $32 \mathrm{I}_{2} / \mathrm{DMSO}$ 促进了芐基 $\mathrm{C}\left(\mathrm{sp}^{3}\right)-\mathrm{H}$ 键氧化构建二酮化 合物

Scheme $32 \quad \mathrm{I}_{2} / \mathrm{DMSO}$-promoted oxidation of benzylic $\mathrm{C}\left(\mathrm{sp}^{3}\right)-$ $\mathrm{H}$ bonds to diketones

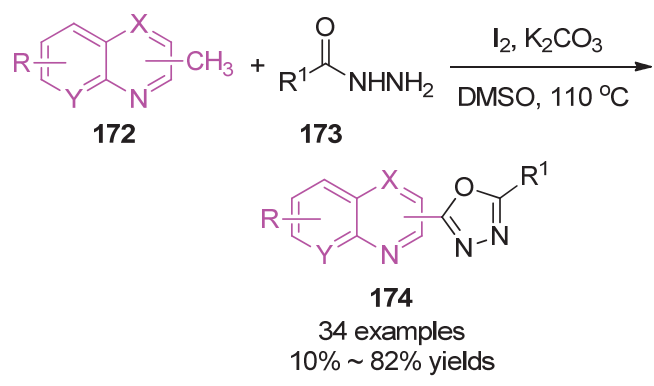

图式 33 碘催化 1,3,4-啞二唑化合物的合成 Scheme 33 Iodine-catalyzed synthesis of 1,3,4-oxadiazoles 
丰富了化学多样性. 使用 $\mathrm{I}_{2} / \mathrm{DMSO}$ 体系扩展活化位点 实现烯丙基 $\mathrm{C}-\mathrm{H}$ 键、羰基 $\beta-\mathrm{C}-\mathrm{H}$ 键以及更多的 $\mathrm{C}\left(\mathrm{sp}^{3}\right)-\mathrm{H}$ 键的精确功能化是今后研究努力的方向.

\section{$2.3 \mathrm{I}_{2} /$ 过氧化物体系催化的 $\mathrm{C}\left(\mathrm{sp}^{3}\right)-\mathrm{H}$ 功能化反应}

有机过氧化物是指含有过氧 $(\mathrm{O}-\mathrm{O})$ 键的有机化合 物, 例如过氧化氢、叔丁基过氧化氢(TBHP)、过氧化苯 甲酸叔丁酯( TBPB)、二叔丁基过氧化物(DTBP)及间氯 过氧苯甲酸 $(m \mathrm{CPBA})$ 等. 过氧化物是一类常用的氧化剂 和自由基引发剂, 广泛应用于各类氧化反应和自由基反 应中 ${ }^{[100-101]}$. 有机过氧化物和分子碘组合参与反应主要 有两种循环方式(Scheme 34). 目前, $I_{2} /$ peroxide 体系是 一种绿色、高效的催化体系, 广泛应用于 CDC 反应、氧 化偶联反应和 HLF 反应中, 是对过渡金属催化的此类 反应的一种有效补充.

(a)

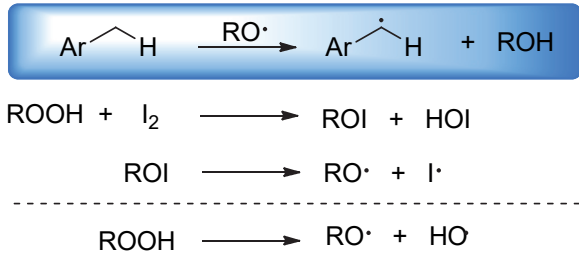

(b)

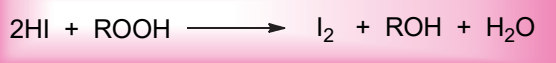

图式 34 由 $\mathrm{I}_{2} /$ 过氧化物引发自由基的一般策略 Scheme 34 General strategies of radical initiation by $\mathrm{I}_{2} /$ peroxide

2015 年, 雷爱文课题组 ${ }^{[102]}$ 报道了一种碘催化的氧 化 $\mathrm{C}\left(\mathrm{sp}^{3}\right)-\mathrm{H} / \mathrm{C}(\mathrm{sp})-\mathrm{H}$ 键交叉偶联反应，有效地构建了 呋喃和吲哚嗪类化合物 $\mathbf{1 7 8}$ (Scheme 35, a). 该反应通过 分子碘催化形成可逆的 $\mathrm{C}-\mathrm{I}$ 键来调节自由基的反应活 性，从而控制反应的选择性. 羰基化合物直接氧化 $\alpha-\mathrm{C}\left(\mathrm{sp}^{3}\right)-\mathrm{H}$ 功能化通常需要使用过量的金属氧化剂, 如 $\mathrm{Mn}(\mathrm{III}) 、 \mathrm{Cu}(\mathrm{II})$ 和 $\mathrm{Ce}(\mathrm{IV})$ 盐等. 过渡金属通过可逆配 位生成稳定的 $\alpha$-羰基烷基自由基，而可逆的 $\mathrm{C}-\mathrm{M}$ 键可 调节自由基活性. 因此, 作者设想可逆的 $\mathrm{C}-\mathrm{X}$ (卤素)键 同样也可能是调节自由基反应活性的另一种方法. 控制 实验证明了该反应是自由基加成/环化的反应机制. DFT 计算表明, 在自由基氧化过程中可能涉及到 HI 消去. 随 后, 该课题组 ${ }^{[103]}$ 通过碘催化实现了 $\beta$-酮酯、2-吡啶- $\beta$ 酯与烯烃的直接氧化偶联/环化反应, 用以制备二氢呋 喃和吲哚嗪化合物 181 (Scheme 35, b). 碘单质在过氧化 苯甲酸叔丁酯(TBPB)氧化下生成了碘自由基, 直接对 $\beta$-酮酯的 $\mathrm{C}\left(\mathrm{sp}^{3}\right)-\mathrm{H}$ 键进行活化, 得到相应的碳自由基. 同年, 雷爱文课题组 ${ }^{[104]}$ 使用碘催化了 $\mathrm{C}-\mathrm{H} / \mathrm{S}-\mathrm{H}$ 氧化 偶联化反应. 该反应由 1,3 -二酮和噻吩醇一步反应直接 构建 $\beta$-二羰基硫醚化合物 184 (Scheme 35, c). 硫原子具 有强配位性, 硫醚产品可能进一步氧化成磺胺类或砜类
化合物，使得酮和硫酚之间的 $\mathrm{C}-\mathrm{H} / \mathrm{S}-\mathrm{H}$ 氧化偶联化 形成硫醚化合物更具挑战性. 该反应使用碘作为催化 剂, 二叔丁基过氧化物(DTBP)作为氧化剂, 乙酸乙酯作 为溶剂, $\mathrm{N}_{2}$ 保护, $120{ }^{\circ} \mathrm{C}$ 下反应. 通过控制实验说明 $\mathrm{C}-$ $\mathrm{S}$ 键是通过自由基取代途径形成的.

(a)
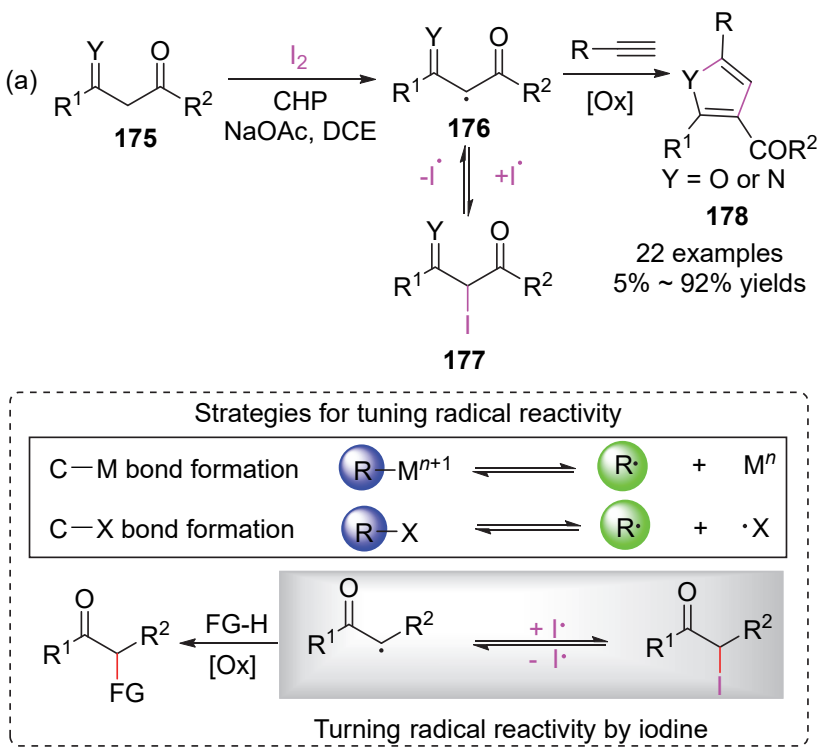

(b)
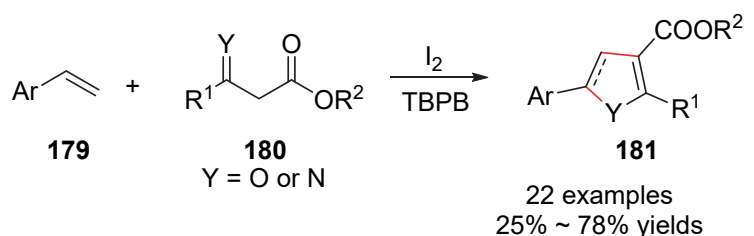

(c)

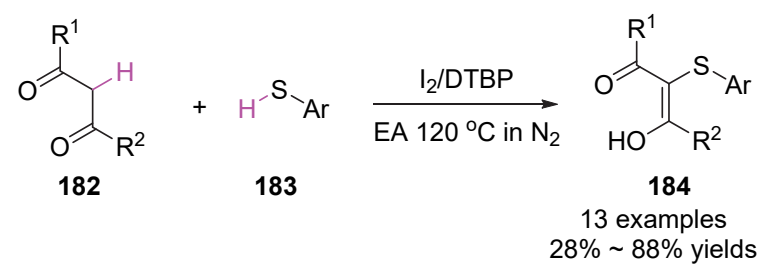

图式 $35 \mathrm{I}_{2} /$ 过氧化物催化氧化偶联反应

Scheme $35 \quad I_{2} /$ Peroxide-catalyzed oxidative coupling reaction

Adimurthy 课题组 ${ }^{[105]}$ 开发了一种碘催化分子内 $\mathrm{C}\left(\mathrm{sp}^{3}\right)-\mathrm{H}$ 功能化新反应，由 $N$-芳基乙酰胺化合物合成 2,5-二取代啞唑类化合物 186 (Scheme 36). 该反应通过 形成 $\mathrm{N}$ - I 键中间体 187 后, 裂解形成氧中心自由基 $\mathbf{1 8 8}$, 再通过 1,5-HAT 进行自由基转移转化为中间体 189. 随 后脱去一分子 $\mathrm{HI}$ 形成双键, 再通过烯烃分子内亲核加 成得到 192, 最后离去 HI 后得到最终目标产物.

2015 年, Chaskar 课题组 ${ }^{[106]}$ 采用一锅法合成了喹喔 啉类化合物 195 (Scheme 37,a). 由易得的乙基芳烃在 $I_{2}$ / TBHP 作用下生成苯乙醛, 随后转化为苯乙二醛, 再与 邻苯二胺缩合得到喹喔啉类化合物. 该方法官能团耐受 性好，催化剂廉价易得，有望被广泛应用于合成复杂分 

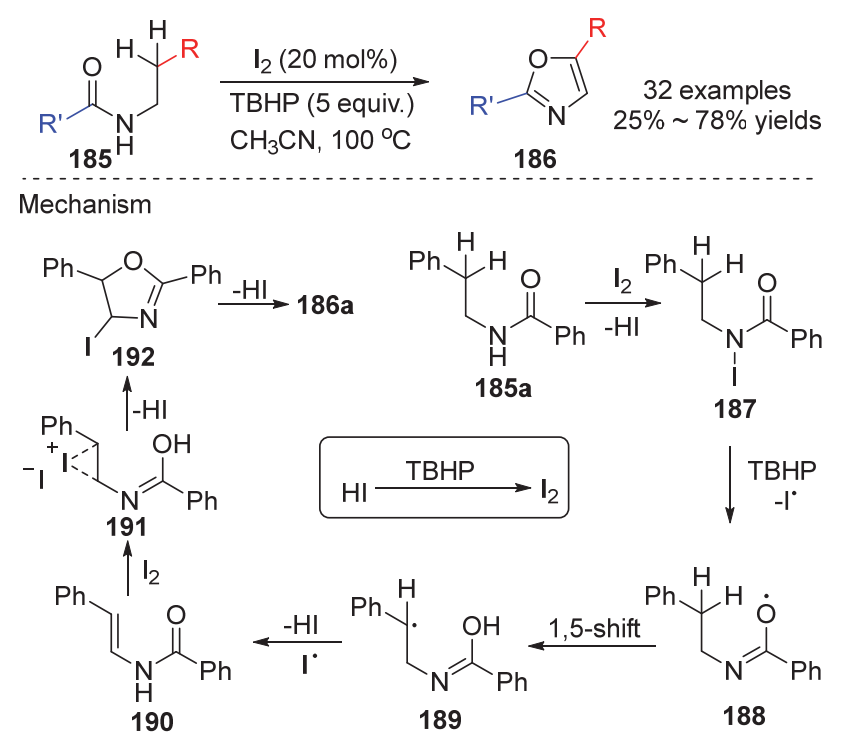

图式 $36 \mathrm{I}_{2}$ /过氧化物催化 $2,5-$ 二取代㤠唑的合成 Scheme $36 \quad I_{2} /$ peroxide-catalyzed synthesis of 2,5-disubstitutedoxazoles

子所需的喹咥啉骨架. 随后, Chaskar 课题组 ${ }^{[107]}$ 还通过 对苄基 $\mathrm{C}\left(\mathrm{sp}^{3}\right)-\mathrm{H}$ 键的直接活化, 实现了由乙基芳烃到 苯酰胺的转变 (Scheme 37, b). 该反应以碘为催化剂, TBHP 为氧化剂, 形成三碘甲基酮中间体, 然后与氨水 进行亲核取代形成酰胺. 该串联方法简单高效, 对环境 友好, 并为合成具有生物活性的苯酰胺提供新思路.

(a)

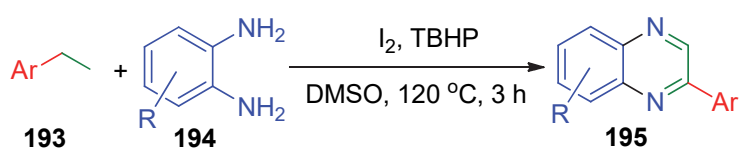
20 examples $29 \% \sim 92 \%$ yields

(b)

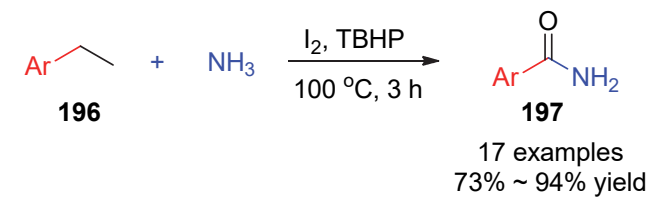

图式 37 碘催化 $\mathrm{C}\left(\mathrm{sp}^{3}\right)-\mathrm{H}$ 功能化合成喹喔啉和苯酰胺化合 物

Scheme 37 Iodine-catalyzed synthesis of quinoxalines and benzamides via $\mathrm{C}\left(\mathrm{sp}^{3}\right)-\mathrm{H}$ functionalization

Kumar 课题组 ${ }^{[108]}$ 报道了一种选择性氧化 $\mathrm{C}\left(\mathrm{sp}^{3}\right)-\mathrm{N}$ 偶联的方法, 高效地由 2-烷基苯酰胺合成了 $N$-芳基异 吲哚酮化合物 199 (Scheme 38). 该方法中加入碘、碳酸 钾和 DTBP, $110 \sim 140{ }^{\circ} \mathrm{C}$ 下乙腈中反应. 通过选择性氧 化偶联 $\mathrm{C}\left(\mathrm{sp}^{3}\right)-\mathrm{H}$ 键和 $\mathrm{N}-\mathrm{H}$ 键, 由 2-烷基茮酰胺化合 物合成了具有重要生物活性的异吲哚酮类衍生物. 同 时, 还通过吲哚洛芬和 dwp205190 药物(2-(3-(环戍氧 基)-4-甲氧基苯基)异吲哚啉-1-酮)的合成，说明了该方 法实用性. 机理研究证明, 在碱性下碘催化形成 $\mathrm{N}-\mathrm{I}$
键. 随后, N-I 键在 DTBP 诱导下裂解形成氮中心自由 基，通过 1,5-HAT 转移自由基.

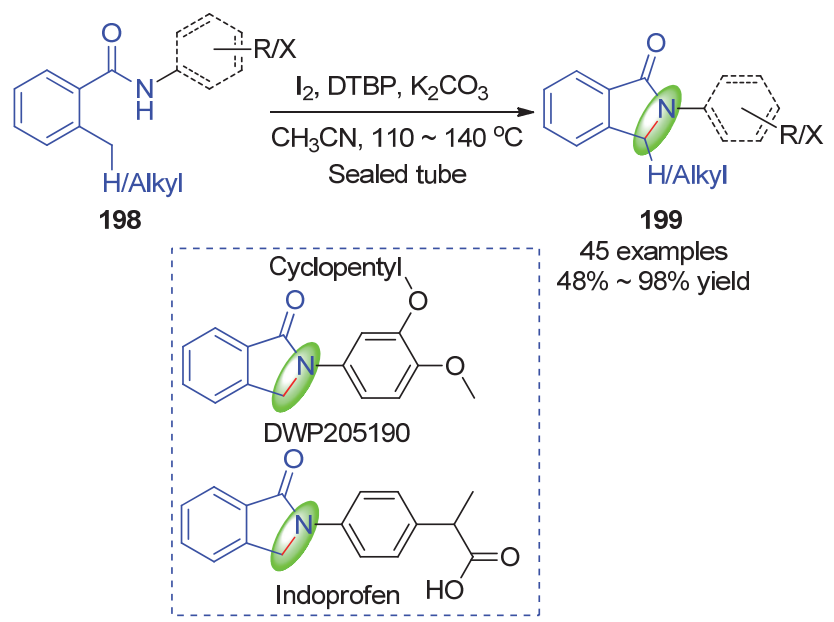

图式 38 碘催化分子内选择性 $\mathrm{C}\left(\mathrm{sp}^{3}\right)-\mathrm{N}$ 氧化偶联 Scheme 38 Iodine-catalyzed intramolecular selective oxidative $\mathrm{C}\left(\mathrm{sp}^{3}\right)-\mathrm{N}$ coupling

$\mathrm{I}_{2}$ /peroxide 体系能够有效地催化甲基芳烃与异喹啉 或喹啉的氧化偶联反应, 选择性地对异喹啉或喹啉进行 结构改造. 下述五种方法很大程度上完善并发展了异喹 啉或喹啉的 $\mathrm{C}\left(\mathrm{sp}^{3}\right)-\mathrm{H}$ 功能化反应. 2016 年, 杨罗课题 组 ${ }^{[109]}$ 开发了一种高效、实用的碘催化茮基 $\mathrm{C}-\mathrm{H}$ 键和氮 杂芳烃的 $N$-烷基化反应，构建了 $N$-烷基-异喹啉-1(2H)酮化合物 202 (Scheme 39, a). 该方法避免了昂贵的贵金 属催化剂的使用以及卤化物/金属废物的产生，是构建 异喹啉酮的一种 “绿色” 途径. 同时，该课题组还通过 两步反应简单高效地得到异吲哚 $[2,1-b]$ 异喹啉-7(5H)-酮 化合物 203，该化合物是一种拓扑异构酶 I 抑制剂. 2017 年, 杨罗课题组 ${ }^{[110]}$ 开发了一种碘催化异喹啉与甲基芳 烃的交叉脱氢偶联反应. 由不同的氧化剂引发反应，选 择性地产生 $\mathrm{C}(1)$-或 $N$-茮基取代的化合物 206 和 207 (Scheme 39, b). 2019 年, 该课题组 ${ }^{[111]}$ 通过 $\mathrm{I}_{2} / \mathrm{TBHP}$ 体系 同时对 $\mathrm{C}\left(\mathrm{sp}^{3}\right)-\mathrm{H}$ 键和 $\mathrm{C}\left(\mathrm{sp}^{2}\right)-\mathrm{H}$ 键进行功能化，同时构 建了 $\mathrm{C}-\mathrm{N}$ 键和 $\mathrm{C}-\mathrm{I}$ 键( Scheme $39, \mathrm{c}$ ). 该反应通过碘 化 $/ N$-苯基化/氧化串联的反应顺序实现转化. 相比较, 2019 年, Reedy 课题组 ${ }^{[112]}$ 采用 $\mathrm{I}_{2} / \mathrm{TBHP}$ 体系的常规催化 策略，对底物结构进行修饰，得到了不同结构的喹啉化 合物 213 和 214 和异喹啉 215 (Scheme 39, d). 2017 年, 马大友课题组 ${ }^{[113]}$ 报道了一种碘催化氧化异喹啉与甲基 芳烃的多个 $\mathrm{C}-\mathrm{H}$ 键的功能化反应, 高效地合成异喹啉1,3,4(2H)-三酮衍生物 218 (Scheme 39, e). 该反应通过 苄基 $\mathrm{C}\left(\mathrm{sp}^{3}\right)-\mathrm{H}$ 键碘化/ $N$-苯基化/酰胺化/双 $\mathrm{C}\left(\mathrm{sp}^{2}\right)-\mathrm{H}$ 氧化的反应顺序实现转化. 
(a)<smiles>[R]c1cccc2cc[nH+]cc12</smiles>

200

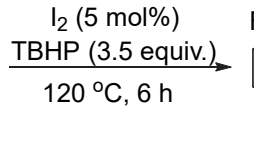

BHP (3.5 equiv.)

201<smiles></smiles>

202

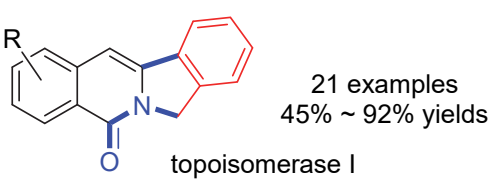

203 inhibitor (b)<smiles>[R]c1ccccc1CN1C=CC2=CC=CC(=O)C2C1=O</smiles>
206

$$
\mathrm{I}_{2}(5 \mathrm{~mol} \%)
$$
TBHP (3 equiv.) $\frac{\text { TBHP (3 equiv.) }}{120^{\circ} \mathrm{C}}$<smiles>Ic1nccc2ccccc12</smiles>
204

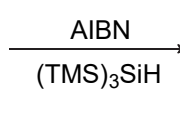

DTBP (3 equiv.) (d)<smiles>[R]c1cccc2c1=CC#[Y]=2</smiles>

211

$\mathrm{X}=\mathrm{Y}=\mathrm{C}, \mathrm{N}$

$\mathrm{R}, \mathrm{R}^{1}=\mathrm{H}, \mathrm{F}, \mathrm{Cl}, \mathrm{Br}, \mathrm{Me}, \mathrm{OMe}$

209

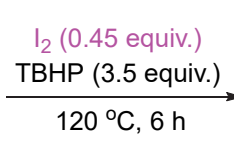<smiles>[R]c1cccc(Cn2cc(I)c3ccccc3c2=O)c1</smiles>

20 examples

$40 \% \sim 72 \%$ yields

21 examples $40 \% \sim 78 \%$ yields
20 examples $45 \% \sim 88 \%$ yields

(e)

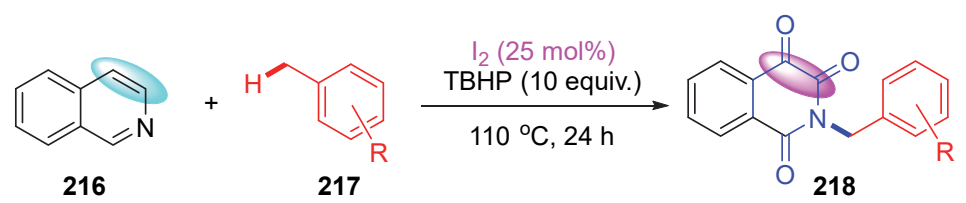

20 examples $49 \% \sim 92 \%$ yields

19 examples $5 \% \sim 79 \%$ yields

图式 39 碘催化氮杂芳烃与苠基 $\mathrm{C}\left(\mathrm{sp}^{3}\right)-\mathrm{H}$ 键的交叉脱氢偶联

Scheme 39 Iodine-catalyzed cross dehydrogenative coupling of azaarenes with benzylic $\mathrm{C}\left(\mathrm{sp}^{3}\right)-\mathrm{H}$ bonds

2016 年，任红军课题组 ${ }^{[114]}$ 报道了在有氧条件下 $\mathrm{I}_{2}$ 催化腙和胺的氧化偶联反应, 合成了 $1,3,5$-三取代 1,2,4三唑类化合物 221 (Scheme 40). 该反应通过串联 $\mathrm{C}-\mathrm{H}$ 功能化、双 $\mathrm{C}-\mathrm{N}$ 键形成和氧化芳构化反应顺序进行转 化, 并且实验证明自由基参与了反应转化. 1,2,4-三唑类 化合物在生物医学和材料学都有广泛应用. 在已有报道 中, 使用非金属催化体系来构建 1,2,4-三唑类化合物往 往区域选择性差且反应活性低. 因此开发非金属的碘高

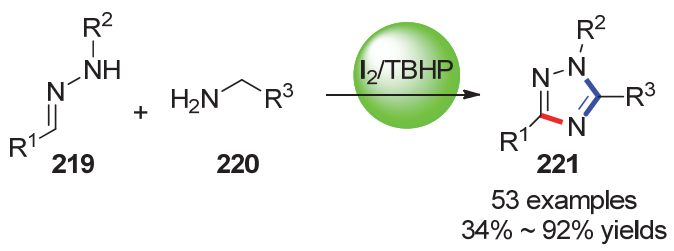

图式 40 碘催化肼和胺的氧化偶联反应

Scheme 40 Iodine-catalyzed oxidative coupling reactions of hydrazones and amines
效介导合成 1,2,4-三唑类化合物的绿色方法具有非常大 的吸引力和发展前景.

2016 年, 王桦课题组 ${ }^{[115]}$ 使用 $\mathrm{I}_{2} / \mathrm{TBHP}$ 催化吡唑啉 酮与亚磺酸钠直接磺化, 在室温下合成了磺化吡唑化合 物 224 (Scheme 41, a). 反应过程中酮式和烯醇式互变异 构, 磺化钠与碘快速反应得到磺酰碘中间体，再与吡唑 反应生成磺化吡唑化合物. 氧化剂 THBP 则实现 HI 和 $\mathrm{I}_{2}$ 的循环．该方法简便，不使用金属，反应条件温和，高 效地合成了一系列结构多样的磺化吡唑类化合物.

之后，王进欣课题组 ${ }^{[116]}$ 通过碘介导的交叉脱氢偶 联策略，合成了苯并噁嗪酮 227 和喹唑啉酮衍生物 228 (Scheme 41, b). 反应中 DTBP 通过热裂解生成叔丁氧基 自由基，直接对 $\mathrm{C}\left(\mathrm{sp}^{3}\right)-\mathrm{H}$ 键进行提取，再通过单电子 转移及分子内亲核取代得到产物. 该方法为一锅法, 反 应条件环境友好，底物范围广泛，产率良好，原子经济 性较高并且操作简单. 2017 年, 孙凯课题组 ${ }^{[117]}$ 通过对芳 
(a)<smiles>[R]C1=NN([R2])C(=O)C1</smiles>

24 examples $44 \% \sim 98 \%$ yields

(b)<smiles>[X]C(=C)N([R])C([R])([R])O</smiles><smiles>[R]C([R5])N([R])C(=O)C1=C(N)C=C[R1]C=C1</smiles>
226

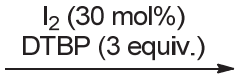

Toluene, $130^{\circ} \mathrm{C}$

$\mathrm{X}=\mathrm{O}, \mathrm{s}$

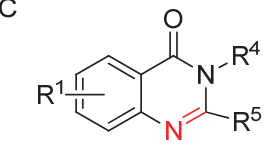

228

5 examples $59 \% \sim 90 \%$ yields (c)

229

230
27 examples $69 \% \sim 90 \%$ yields

图式 $41 \mathrm{I}_{2}$ /过氧化物催化磺化吡唑、苯并噁嗪酮(喹唑啉酮) 和 $\alpha$-羰基硒氰酸酯化合物的合成

Scheme 41 I2/peroxide-catalyzed synthesis of sulfonated pyrazoles, benzoxazinones (quinazolinones) and $\alpha$-carbonyl

基酮的硒氰化, 构建了 $\alpha$-羰基硒氰酸酯 230 , 开发了一 种新型的无金属合成方法(Scheme 41, c). 该方法无需预 先制备 $\alpha$-卤代酮, 通过碘催化快速构建了 $\alpha$-羰基硒氰酸 酯. 机理研究表明, 该反应通过自由基碘化和亲核取代 完成反应.

Baruah 课题组 ${ }^{[118]}$ 在常温下以分子碘为催化剂, 以 过氧化氢为氧化剂, 实现醇分子内氧化 $\mathrm{C}-\mathrm{O}$ 键的构建, 提供了一种构建 1,3-噁嗪化合物 232 的绿色途径 (Scheme 42). 该反应使用乙醇作为友好溶剂, 室温下顺 利进行反应. 作者认为该反应是无自由基参与的过程.

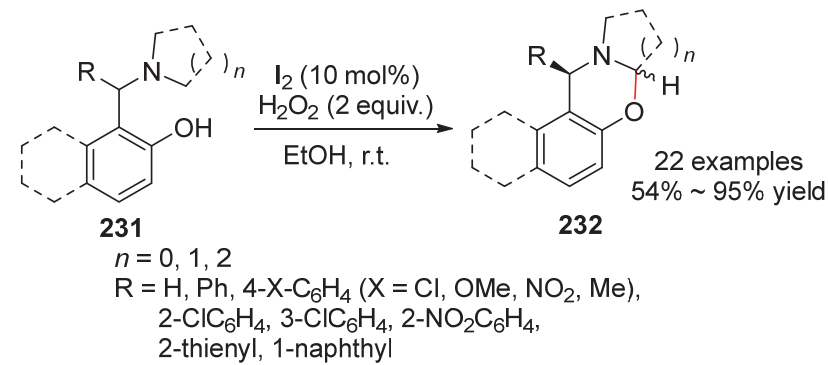

图式 42 碘/过氧化氢促进分子内氧化 $\mathrm{C}-\mathrm{O}$ 键的形成 Scheme 42 Iodine $/ \mathrm{H}_{2} \mathrm{O}_{2}$ promoted intramolecular oxidative $\mathrm{C}-\mathrm{O}$ bond formation
2017 年, Kambe 课题组 ${ }^{[119]}$ 报道了碘介导的惰性 $\mathrm{C}\left(\mathrm{sp}^{3}\right)-\mathrm{H}$ 键的分子间胺化反应，该方法适用于合成吲 哚衍生物 234, 并且具有较高的区域选择性(Scheme 43). 以往文献报道中，该类反应仅对 $\mathrm{C}(\mathrm{sp})-\mathrm{H}$ 和 $\mathrm{C}\left(\mathrm{sp}^{2}\right)-\mathrm{H}$ 键进行活化. 关于惰性 $\mathrm{C}\left(\mathrm{sp}^{3}\right)-\mathrm{H}$ 键的分子间胺化反应, 报道仅局限于基于 HLF 反应策略. 因此，该工作首次使 用非金属体系, 创新地对此类底物进行 $\mathrm{C}\left(\mathrm{sp}^{3}\right)-\mathrm{H}$ 键功 能化. 该方法有着中等到较高的产率, 实验证明该反应 官能团高度耐受.

作者提出一种合理的机理. 反应最初, DTBP 和分 子碘反应原位生成 ${ }^{t} \mathrm{BuOI}$, 随后与底物 $\mathrm{N}-\mathrm{H}$ 键反应生 成中间体 235. 在加热条件下，中间体 235 的 N-I 键裂 解得到氮中心自由基中间体 236. 根据 HLF 反应策略, 中间体 236 通过 1,5-HAT 转移氢原子, 生成碳中心自由 基中间体 237. 之后，中间体 237 被碘自由基捕获后转 化为含 $\mathrm{C}-\mathrm{I}$ 键的中间体 238. 最后通过亲核取代得到目 标产物 234a. 而当中间体 236 的氮自由基通过 1,5-HAT 策略迁移到苄基碳上时则生成另一产物 234b.

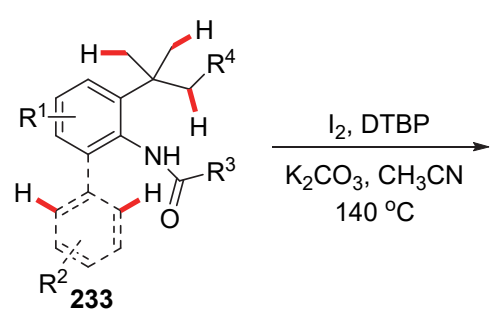

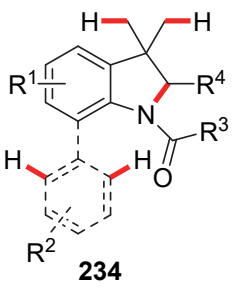

39 examples $18 \% \sim 97 \%$ yields

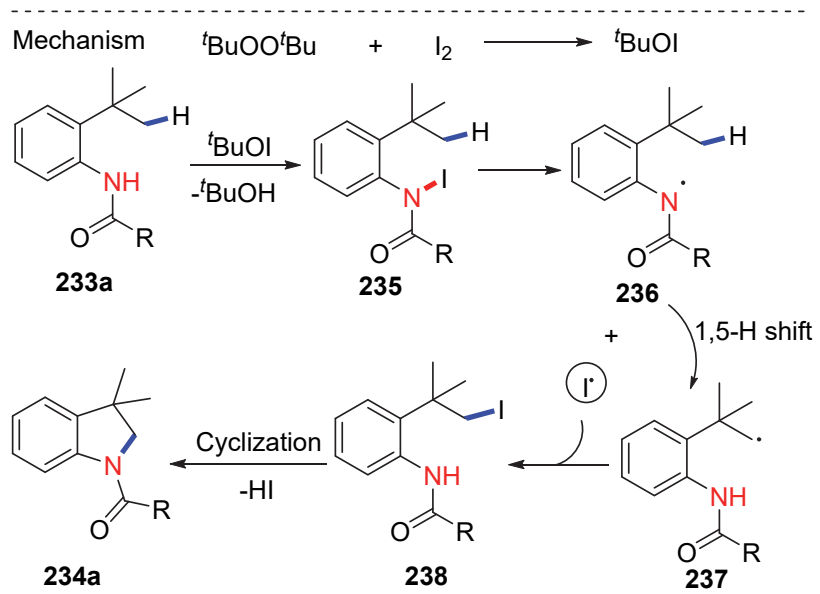

$234 a$ 237

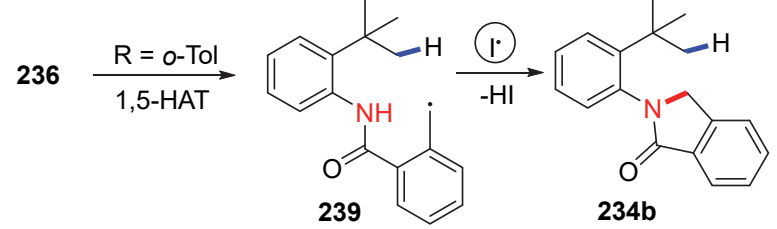

图式 43 碘介导的苯胺分子内氧化胺化

Scheme 43 Iodine-mediated oxidative intramolecular amination of anilines 
Babu 课题组 ${ }^{[120]}$ 开发了 2-甲基杂芳烃的氧化 $\mathrm{C}\left(\mathrm{sp}^{3}\right)$ - $\mathrm{H}$ 功能化反应，合成了苯并噻唑化合物 242 (Scheme 44). 一般情况下, 2-甲基杂芳烃的甲基作为碳 亲核基团，而此工作中，甲基基团作为亲电碳和 2-氨 基硫代苯酚进行缩合. 该方法在开放体系下进行, 条 件温和.

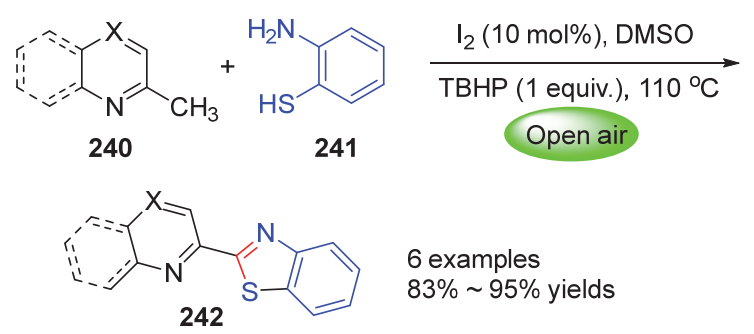

图式 $44 \mathrm{I}_{2} / \mathrm{TBHP}$ 催化 2-氮杂芳基-苯并咪唑和苯并噻唑化合 物的合成

Scheme 44 I2/TBHP-catalyzed synthesis of 2-azaarenylbenzimidazoles and benzothiazoles

2017 年, 陈保华课题组 ${ }^{[121]}$ 通过 $\mathrm{I}_{2} / \mathrm{TBPB}$ 体系介导 了芳基醛与脒类化合物的氧化反应, 合成 1,2,5-三芳基1H-咪唑类化合物 245 (Scheme 45, a). TBPB 在反应中参 与催化循环, 用以提供碘催化剂. 该反应有着良好的产 率和较高的区域选择性. 魏文廷课题组 ${ }^{[122]}$ 首次实现了 无金属的 $\mathrm{I}_{2} / \mathrm{TBHP}$ 体系催化分子间的 $\mathrm{C}\left(\mathrm{sp}^{3}\right)-\mathrm{H}$ 胺化反 应(Scheme 45, b), 合成了一系列 3-取代-3-氨基吲哚酮 化合物 248. 伯/仲胺底物都具有良好的耐受性, 相应的 3-取代-3-氨基吲哚酮的产率为 43\% 92\%. 该方法采用 经济、环保的“ $\mathrm{I}_{2} / \mathrm{TBHP}$ ”体系, 机理研究表明, 该过程是 通过自由基篗氢进行的.

(a)

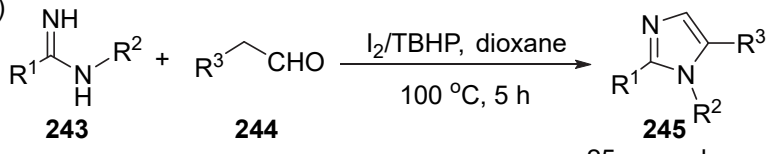

$$
\begin{aligned}
& 25 \text { examples }
\end{aligned}
$$
$44 \% \sim 95 \%$ yields

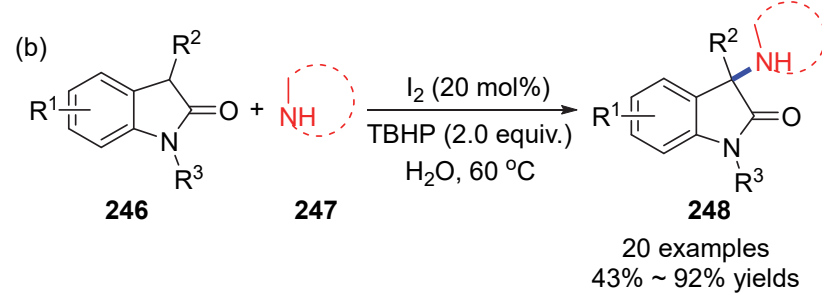

图式 $45 \mathrm{I}_{2} / \mathrm{TBHP}$ 催化 1,2,5-三芳基-1H-咪唑和 3-取代-3-氨基 吲哚酮的合成

Scheme $45 \mathrm{I}_{2} /$ TBHP-catalyzed synthesis of 1,2,5-triaryl- $1 H$ imidazoles and 3-substituted 3 -aminooxindoles

刘海灵课题组 ${ }^{[123]}$ 建立了一种高效的氧化方法, 有 效地催化酮类化合物实现 $\alpha$-苯甲酰氧基化反应(Scheme 46). 在 $\mathrm{I}_{2} / \mathrm{TBHP}$ 条件下, 实现了酮和甲苯衍生物的氧化

偶联，能简便制备 $\alpha$-苯甲酰氧基酮化合物 251. 该方法 使用简单的芳基甲烷化合物对一系列结构不同的酮直 接氧化，有着良好到优异的产率. 同时，苯乙酮也能与 苯甲醇、苯甲醛、苯甲酸和乙基苯发生 $\alpha$-苯甲酰氧基化 反应.

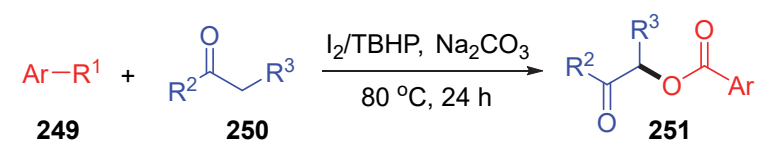

$\mathrm{R}^{1}=\mathrm{Me}, \mathrm{Et}, \mathrm{CH}_{2} \mathrm{OH}, \mathrm{CHO}, \mathrm{COOH}$;

$\mathrm{R}^{2}=\mathrm{Ar}$, HetAr, Alkyl; $\mathrm{R}^{3}=\mathrm{H}$, Alkyl

16 examples $62 \% \sim 87 \%$ yields

图式 $46 \mathrm{I}_{2} / \mathrm{TBHP}$ 介导酮和甲苯化合物的氧化偶联反应 Scheme $46 \quad \mathrm{I}_{2} / \mathrm{TBHP}-\mathrm{mediated}$ oxidative coupling of ketones and toluene derivatives

2018 年, Muñiz 课题组 ${ }^{[124]}$ 报道了一种有趣的均相条 件下的分子碘催化的分子内 $\mathrm{C}\left(\mathrm{sp}^{3}\right)-\mathrm{H}$ 胺化反应 (Scheme 47, a). 该方法使用 $m \mathrm{CPBA}$ 作为末端氧化剂, 在可见光下，单质碘催化，通过酰基自由基对烷基进行 链内 $\mathrm{C}-\mathrm{H}$ 胺化. 该反应在温和的条件下进行, 具有特 异的化学选择性, 与自由基中间体相容, 允许二级和三 级的 $\mathrm{C}-\mathrm{H}$ 键进行选择性分子内胺化反应，不限于茮基 $\mathrm{C}-\mathrm{H}$ 键胺化. 值得注意的是, 在 $m \mathrm{CPBA}$ 氧化下, 是由 碘(I/III)催化反应. 该课题组之前报道了同类反应 ${ }^{[125-126]}$, 使用高价碘作为氧化剂生成亲电碘物种 $\mathrm{IO}_{2} \mathrm{CR}$, 或者加 入有机光氧化催化剂 2,4,6-三苯基吡喃四氟硣酸盐 (TPT) (Scheme 47, b). 相比之下, 过氧化物和分子碘催化 的策略更为经济和高效.

(a)

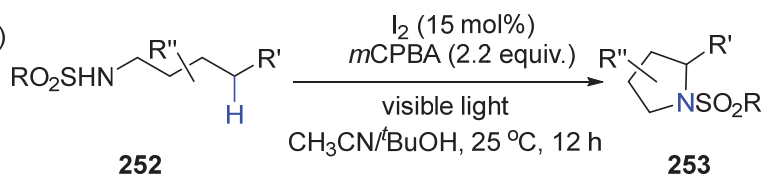

26 examples $36 \% \sim 99 \%$ yields

(b) iodine(I/III) catalysis: requirement for a preformed iodine(III) oxidant

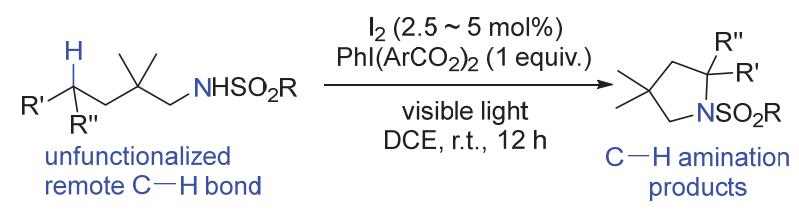

iodine $(-\mathrm{I} / \mathrm{I})$ catalysis: limitation to benzylic $\mathrm{C}-\mathrm{H}$ positions

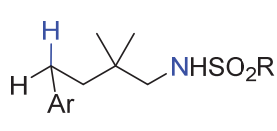

unfunctionalized remote benzylic $\mathrm{C}-\mathrm{H}$ bond

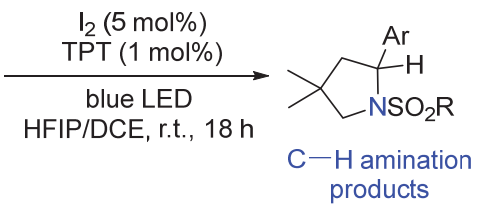

图式 47 碘催化烷烃分子内 $\mathrm{C}-\mathrm{H}$ 胺化反应 Scheme 47 Intramoleclar $\mathrm{C}-\mathrm{H}$ amination of alkanes catalyzed by iodine 
2018 年, 纪顺俊课题组 ${ }^{[127]}$ 采用 $\mathrm{I}_{2} / \mathrm{TBHP}$ 体系催化 了异氧化物与含氮芳烃化合物的氧化偶联反应, 用以合 成 2-氨基苯并噁嗪酮 256 和 2-氨基喹唑啉类化合物 257 (Scheme 48). 腈类化合物在此条件下首先生成 1,1-2-碘 化合物，再通过与底物 $\mathrm{N}-\mathrm{H}$ 键结合，随后通过羟基的 亲核取代反应得到最终产物. 该方法为构建潜在的功能 化生物活性分子提供了一种简单实用的方法.

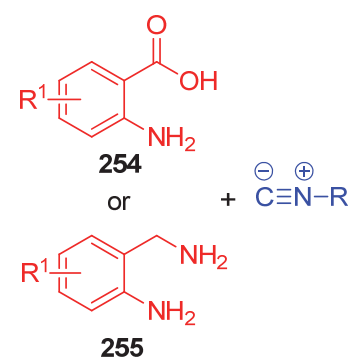

255

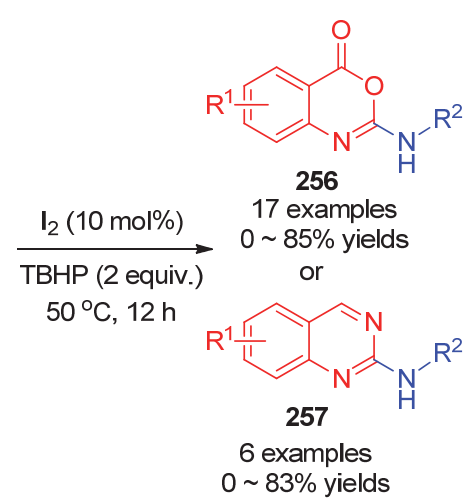

图式 $48 \mathrm{I}_{2} / \mathrm{TBHP}$ 催化异氰化物与氨基双核化合物的氧化偶 联反应

Scheme $48 \quad \mathrm{I}_{2} / \mathrm{TBHP}$-mediated oxidative coupling of aminobased bisnucleophiles and isocyanides

2019 年, 谭嘉靖课题组 ${ }^{[128]}$ 报道了一种 2-取代噻唑 化合物 260 和苯并噻唑化合物 262 的合成方法(Scheme 49). 分子碘催化, TBHP 或 DTBP 作为末端氧化剂, $\mathrm{K}_{2} \mathrm{CO}_{3}$ 作为碱性添加剂, 加入 $4 \AA$ 分子篮, 底物苯甲醛 分别与苯硫醇或盐酸半胱氨酸乙酯反应.

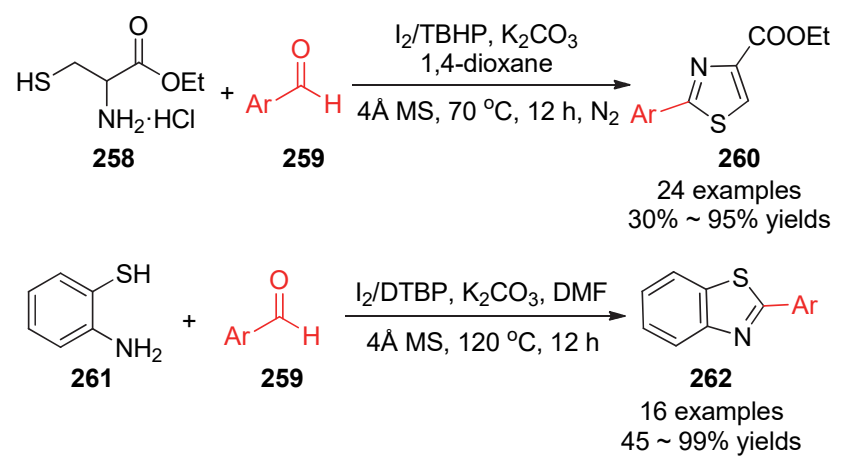

图式 49 碘介导串联环化和氧化反应

Scheme 49 Iodine-mediated tandem cyclization and oxidation reaction

$\mathrm{I}_{2} /$ peroxide 体系运用于 $\mathrm{C}\left(\mathrm{sp}^{3}\right)-\mathrm{H}$ 功能化反应中, 一方面生成的自由基通过 HAT 策略实现碳氢键的擢氢, 另一方面生成的自由基直接对氢进行活化. 该体系有效 扩展了过氧化物在有机合成的应用.

\section{$2.4 \mathrm{I}_{2} / \mathrm{O}_{2}$ 催化的 $\mathrm{C}\left(\mathrm{sp}^{3}\right)-\mathrm{H}$ 功能化反应}

在氧气或开放条件下碘参与的 $\mathrm{C}\left(\mathrm{sp}^{3}\right)-\mathrm{H}$ 功能化反
应的反应体系更加生态环境友好，符合绿色化学理念. 至今，使用碘在氧气作为氧化剂的条件下，已经成功地 实现了许多有用转化，例如选择性地分子间 $\mathrm{C}-\mathrm{H}$ 胺 化、分子间烯烃化、氧化着化、 $\mathrm{C}-\mathrm{H}$ 偶联化和脱芳构 化等.

传统的肽和酰胺的合成通常通过羧酸的亲电衍生 化，一种羧酸选择性地被一种胺活化形成酰化化合物. 当然也有一些特殊的例子，由醇、醛和炔作为前体，氧 化反应形成 $N$-酰基化合物 ${ }^{[29-130]} .2015$ 年, Hayashi 课题 组 ${ }^{[131]}$ 创新地通过 $\mathrm{I}_{2}$ 催化, 添加碱性添加剂 $\mathrm{K}_{2} \mathrm{CO}_{3}$ 和氧 化剂 $\mathrm{O}_{2}$, 实现了伯胺和硝基烷烃氧化酰胺化 (Scheme 50). 与预期相反, 分子碘和胺之间形成了 $1: 1$ 卤素键 络合物，它与硝基反应形成一种碘硝基烷烃，是酰胺形 成的前体. 该方法操作简单，官能团不仅耐受同时具有 化学选择性, 对潜在的有差异的底物和产物具有立体化 学刚性. 另外, 使用含光学活性的伯硝基烷烃作为起始 原料，通过该方法可制备手性酰胺类化合物。该反应可 能涉及到胺络合、卤素键合及亲电碘化等过程.
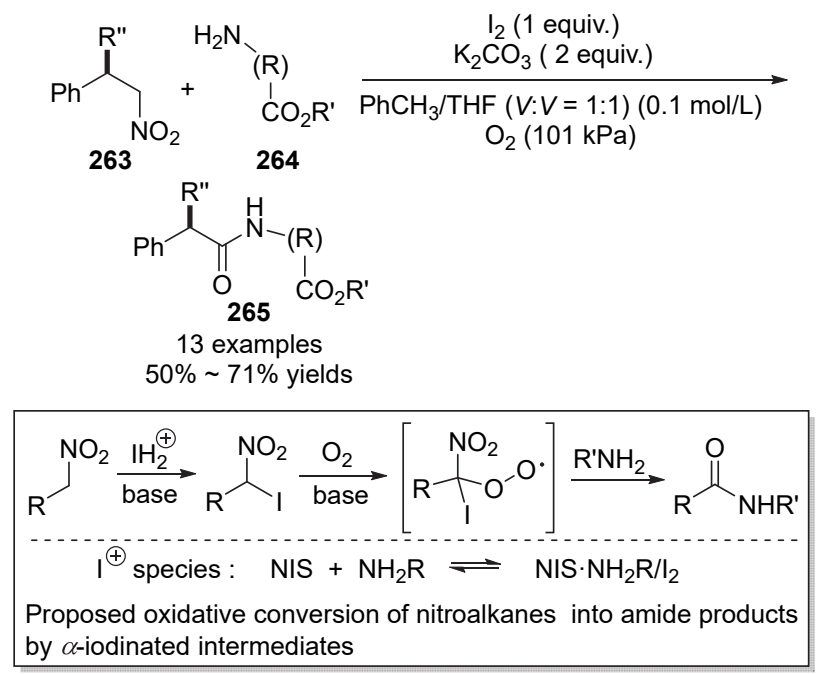

图式 50 通过分子氧和碘实现硝基烷烃与胺亲核试剂的氧化 酰胺化反应

Scheme 50 Oxidative amidation of nitroalkanes with amine nucleophiles by molecular oxygen and iodine

同年, 刘利课题组 ${ }^{[132]}$ 通过对烯烃 $\mathrm{C}\left(\mathrm{sp}^{2}\right)-\mathrm{H}$ 键和 2吲哚酮的茮位 $\mathrm{C}\left(\mathrm{sp}^{3}\right)-\mathrm{H}$ 键的直接氧化交叉脱氢偶联化, 开发了一种在开放条件下的 $\mathrm{C}\left(\mathrm{sp}^{3}\right)-\mathrm{H}$ 键直接烯烃化的 有效策略(Scheme 51). 在没有附加碱的情况下，使用碘 作为催化剂, $\mathrm{O}_{2}$ 作为氧化剂, 得到了中等到优良的产率. 控制实验结果初步表明自由基参与了反应过程.

2016 年, Al-Mourabit 课题组 ${ }^{[133]}$ 开发了一种在有氧 条件下分子碘催化环己酮与 2-氨基嘧啶和 2-氨基吡啶 的 $\alpha, \beta$-二胺化反应(Scheme 52). 该反应中使用氧气作为 


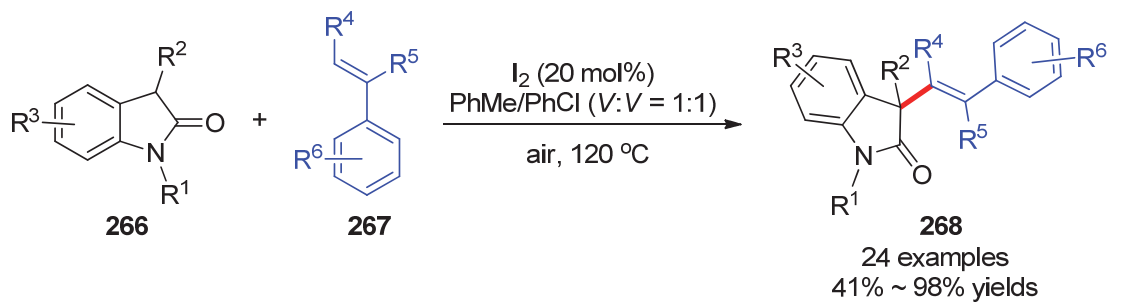

图式 51 碘催化 2-吲哚酮和烯烃的直接烯烃化反应

Scheme 51 Iodine catalyzed direct olefination of 2-oxindoles and alkenes
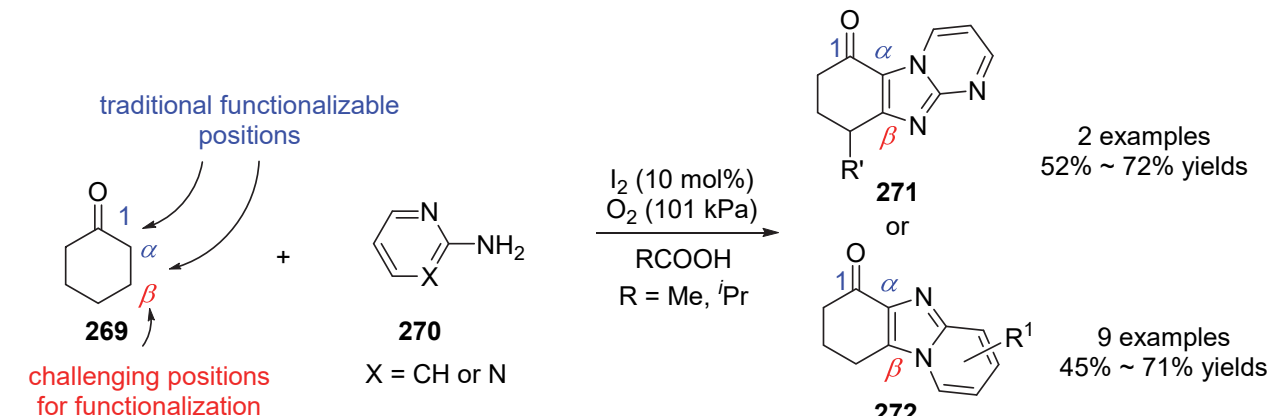

Mechanism<smiles>O=C1CCCCC1</smiles>

269<smiles>CC1CCCCC1=O</smiles>

273<smiles>Nc1ccccc1I</smiles><smiles>O=C1CCCCC1Nc1ccccn1</smiles>

[O]<smiles>O=C1CCCCC1=Nc1ccccn1</smiles>

275

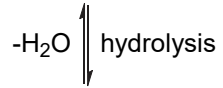<smiles></smiles>

278

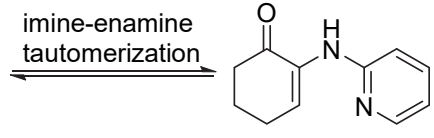

276<smiles>CC(C)C</smiles>

279

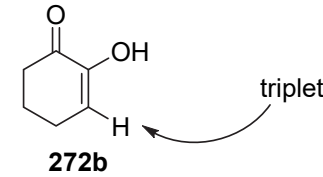

图式 52 有氧下分子碘催化环己酮与 2-氨基嘧啶或 2-氨基吡啶 $\alpha, \beta$-二胺化

Scheme 52 Molecular iodine catalyzed aerobic $\alpha, \beta$-diamination of cyclohexanones with 2-aminopyrimidine or 2-aminopyridines

氧化剂, 水分子作为反应的唯一副产物, 使得该方法绿 色环保. 该方法有望运用于天然产物骨架合成. 作者提 出了可能的机理, 首先在碘和酸性条件下, 对环己酮 $\alpha$ 位进行功能化得到中间体 273. 随后 270a 与中间体 273 发生亲核取代得到中间体 274, 随后氧化得到中间体 275. 中间体 275 通过氧化/亚胺与烯胺互变/分子内亲核 取代/氧化的反应顺序得到产物 272a.

2017 年, Itoh 课题组 ${ }^{[134]}$ 用催化量的分子碘催化了噻 吩 $\mathrm{C}-\mathrm{H}$ 键与羰基化合物 $\alpha-\mathrm{C}-\mathrm{H}$ 键的分子间光氧化偶 联反应(Scheme 53). 在该体系中, $\mathrm{O}_{2}$ 作为末端氧化剂再 生分子碘. 控制实验结果表明, 酯和分子碘的混合物生 成一个含有 $\mathrm{C}-\mathrm{I}$ 键的反应中间体, 并可通过可见光诱 导 $\mathrm{C}-\mathrm{I}$ 裂解形成碳自由基. 与传统方法相比, 该方法具 有反应条件温和、操作简单、使用的催化剂廉价和无需
外加氧化剂等优点.

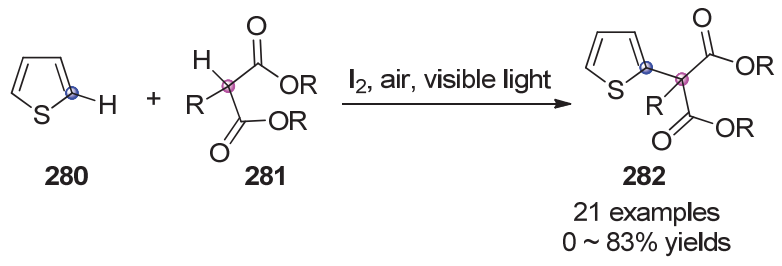

图式 53 碘催化的光氧化分子间 $\mathrm{C}-\mathrm{H} / \mathrm{C}-\mathrm{H}$ 偶联反应 Scheme 53 A photo-oxidative intermolecular $\mathrm{C}-\mathrm{H} / \mathrm{C}-\mathrm{H}$ coupling reaction via iodine-catalyzed

2018 年, 杨靖亚课题组 ${ }^{[135]}$ 报道了一种可见光介导 的 $\alpha$-亚甲基酮在有氧条件下的羟基化反应(Scheme 54). 有氧条件下，甲醇作为溶剂，在室温下进行反应，对亚 甲基酮具有特异选择性. 底物范围仅限二级的 $\alpha-\mathrm{C}-\mathrm{H}$ 
键. 可再生能源、无金属催化剂、丰富的氧源、广泛的 底物范围和专一选择性使得这一策略实用和生态友好.

反应机制如 Scheme 54 所示. 底物在碘和碱性下容 易得到 $\alpha$-碘代中间体 285. C-I 键由可见光诱导裂解生 成自由基中间体 286. 随后 286 与分子氧迅速反应生成 过氧自由基中间体 $\mathbf{2 8 7}$. 中间体 $\mathbf{2 8 7}$ 从底物中提取氢原 子, 得到 $\alpha$-过氧基酮中间体 $\mathbf{2 8 8}$ 以及自由基中间体 $\mathbf{2 8 6}$. 过氧化物 $\mathbf{2 8 8}$ 的均解产生氧自由基中间体 $\mathbf{2 8 9}$ 和羟基自 由基. 最后, 氧自由基中间体 289 再次从底物中提取氢 原子，得到产物 $\alpha$-羊基酮 284 .

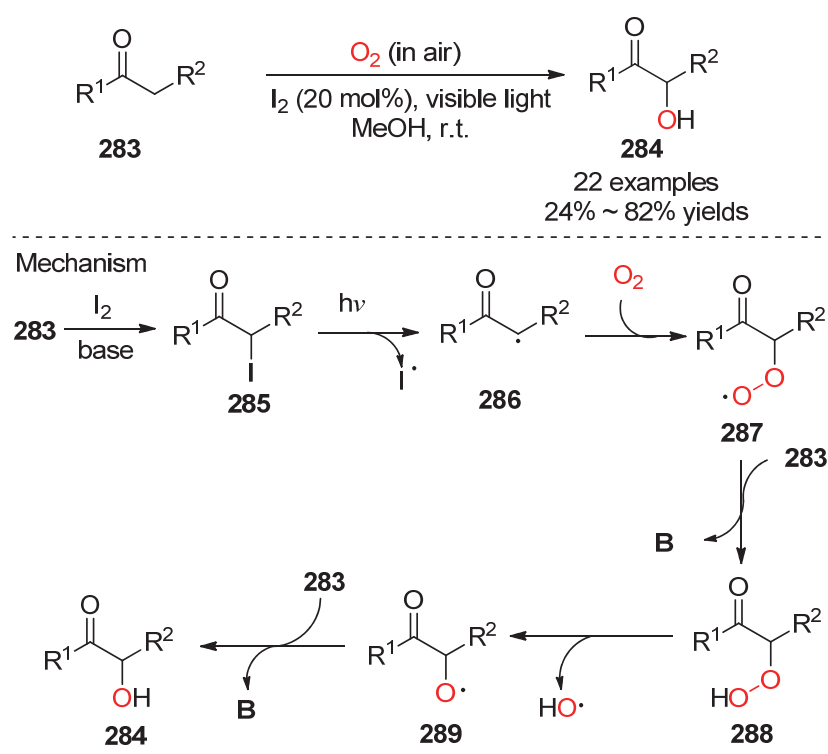

图式 54 有氧条件下可见光介导碘催化 $\alpha$-亚甲基酮的 $\alpha$-羟基 化

Scheme 54 Visible-light-mediated iodine-catalyzed $\alpha$-hydroxylation of $\alpha$-methylene ketones under aerobic conditions

2020 年, 邓国军课题组 ${ }^{[136]}$ 报道了一种碘催化脱氢 芳构化反应, 直接高效地构建各种吲哚 292 和喹啉类化 合物 293 (Scheme 55). 该方法以分子碘为催化剂, 氧为 绿色氧化剂，在简单的无过渡金属条件下，能以中等到 良好的产率得到产物, 实现了四氢吲哚和四氢喹啉的绿 色脱芳构化.
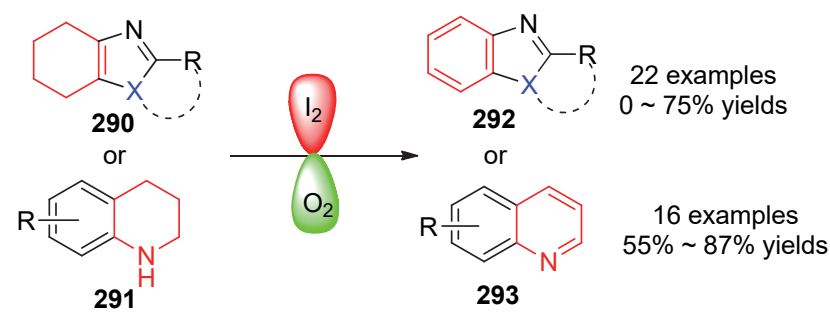

图式 55 有氧条件下碘催化脱氢芳构化合成苯并唑和苯并嗪 化合物

Scheme 55 Iodine-catalyzed convergent aerobic dehydroaromatization toward benzazoles and benzazines
分子碘和氧气都是廉价易得的绿色的化学试剂, 它 们的组合开发了一种更为绿色的催化体系, 有望将其运 用于更多类型的 $\mathrm{C}\left(\mathrm{sp}^{3}\right)-\mathrm{H}$ 功能化反应中.

\section{5 含碘化合物催化的 $\mathrm{C}\left(\mathrm{sp}^{3}\right)-\mathrm{H}$ 功能化反应}

碘催化碳氢功能化已成为构建各种 $\mathrm{C}-\mathrm{X}$ 键 $(\mathrm{X}=\mathrm{C}$, $\mathrm{N}, \mathrm{O}$ 和 $\mathrm{S}$ 等)的一种非常有吸引力的工具, 分子碘催化 剂的再生通常需要使用强化学氧化剂. 前部分总结了分 子碘和不同氧化剂构成的经典氧化体系，包括高价芳基 碘试剂、DMSO、过氧化物以及氧气. 分子碘在该类体 系中直接催化活化 $\mathrm{C}\left(\mathrm{sp}^{3}\right)-\mathrm{H}$ 键, 实现功能化. 此外, 含 碘化合物则可在特定条件下原位生成分子碘, 实现 $\mathrm{C}\left(\mathrm{sp}^{3}\right)-\mathrm{H}$ 功能化. 一方面, 含碘试剂可在氧化剂的作 用下，原位生成分子碘从而催化有机反应. 另一方面, 在有机电化学中通过电极的氧化还原, 可有效地将各种 碘负离子应用于 $\mathrm{C}\left(\mathrm{sp}^{3}\right)-\mathrm{H}$ 功能化反应, 为各种化学键 的绿色构建提供了新的机遇. 下面将从以上两个方面对 含碘化合物在 $\mathrm{C}\left(\mathrm{sp}^{3}\right)-\mathrm{H}$ 功能化反应中的最新成果进行 综述, 意在拓展分子碘在有机合成中的相关应用.

\subsection{1 碘负离子催化的 $\mathrm{C}\left(\mathrm{sp}^{3}\right)-\mathrm{H}$ 功能化反应}

含碘化合物例如 KI、NaI、NIS、 $n \mathrm{Bu}_{4} \mathrm{NI}$ 等均可在 氧化剂作用下原位生成分子碘化合物, 从而氧化催化 $\mathrm{C}\left(\mathrm{sp}^{3}\right)$ - $\mathrm{H}$ 功能化反应. 2015 年, 吕允贺课题组 ${ }^{[137]}$ 报道 了一种由 $n \mathrm{Bu}_{4} \mathrm{NI}$ 催化的分子间高选择性 $\mathrm{C}-\mathrm{O}$ 键构建 的方法(Scheme 56, a). 该方法催化茮基 $\mathrm{C}-\mathrm{H}$ 键或烯丙 基 $\mathrm{C}-\mathrm{H}$ 键与羟基邻苯二甲酰亚胺(NHPI)偶联构建 $\mathrm{C}-$ $\mathrm{O}$ 键, 对各种官能团具有耐受性. 作者对反应机理进行 了探讨，实验证明该反应是自由基的过程. 2016 年，吕 允贺课题组 ${ }^{[138]}$ 以 $n \mathrm{Bu}_{4} \mathrm{NI}$ 为催化剂构建 $\mathrm{C}-\mathrm{N}$ 键用以合 成烯丙基 $\mathrm{N}$ 杂环 300 和 303 (Scheme 56, b). 一系列烯丙 基化合物与具有生物活性的嘌呤、苯并咪唑、苯并三唑 及糖精都适用于该偶联反应. 之后, 吕允贺课题组 ${ }^{[139]}$ 报道了在温和条件下，由 $n \mathrm{Bu}_{4} \mathrm{NI}$ 催化的 $\beta$-二羰基与丙 酮的氧化交叉脱氢偶联反应(Scheme 56, c). 该方法体系 简单, 反应温度低, 对环境友好, 为 2-羰基-1,4-二酮化 合物 306 的合成提供了一条简便的途径. 2019 年, 张治 国课题组 ${ }^{[140]}$ 以 $\mathrm{TBHP}$ 为末端氧化剂, $n \mathrm{Bu}_{4} \mathrm{NI}$ 为催化剂, 实现了异色满的 $\alpha-\mathrm{C}\left(\mathrm{sp}^{3}\right)-\mathrm{H}$ 和 $N$-羟基邻苯二甲酰亚胺 的交叉脱氢偶联反应(Scheme 56,d).

另外, KI-TBHP 体系则可用于酰胺、苯并噻唑和氮 杂环丙烷的有效构建. 2019 年, Selvaraj 课题组 ${ }^{[141]}$ 首次 报道了一种高效的 KI-TBHP 介导的乙基芳烃合成一级、 二级和三级丙烯酩酰胺的方法 (Scheme 57, a). 此外, 他 们还成功地通过 KI-TBHP-I I $_{2}$ 体系在水中合成了芳香族 酰胺化合物 312. 该方法条件温和, 底物范围广泛, 并 
(a)

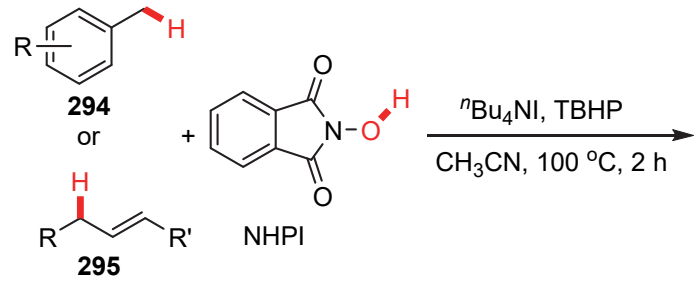<smiles>CCCCON1C(=O)c2ccccc2C1=O</smiles>

296

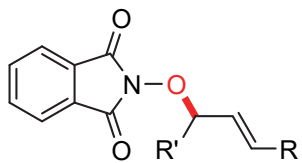

297
20 examples $70 \% \sim 93 \%$ yields

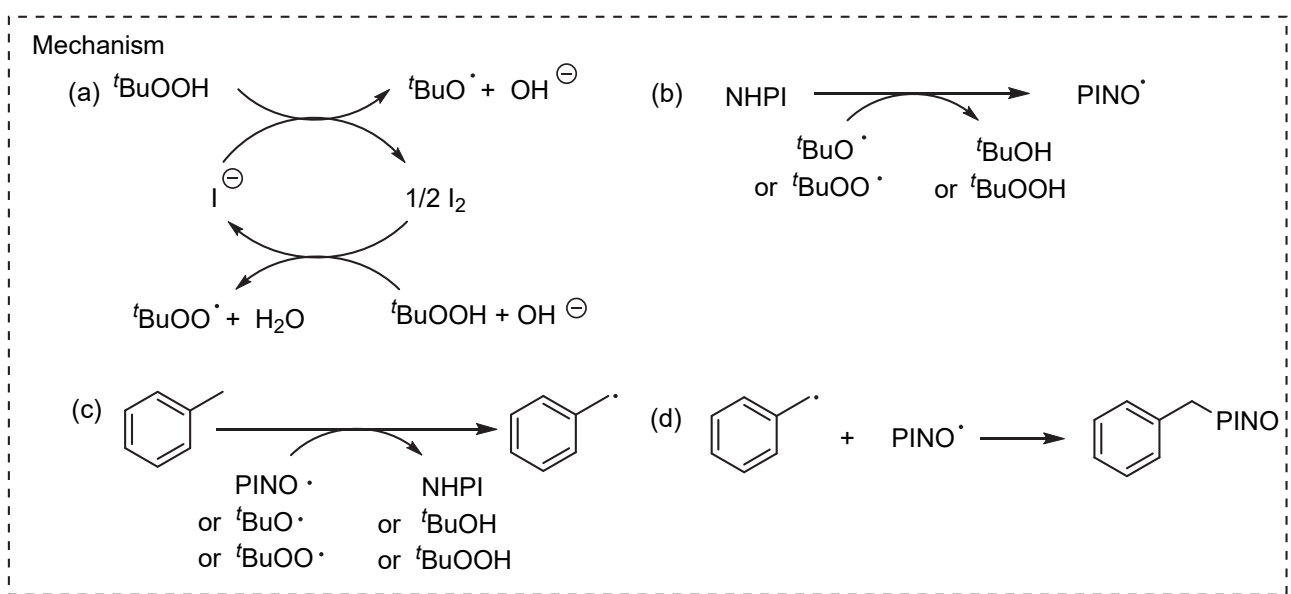

(b)

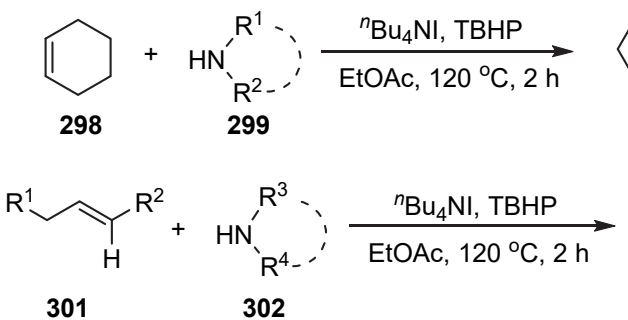<smiles>[Te][Te]N(C1C=CCCC1)C1CCCCC1</smiles>

300<smiles></smiles>

11 examples $68 \% \sim 92 \%$ yields

303

(c)<smiles>[R]C(=O)C([R])C([R])=O</smiles>

304

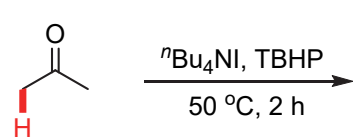

305<smiles>[R]C(=O)C(CC(C)=O)C([R])=O</smiles>

32 examples $43 \% \sim 77 \%$ yields (d)

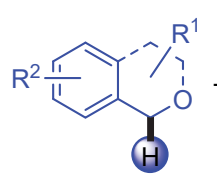

307<smiles>O=C1c2ccccc2C(=O)N1O[Hg]</smiles>
$\underset{\mathrm{CH}_{3} \mathrm{CN}, \mathrm{N}_{2}, 80^{\circ} \mathrm{C}, 2 \mathrm{~h}}{\stackrel{{ }^{n} \mathrm{Bu}_{4} \mathrm{NI} / \mathrm{TBHP}}{\mathrm{R}^{2}}}$<smiles>[R]COC(ON1C(=O)c2ccccc2C1=O)c1cc[R]([13CH3])cc1C</smiles>

13 exampls $0 \sim 94 \%$ yields

图式 $56{ }^{n} \mathrm{Bu} 4 \mathrm{NI}$ 催化分子间 $\mathrm{C}-\mathrm{X}$ 交叉偶联反应

Scheme $56{ }^{n} \mathrm{Bu} 4 \mathrm{NI}$-catalyzed intermolecular $\mathrm{C}-\mathrm{X}$ cross-coupling reactions

直接得到多样的酩酰胺类物质, 具有合成应用潜力. 基 于控制实验, 作者提出了合理的机理. 反应最初 TBHP 氧化碘负离子为碘和叔丁氧基自由基(Scheme 57, a), 叔 丁氧基自由基对苄基氢进行提取转化为芐基自由基 $\mathbf{A}$, 再通过羟基化和氧化得到苯乙酮 $\mathbf{C}$. 途径 $1, \mathbf{C}$ 通过 $\alpha$ 碘代/胺取代得到中间体 $\mathbf{E}$. 中间体 $\mathbf{E}$ 再通过 TBHP 作用 则得到目标产物 311a. 途径 2, 苯乙酮 $\mathbf{C}$ 在单质磑和氨
水作用下降解生成少一个碳的酰胺 312a. 同年，孙培培 课题组 ${ }^{[142]}$ 通过在无过渡金属条件下选择性地裂解醚的 $\mathrm{C}-\mathrm{O}$ 键, 使用 $\mathrm{TBHP} / \mathrm{KI}$ 促进了苯胺与醚和单质硫的环 化反应(Scheme 57,b). 在 TBHP/KI 体系下, 苯胺环化是 由醚的选择性 $\mathrm{C}\left(\mathrm{sp}^{3}\right)-\mathrm{H}$ 键裂解引起的. 同时作者合成 了两个具有抗肿瘤活性的杂环化合物, 进一步体现了该 方法的合成价值. 因此, 这一构建苯并噻唑的简便方案 
(a)
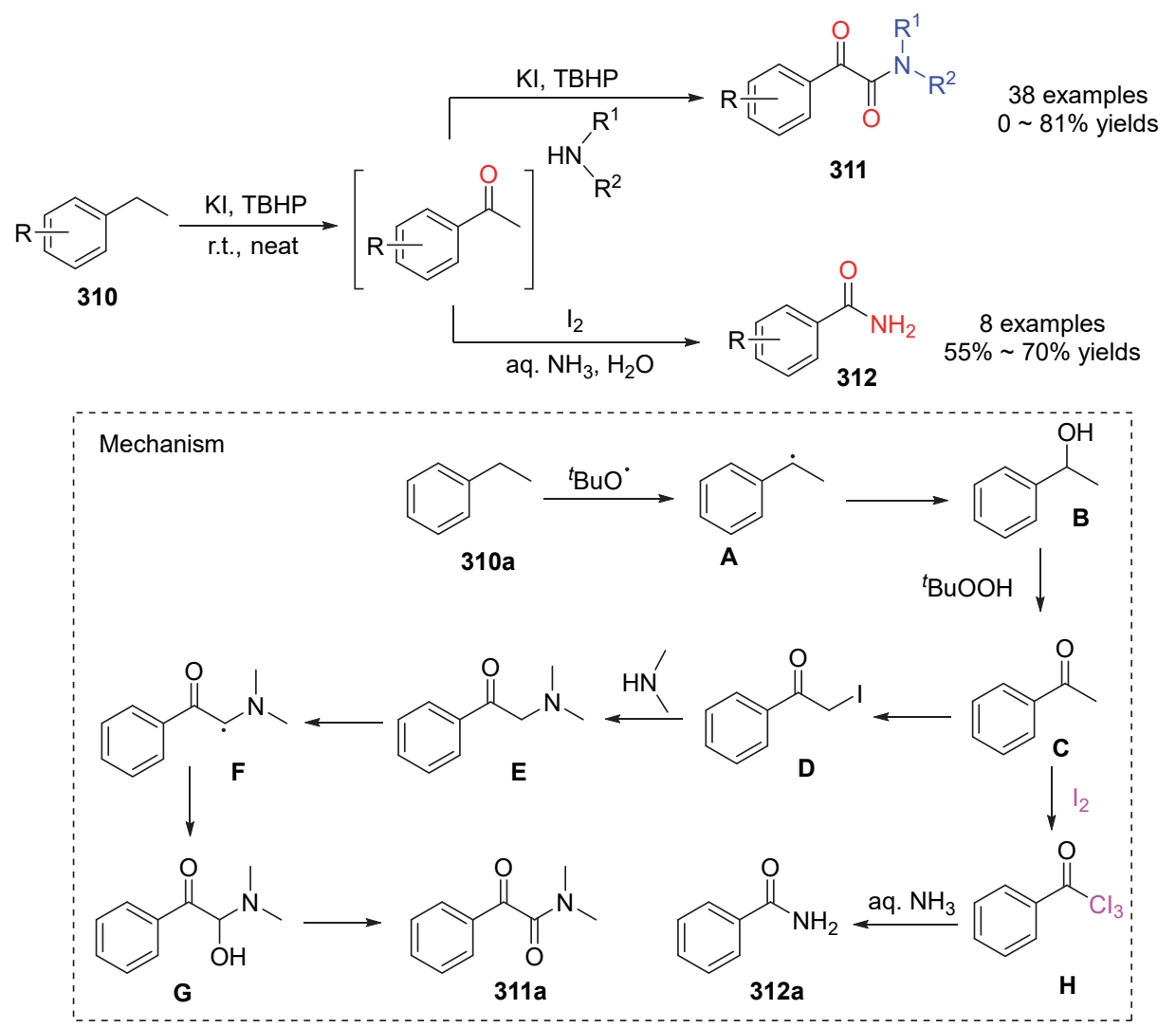

(b)
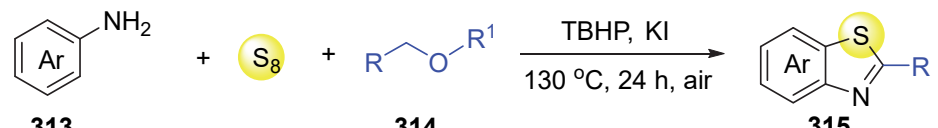

36 examples

313

314

315

图式 $57 \mathrm{KI}-\mathrm{TBHP}$ 体系促进 $\mathrm{C}\left(\mathrm{sp}^{3}\right)-\mathrm{H}$ 键功能化反应

Scheme 57 KI-TBHP-promoted $\mathrm{C}\left(\mathrm{sp}^{3}\right)-\mathrm{H}$ bond functionalization

可能在有机合成和药物合成中得到应用.

氮杂环丙烷在生物活性分子中普遍存在, 经常作为 合成的关键材料. 2020 年, 谭嘉靖课题组 ${ }^{[143]}$ 报道了分子 内 KI/TBHP 介导的氧化脱氢反应(Scheme 58). 在温和 的条件下，通过 $\mathrm{C}\left(\mathrm{sp}^{3}\right)-\mathrm{H}$ 胺化反应合成了多种反式的 2,3-二取代氮杂环丙烷 317/318. 运用一锅两步的合成方 法高效地合成了 50 种氮杂环丙烷, 显示了该合成方法 的实用性. 控制实验表明, 该反应涉及 $\mathrm{I}_{2}-\mathrm{I}^{+}$的氧化还原 过程, 并提出了合理的反应过程. 碘负离子在 TBHP 作 用下氧化为 $\mathrm{I}^{+}$, 随后底物 316a 中的酸性 $\mathrm{N}-\mathrm{H}$ 进一步与 $\mathrm{I}^{+}$发生取代反应, 得到碘化中间体 319. 中间体 319 被碱 去质子化, 最后分子内环化生成反式氮杂环丙烷产物 $317 \mathrm{a}$, 同时释放碘离子.

2016 年, Braun 课题组 ${ }^{[144]}$ 通过对双 $\mathrm{C}\left(\mathrm{sp}^{3}\right)-\mathrm{H}$ 键氧 化胺化构建了高度取代的含 5,5-和 5,6-稠合双环咪唑类 化合物 322 (Scheme 59). 他们使用 NIS-TBHP 开发了一 种高化学选择性、稳定性和实用性的方法来合成一系列 难以获得的杂环化合物, 产率中等到优异. 这种方法可

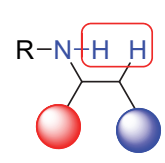

316

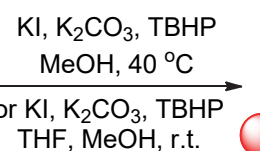
THF, $\mathrm{MeOH}$, r.t.$$
\text { THF, } \mathrm{MeOH} \text {, r.t. }
$$

$( \pm)$ or

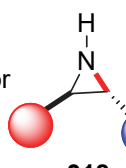
$( \pm)$
317

50 examples $45 \% \sim 97 \%$ yields
图式 58 反式氮杂环丙烷的立体选择性合成 Scheme 58 Stereoselective synthesis of trans-aziridines 
<smiles>[R]C(=O)C([R]#[R])C1CCCCN1</smiles>

320

321

$n=1,2 ; \mathrm{X}=\mathrm{N}, \mathrm{S}, \mathrm{O}, \mathrm{CH}$

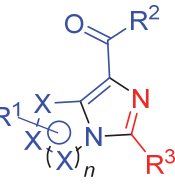

322

34 examples $0 \sim 90 \%$ yields
图式 59 NIS/TBHP 介导稠合环咪唑类衍生物的合成 Scheme 59 NIS/TBHP-mediated synthesis of fused imidazole-containing ring systems

以运用于药物化学、农用化学品和材料等领域, 用于快 速合成多种多样的稠杂环化合物.

2.5.2 有机电化学中碘试剂在 $\mathrm{C}\left(\mathrm{sp}^{3}\right)-\mathrm{H}$ 功能化反应 的应用

有机电化学合成与传统的有机合成法相比, 可借助 电极实现化合物的氧化还原, 避免了其它还原剂或氧化 剂的使用, 从而减少了环境污染 ${ }^{[37,145]}$. 并且可在常温常 压下进行，有利于节约能源，降低设备投资. 此外，还 可以借助调节电压和电流(密度)以控制反应的进行, 便 于整个过程的自动化控制. 因此, 有机电化学合成工艺 作为一种崭新有效的化学合成方法 ${ }^{[146-148]}$, 日益受到人 们的重视. 近年来, 碘负离子可在阳极被氧化为分子碘, 从而有效地催化各种 $\mathrm{C}\left(\mathrm{sp}^{3}\right)-\mathrm{H}$ 功能化反应. 该类方法
可作为分子碘催化 $\mathrm{C}\left(\mathrm{sp}^{3}\right)-\mathrm{H}$ 功能化反应的新型绿色方 法.

2016 年, 任发政课题组 ${ }^{[149]}$ 开发了一种电化学方法, 高效地合成 $\alpha$-氨基酮类化合物 325 (Scheme 60, a). 恒流 条件下，以廉价石墨板作为正极和阴极，在一个简单的 未分裂电池中使用 $\mathrm{NH}_{4} \mathrm{I}$ 作为氧化还原催化剂介导了酮 和二级胺的电化学交叉脱氢偶联反应. 由于伯胺的亲核 性较低, 只有仲胺能参与该反应. 作者提出了可能的反 应机理. 反应最初, 碘离子在阳极氧化生成 $\mathrm{I}_{2}$, 它能与 酮反应生成 $\alpha$-碘代酮 326. 最后，中间体 326 和仲胺 324 发生亲核取代生成 $\alpha$-氨基酮化合物 325 .

2018 年, 该课题组 ${ }^{[150]}$ 使用 $\mathrm{NaI}$ 作为氧化还原催化 剂, 多相固体盐 Amberlyst-15(H)(固体酸催化剂)作为质 子催化剂, 高效地建立了一种䣶类化合物硫氰化和磺酰 化的电化学方法(Scheme 60, b). 控制实验和循环伏安 分析表明，该方法经历 $\alpha-\mathrm{C}\left(\mathrm{sp}^{3}\right)-\mathrm{H}$ 键碘代/亲核取代的 过程来实现硫氰化和磺酰化.

2018 年, 汪志勇课题组 ${ }^{[151]}$ 通过阳极氧化, 开发了 一种 $\mathrm{NH}_{4} \mathrm{I}$ 介导的甲基 $\mathrm{N}$-杂环芳烃与胺/氨基酸的分子 间环化的方法，以优良的产率构建了一系列咪唑稠合 $N$-杂环化合物(Scheme 61, a). 该方法的实用性体现在起 始材料易获得容、底物范围广泛、水容忍性、可扩展性 以及电解产品可进行多种转变.同时，该方法还可以

(a)

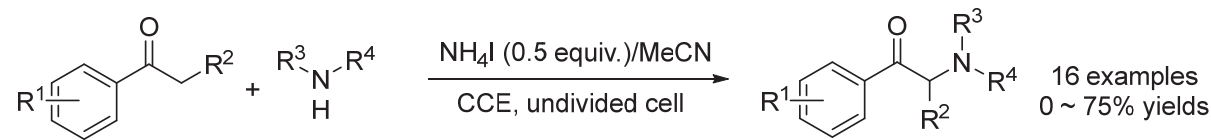

323 324 325

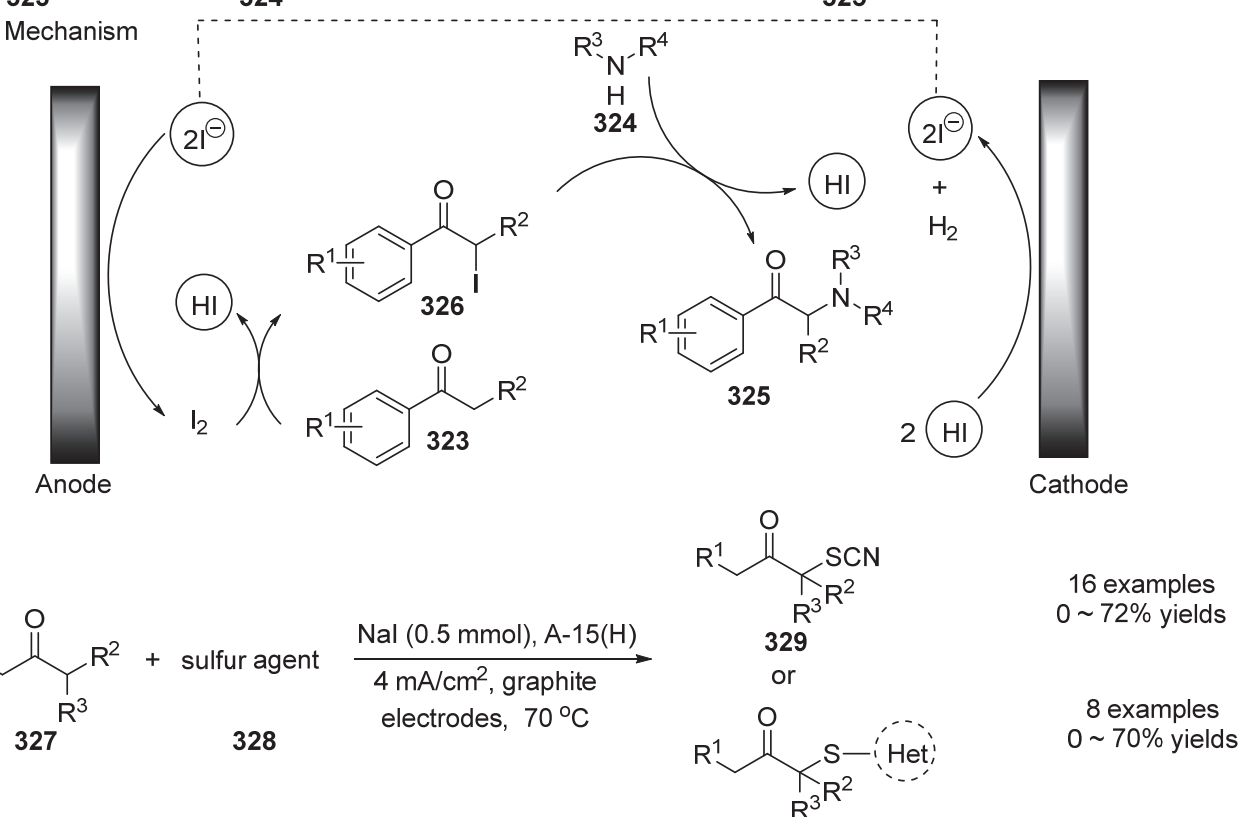

图式 60 酮类化合物的电化学氧化 $\alpha-\mathrm{C}-\mathrm{H}$ 功能化

Scheme 60 Electrochemically oxidative $\alpha-\mathrm{C}-\mathrm{H}$ functionalization of ketones 
(a)

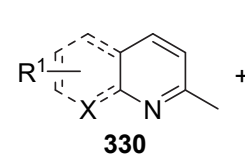

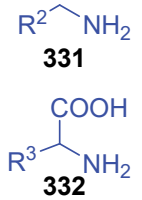

Mechanism

(

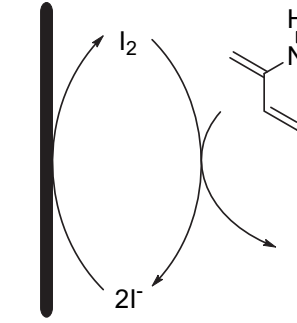

Anode

\section{$\mathrm{H}$}
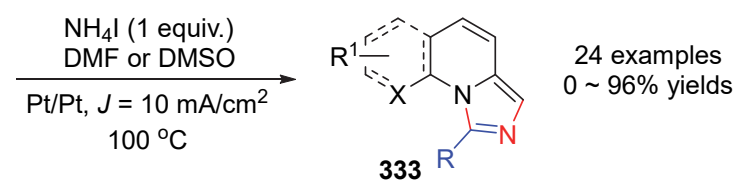

333

\section{$\underset{\mathrm{H}^{+}}{\stackrel{\Delta}{\longrightarrow}}$}

$330 a^{\prime} \quad 330 a$<smiles>NCc1ccc2ccccc2n1</smiles>

334

335<smiles>CCCCCC=N</smiles><smiles>C(=NCc1ccc2ccccc2n1)c1ccccc1</smiles>

336<smiles>CS(=O)(=O)C=[N+](C=Cc1ccccc1)c1ccccc1</smiles><smiles>CCCc1ccccc1</smiles>

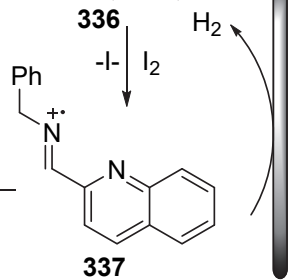

Cathode

(b)<smiles>[R]CNC(=O)[C@H](C)N</smiles>
339

(c)<smiles>[R]CC([R3])=O</smiles>

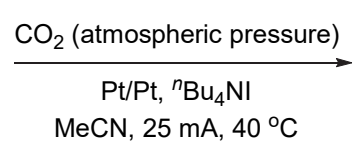<smiles>[R]C(=O)C([R14])OC(=O)N([R])[R]</smiles>

21 examples $38 \% \sim 76 \%$ yields

图式 61 电催化分子间交叉偶联反应

Scheme 61 Electrocatalytic intermolecular cross-coupling reaction reactions

在不影响效率的前提下, 将 $\mathrm{NH}_{4} \mathrm{I}$ 的负载量降低到 $50 \%$. 反应机理表明, 2-甲基喹啉的同分异构体 330a' 与在阳极 原位生成的分子碘反应生成 2-(碘甲基)喹啉 334, 中间 体 334 极易被苠胺亲核取代形成中间体 335 . 中间体 335 可被分子碘连续氧化生成亚胺中间体 338. 亚胺中间体 338 可以通过胺化/芳构化过程转化为目标产物 333a.

基于上述结果, 汪志勇课题组 ${ }^{[152]}$ 通过 $\mathrm{NH}_{4} \mathrm{I}$ 介导的 三组分反应, 实现了氰化物功能化咪唑稠合 $\mathrm{N}$-杂环化 合物 341 的电合成(Scheme 61, b). 机理研究表明, 亚胺 中间体在环化前引入了氰基, 该过程可能涉及 Strecker 反应机理. 汪志勇课题组 ${ }^{[153]}$ 还通过简单的电化学氧化, 在温和无金属的条件下, 实现了二氧化碳与胺和芳基酮 的交叉串联反应, 以中等到较好的产率得到了各种邻 - $\beta$-氧烷基氨基甲酸酯化合物 344 (Scheme 61, c). 该课 题组发展了一种固定二氧化碳到各种氨基甲酸盐的温 和有效的电化学方法, 其优势之一是不需要任何氧化
剂.

2017 年, Stahl 课题组 ${ }^{[154]}$ 开发了一种 $N$-着基葓酰亚 胺(NHPI)介导甲基芳烃选择性的苄碘化的电化学方法 (Scheme 62). 通过电化学原理, NHPI 可以在没有氧气及 过氧化物等化学计量氧化剂的情况下被氧化成邻苯二 酰亚胺- $N$-氧基(PINO). 以 NHPI 为中介, $\mathrm{I}_{2}$ 为捕获剂, 可 以在较低的应用电位与一系列甲基芳烃进行反应，并且 对底物的电子效应不敏感. 用该方法得到了不同的碘取 代产物 346, 并可进一步转化为相应的苄基吡啶衍生物 347. 作者还通过三个关键的药用靶分子的简便合成 (348 350) 说明该方法的实用性.

2018 年, 徐坤课题组 ${ }^{[155]}$ 发展了一种分子内 $\mathrm{C}\left(\mathrm{sp}^{3}\right)-\mathrm{H}$ 键功能化的电化学方法(Scheme 63). 以 $\mathrm{KI}$ 为 催化剂和电解质, 合成了多种三取代 2-啞唑啉衍生物 352. 这种新型的电化学脱氢方法无需外部氧化剂和添 加剂，具有环境友好性. 
<smiles>CC1=C[R]=[C+]C=C1</smiles>

345

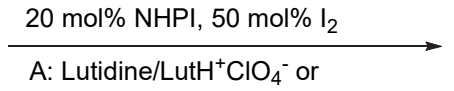

B: 2,6-di- ${ }^{t} \mathrm{BuPy} / 2,6-\mathrm{di}^{-}{ }^{-} \mathrm{BuPyH}^{+} \mathrm{ClO}_{4}{ }^{-}$

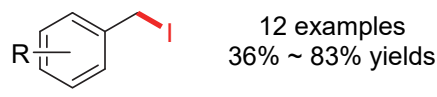

346

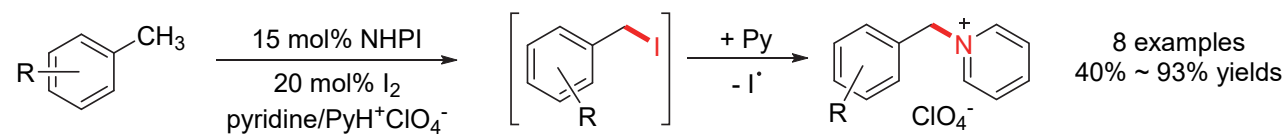

345

347

Mechanism<smiles>[R]c1cccc(C)c1</smiles>

(a) $\mathrm { C } - \mathrm { N } \longdiv { 8 8 \% }$

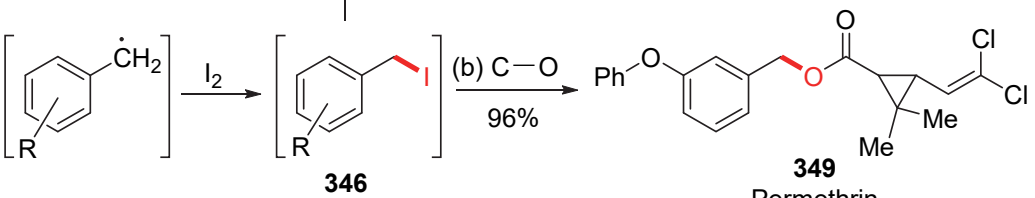

(c) $\mathrm{C}-\mathrm{C} \downarrow \begin{aligned} & 91 \% \\ & (p: 0=4: 4)\end{aligned}$

Permethrin

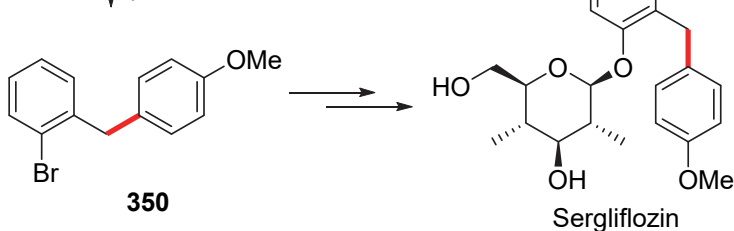

图式 $62 N$-羟基邻苯二甲酰亚胺介导的甲基杂环化合物的电化学碘化反应

Scheme $62 N$-Hydroxyphthalimide-mediated electrochemical iodination of methylarenes

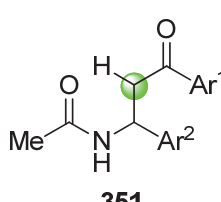

$\mathrm{Pt}(+)-\mathrm{Pt}(-), J=4 \mathrm{~mA} / \mathrm{cm}^{2}$ undivided cell $0.06 \mathrm{~mol} / \mathrm{L} \mathrm{KI}$ in $\mathrm{CH}_{3} \mathrm{CN} / \mathrm{MeOH}$, r.t.

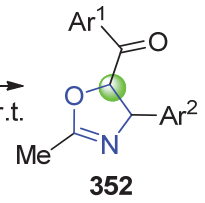

22 examples $63 \% \sim 85 \%$ yields

图式 $63 \beta$-氨基芳基酮的脱氢环化电化学合成三取代的 2-噁 唑啉反应

Scheme 63 Electrosynthesis of trisubstituted 2-oxazolines via dehydrogenative cyclization of $\beta$-amino arylketones

\section{$2.6 \mathrm{I}_{2}$ 与过渡金属联合催化 $\mathrm{C}\left(\mathrm{sp}^{3}\right)-\mathrm{H}$ 功能化反应}

过渡金属催化剂是 $\mathrm{C}-\mathrm{H}$ 键功能化研究的热点. 过 渡金属催化剂与底物分子中的路易斯碱性官能团相配 合, 使催化剂与特定的 $\mathrm{C}-\mathrm{H}$ 键结合, 从而降低了 $\mathrm{C}-\mathrm{H}$ 键断裂的能量障碍 ${ }^{[24]}$. 在分子碘催化的 $\mathrm{C}\left(\mathrm{sp}^{3}\right)-\mathrm{H}$ 功能 化反应中, 过渡金属可作为氧化剂或添加剂联合高效的 催化反应转化. 过渡金属和分子碘的协同催化极大地丰 富了分子碘催化的反应体系.
2015 年, Adimurthy 课题组 ${ }^{[156]}$ 通过活化 2-吡啶乙酸 酯中双 $\mathrm{C}\left(\mathrm{sp}^{3}\right)-\mathrm{H}$ 键、 $\mathrm{C}-\mathrm{C}$ 键和 $\mathrm{C}-\mathrm{N}$ 键的氧化串联合 成了吲哚嗪类化合物 355 (Scheme 64). 该反应通过 Aldol Condensation 反应(羟醛缩合)和 Ortoleva-King 反 应(活性甲基或次甲基与碘及呲啶作用直接生成呲啶季 铵盐类)策略, 使用碘和酮作为双催化剂, DTBP 作为氧 化剂，一步制备了吲哚嗪类化合物.

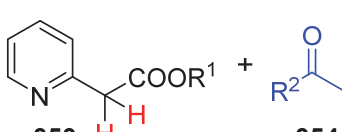

$353 \mathrm{H}$

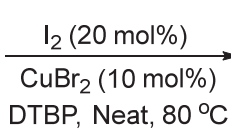

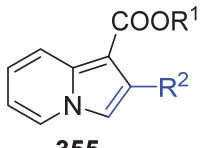
22 examples $0 \sim 79 \%$ yields
图式 $64 \quad \mathrm{I}_{2} /$ 过氧化物催化吲嗪化合物的合成

Scheme $64 \quad I_{2} /$ peroxide-catalyzed synthesis of indolizines

2015 年, 赵军锋课题组 ${ }^{[157]}$ 开发了一种高效的方法, 直接氧化酰化磺酰亚胺与甲基芳烃构建 $N$-芳基化亚砜 亚胺化合物 358 (Scheme 65). 该方法使用 $\mathrm{I}_{2}$ 作为催化 剂, $\mathrm{FeCl}_{3} \cdot 6 \mathrm{H}_{2} \mathrm{O}$ 作为添加剂, TBHP 作为氧化剂, 使用含 
不同取代基的甲基芳烃和亚砜肟作为底物，80 ${ }^{\circ} \mathrm{C}$ 下反 应实现氧化酰化. 甲基芳烃首先被氧化为苯甲醛中间 体, 随后苯甲醛和亚砜亚胺原位生成的 $N, O$-半胺进一 步氧化得到相应的酰化产物, 该过程避免了底物预先功 能化和活化.

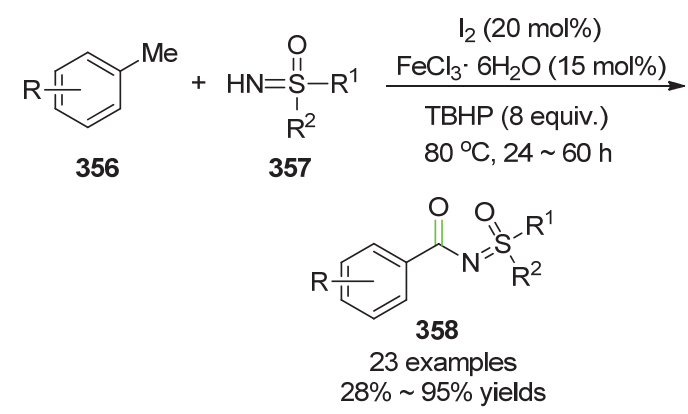

图式 65 以甲基芳烃为酰基供体的亚砜亚胺氧化酰基化反应 Scheme 65 Oxidative acylation of sulfoximines with methylarenes as acyl donor

吴安心课题组采用分子碘与过渡金属协同催化的 方法, 合成了双吡唑一吡啶化合物、2-甲酰-吡咯衍生物、 咪唑衍生物以及多取代吡啶化合物(Scheme 66). 通过 碘/铜介导选择性地合成了双吡唑一吡啶化合物 $\mathbf{3 6 1}^{[158]}$ (Scheme 66, a). 该方法通过甲基酮与吡唑-5-胺化合物 的 $[3+2+1]$ 形式杂环化, 构建了两个 $\mathrm{C}-\mathrm{C}$ 键和一个 $\mathrm{C}-\mathrm{N}$ 键. 初步机理研究表明, $\mathrm{I}_{2} / \mathrm{DMSO}$ 体系实现了甲基
酮 $\mathrm{C}\left(\mathrm{sp}^{3}\right)-\mathrm{H}$ 的氧化羰基化, $\mathrm{Cu}(\mathrm{OTf})_{2}$ 的参与加速了这 一转变. 目前直接通过 $\mathrm{C}-\mathrm{H}$ 键氧化合成杂芳香醛的方 法尚未见报道, 主要是因为难以实现高位点选择性且苯 甲酸较容易过度氧化 ${ }^{[159]} .2018$ 年, 吴安心课题组 ${ }^{[160]}$ 报 道了碘/铜介导的选择性氧化反应(Scheme 66, b). 以芳 基甲基酮、芳胺和乙酰乙酸酯为底物, 通过氧化环化由 $\mathrm{C}\left(\mathrm{sp}^{3}\right)-\mathrm{H}$ 键氧化为 $\mathrm{C}=\mathrm{O}$ 键, 高效地制备了 2-甲酰一吡 咯衍生物 365. 2020 年, 该课题组 ${ }^{[161]}$ 通过 $\mathrm{I}_{2} / \mathrm{FeCl}_{3}$ 共同 促进的 $[2+2+1]$ 环化反应, 高效地合成了咪唑衍生物 369 (Scheme 66, c). 有趣的是, 该反应由相邻基团 $\left(\mathrm{CH}_{2} \mathrm{OH}\right)$ 辅助进行, 使用 TosMIC 提供“ C $\mathrm{C} / \mathrm{N}$ ”来源合成咪 唑化合物 369. 对机理进行了研究, 表明 $\mathrm{TsCH}_{2} \mathrm{NH}_{2}$ 可能 是关键的中间体. 吴安心课题组 ${ }^{[162]}$ 还通过 $\mathrm{C}\left(\mathrm{sp}^{3}\right)-\mathrm{H}$ 键 氧化和甲基亚砜的 $\mathrm{C}-\mathrm{S}$ 键裂解有效地合成了多取代吡 啶化合物 371 和 372 (Scheme 66, d). 该转化底物范围广 泛，通过使用不同类型的酮，可以得到相应的取代吡咯 烷酮类化合物.

2017 年, 席婵娟课题组 ${ }^{[163]}$ 报道了分子碘催化的邻 烷基芳烃氧化 $\mathrm{C}-\mathrm{H}$ 官能化反应, 有效地构建 $2 H$-吲唑 类化合物 374 (Scheme 67). 在该催化循环中, $\mathrm{CuI}$ 是促 进碘循环再生的有效添加剂. 该催化体系适用于富电子 和缺电子的偶氮化合物, 反应产率中等至较好. 作者还 进行了克级放大反应, 证明了该反应的实用性. (a)<smiles>[R]C(=O)[O-]</smiles>

359<smiles>Cc1cc(N)n(Cc2ccccn2)n1</smiles>

(b)<smiles>[R]CC(C)=O</smiles>
364<smiles></smiles>

361 22 examples
$30 \% \sim 82 \%$ yields $38 \% \sim 74 \%$ yields

365

(c)

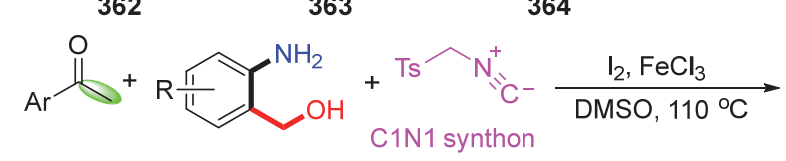
368 $366 \quad 367$

(d)

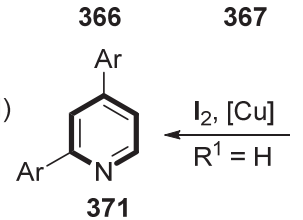

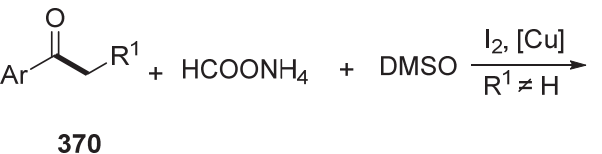

29 examples $19 \% \sim 88 \%$ yields

图式 66 碘和金属共同催化构建杂环

Scheme 66 Cooperative iodine and metal catalysis for construction of heterocyclic 
<smiles>[R]Cc1c([Z16])cc([R])cc1[R1]</smiles>

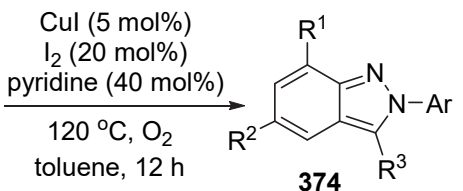

20 examples $0 \sim 97 \%$ yields

图式 67 碘催化邻烷基芳烃有氧氧化为 $2 H$-吲哚化合物 Scheme 67 Iodine-catalyzed aerobic oxidation of $o$-alkylazoarenes to $2 \mathrm{H}$-indazoles

咪唑并 $[1,2-a]$ 吡啶衍生物是制药工业中许多药物的 基础骨架, 具有多种生物活性. 2019 年, Anilkumar 课题 组 ${ }^{[164]}$ 首次采用铁催化 Ortoleva-King 型的合成方法, 制 备了稠杂环化合物 377 (Scheme 68). 该方法采用廉价易 得的 $\mathrm{FeCl}_{3} \cdot 6 \mathrm{H}_{2} \mathrm{O}$ 和分子碘作为催化剂, 以中等到良好 的产率构建了咪唑并 $[1,2-a]$ 吡啶衍生物. 作者通过佐利 米定(胃保护药物)的直接一步合成证明了该方法的合成 实用性.

2019 年, Sekar 课题组 ${ }^{[165]}$ 使用铜作为催化剂, 以黄 原酸酯作为硫源，从容易获得的 2'-卤代查耳酮制备了 多种 2-芳基硫代色烯酮(Scheme 69).

该方法证明了以 2'-卤代查耳酮为原料合成的交叉 偶联产物硫代色满酮(上游反应), 在一锅反应中用第一<smiles>CC(=O)c1ccccc1</smiles><smiles>[R]c1ccnc(N)c1</smiles>
$\mathrm{FeCl}_{3} \cdot 6 \mathrm{H}_{2} \mathrm{O}(20 \mathrm{~mol} \%)$ $\mathrm{I}_{2}(20 \mathrm{~mol} \%)$

Chlorobenzene $110^{\circ} \mathrm{C}$, air, $20 \mathrm{~h}$<smiles>[R]c1ccc(-c2cn3ccc([R])cc3n2)cc1</smiles>

377

18 examples $22 \% \sim 75 \%$ yields

图式 68 铁/碘催化咪唑并 $[1,2-a]$ 吡啶衍生物的合成 Scheme 68 Iron/iodine-catalyzed synthesis of imidazo[1,2- $a]$ pyridines

步的副产物 $\mathrm{KI}$ 作为强氧化剂分子碘来源, 氧化合成了 硫代色烯酮(下游反应)。该一锅合成法可以使用 DMSO 作为溶剂和亚甲基来源构建 3,3'-亚甲基二硫代黄酮. 作 者提出了合理的催化机理. 反应途径(1)：2'-碘查耳酮 378 在铜盐和黄原酸酯作用下, 通过氧化加成/配体交 换/还原消除/迈克尔加成的反应顺序得到目标化合物硫 代色满酮 379, 同时生成副产物 KI. 随后，副产物 KI 与 $\mathrm{H}_{2} \mathrm{SO}_{4}$ 反应生成 $\mathrm{HI}, \mathrm{HI}$ 在二甲基亚砜中被氧化生成 $\mathrm{I}_{2}$. 反应途径(2)：原位生成的 $\mathrm{I}_{2}$ 和烯醇互变化合物 $379^{\prime}$ 反应 生成 3-碘硫代黄酮中间体 D. 中间体 D 通过消除 HI 得 到目标产物 380. 之后 $\mathrm{HI}$ 又被 $\mathrm{DMSO}$ 氧化为 $\mathrm{I}_{2}$.

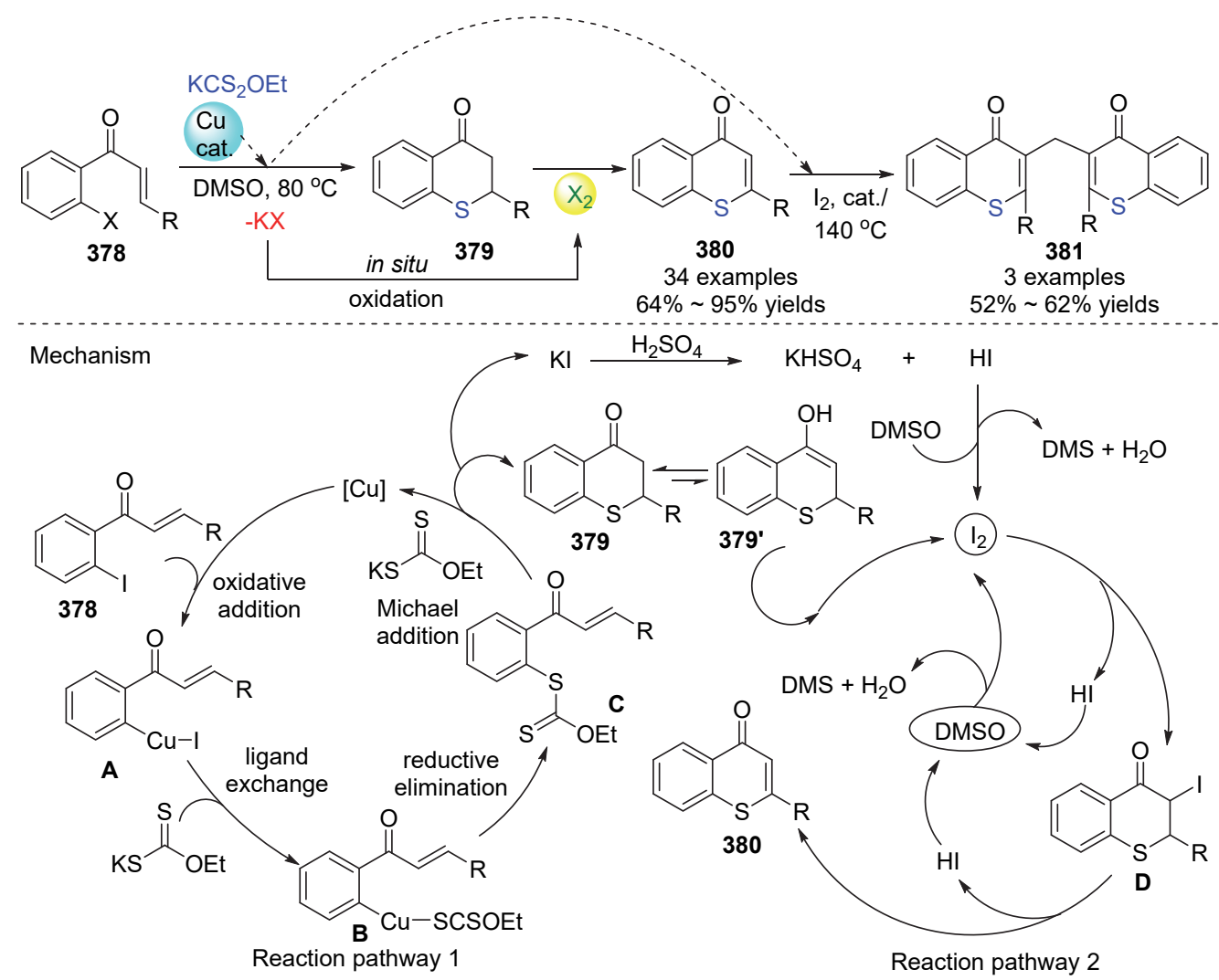

图式 69 铜催化一锅合成 2-芳基硫代色烯酮: 原位回收副产物(KI)作为有用试剂

Scheme 69 Copper-catalyzed one-pot synthesis of 2-arylthiochromenones: an in situ recycle of byproduct (KI) as useful reagent 
之后, Sekar 课题组 ${ }^{[166]}$ 同样以 2-碘酮为原料, 采用 铜作为催化剂, 以黄原酸酯为硫源, 合成了多种取代的 2-酰基苯并噻吩 383 和 2-酰基二氢苯并噻吩 384 (Scheme 70). 作者推测的反应机理: 反应最初, $\mathrm{Cu}(\mathrm{II})$ 和 黄原酸酯反应生成 $\mathrm{Cu}(\mathrm{I}), 2$-卤代酮通过氧化加成/配体 交换/还原消除得到中间体 A. 途径(a)：中间体与原位生 成的 $\mathrm{I}_{2}$ 反应生成 $\alpha$-碘酮硫酯 B. 随后在碱性条件下进一 步水解, 得到中间体 C. 之后, 中间体 $\mathbf{C}$ 将以 $\mathrm{S}_{\mathrm{N}} 2$ 的方 式通过分子内亲核进攻得到产物 383. 然而, 当淀粉和 硫代硫酸盐溶液处理反应混合物时, 反应物的颜色没有 变化, 所以侧面证明这种途径不成立. 途径(b): 中间体 A 在过量黄原酸酯作用下通过配体交换/金属化/氧化转 化为中间体 $\mathbf{D}$, 在 $\mathrm{Cu}(\mathrm{II})$ 催化剂和大气氧作用下将转化 为中间体 $\mathbf{E}$. 中间体 $\mathbf{E}$ 通过还原消除得到产物 $\mathbf{3 8 3}$. 产 物 383 与原位生成的 $\mathrm{I}_{2}$ 和 $\mathrm{H}_{2} \mathrm{SO}_{4}$, 在 DMSO 中得到中间 体 F. 最后消除 HI 则得到产物 384 .

2020 年, 刘永泉课题组 ${ }^{[167]}$ 报道了一种通过新的 $\mathrm{CuBr}_{2} / \mathrm{I}_{2}$-协同催化合成 1,3-二羰基化合物 386 的通用氧 化方法(Scheme 71). 该方法适用于各类 1,3-二羰基化合 物, 包括 1,3-二酮、1,3-酮酯和 1,3-酮酰胺. 机理研究表 明, 该反应通过 $\mathrm{C}-\mathrm{C}$ 键断裂和 $\mathrm{CO}$ 释放实现串联.

\section{$2.7 \mathrm{I}_{2}$ 在其他体系下催化的 $\mathrm{C}\left(\mathrm{sp}^{3}\right)$ - $\mathrm{H}$ 功能化反应}

分子碘和光氧化还原催化剂作为共同催化剂来催 化 $\mathrm{C}\left(\mathrm{sp}^{3}\right)-\mathrm{H}$ 功能化反应是一种新型的催化方式. 同时, 分子碘在其他体系下催化的 $\mathrm{C}\left(\mathrm{sp}^{3}\right)-\mathrm{H}$ 功能化反应也得
到发展, 开发了新型的分子碘参与有机转化的方式.

Muñiz 课题组 ${ }^{[168]}$ 对他们之前的催化体系进行了创 新, 开发了一种分子内 $\mathrm{C}\left(\mathrm{sp}^{3}\right)-\mathrm{H}$ 胺化反应, 选择性地 合成了哌啶化合物 388 (Scheme 72, a). 该方法采用分子 碘与末端氧化剂 $\mathrm{N}$-溴代琥珀酰亚胺(NBS) 作为衍生的均 相碘催化剂(卤素配位作用), 在可见光诱导下实现分子 内 $\mathrm{C}\left(\mathrm{sp}^{3}\right)-\mathrm{H}$ 胺化反应. 通过自由基 $\mathrm{C}-\mathrm{H}$ 功能化和碘 催化 $\mathrm{C}-\mathrm{N}$ 键形成两个循环过程实现哌啶类化合物的合 成. 在该条件并没有按照 Hofmann-Loffler 反应由磺酰 胺自由基中间体合成吡咯化合物, 这种选择偏好被有效 地转变. 该反应显著扩大了光诱导碘催化位点选择性 C $-\mathrm{H}$ 胺化反应的范围, 同时使得哌啶的化学结构多样 化.

随后, Muñiz 课题组 ${ }^{[125]}$ 开发了另一种光活化碘和光 氧化还原催化剂共同催化茮基 $\mathrm{C}\left(\mathrm{sp}^{3}\right)$ - $\mathrm{H}$ 胺化的反应 (Scheme 72, b). 该反应中碘作为催化剂, 通过可见光照 射激活远程 $\mathrm{C}\left(\mathrm{sp}^{3}\right)-\mathrm{H}$ 键(1,5-HAT 过程), 形成新的 $\mathrm{C}-$ $\mathrm{N}$ 键, 而 TPT(有机光氧化还原催化剂)则有效地催化了 分子碘的再生循环. 作者为了解释这两个光化学步骤的 相容性，用计算方法阐明了反应关键步骤是 $\mathrm{N}-\mathrm{I}$ 键的 裂解. 这种方法引入了一种新的双光激活协同碘和光氧 化还原催化的概念, 并被应用于远程 $\mathrm{C}\left(\mathrm{sp}^{3}\right)-\mathrm{H}$ 键的分 子内胺化. 在已有对分子碘和光催化剂共同催化 $\mathrm{C}\left(\mathrm{sp}^{3}\right)$ - $\mathrm{H}$ 功能化反应的研究基础上, 2019 年, Muñiz 课 题组 ${ }^{[126]}$ 开发了一种从羧酸中通过苄基 $\mathrm{C}-\mathrm{H}$ 键直接转

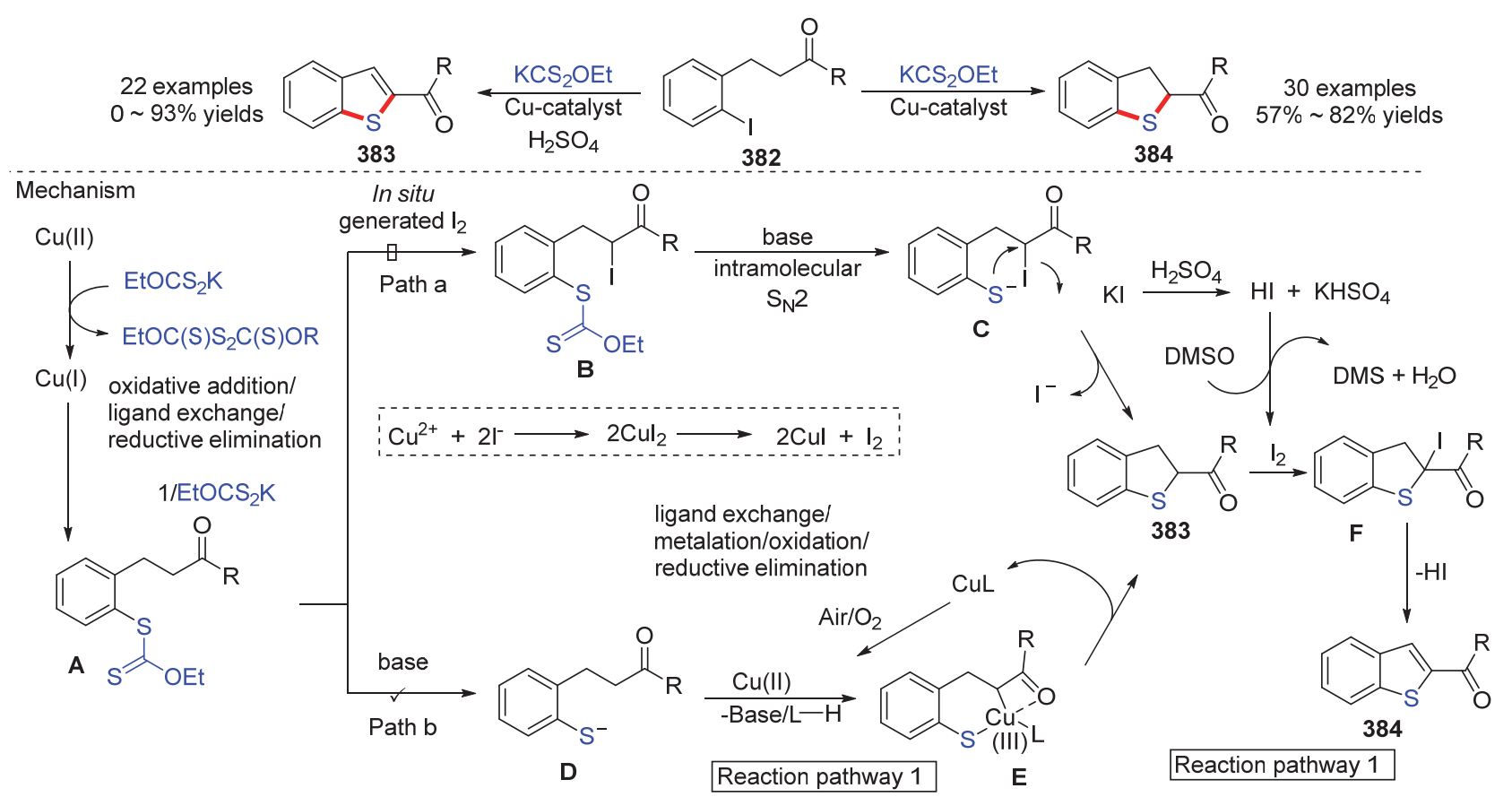

图式 70 铜催化 2-酰基二氢苯并噻吩和 2-酰基苯并噻吩化合物的合成

Scheme 70 Copper-catalyzed synthesis of 2-acyldihydrobenzo $[b]$ thiophenes and 2-acylbenzo $[b]$ thiophenes 


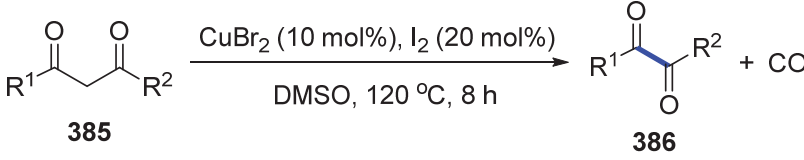

$$
\begin{aligned}
& \text { 0 96\% yields }
\end{aligned}
$$

图式 71 铜/碘共同催化 1,3-二羰基化合物的 $\mathrm{C}-\mathrm{C}$ 键裂解为 1,2-二羰基化合物

Scheme 71 Copper/iodine-cocatalyzed C-C cleavage of 1,3-dicarbonyl compounds toward 1,2-dicarbonyl compounds

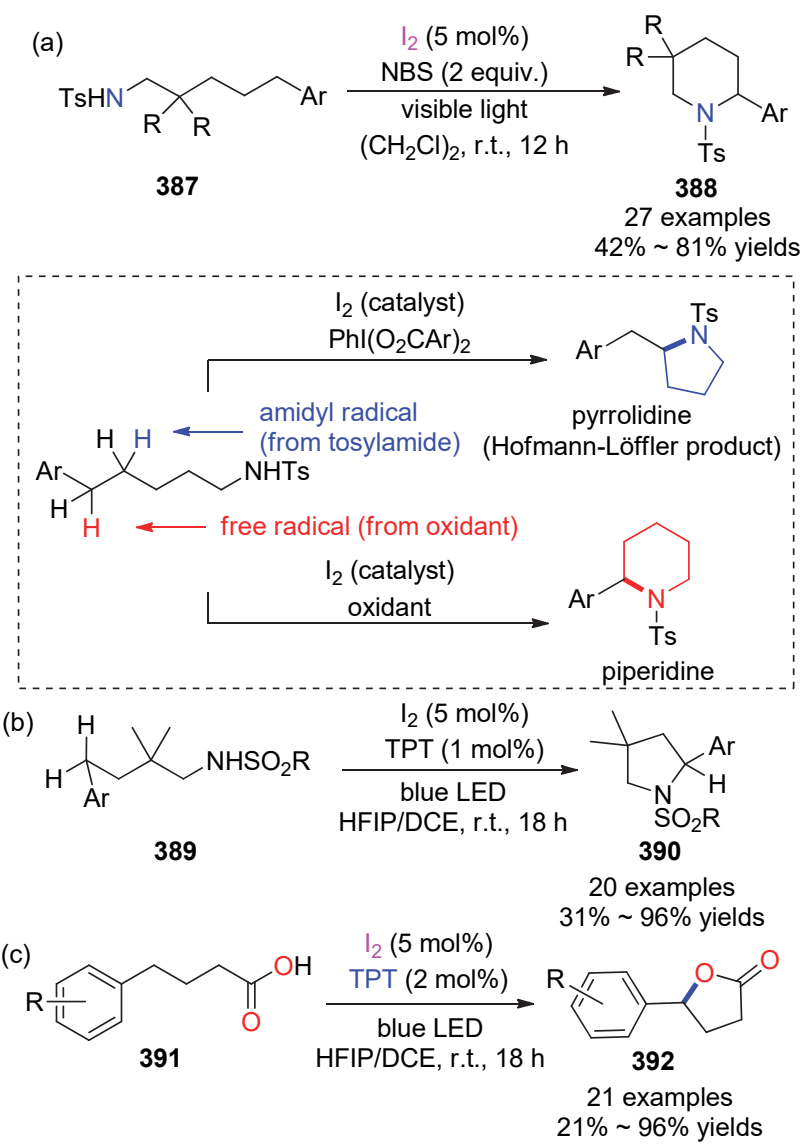

图式 72 碘催化分子内 $\mathrm{C}\left(\mathrm{sp}^{3}\right)-\mathrm{H}$ 胺化反应 Scheme 72 Iodine-catalyzed intramolecular $\mathrm{C}\left(\mathrm{sp}^{3}\right)-\mathrm{H}$ amination
化为 $\mathrm{C}-\mathrm{O}$ 键形成 $\gamma$-和 $\delta$-内酯的新方法 (Scheme 72, c). 该反应结合了催化量的分子碘和有机染料，并依赖光氧 化还原催化实现末端氧化，在一定程度上丰富了分子碘 催化的反应类型, 对相关 $\mathrm{C}-\mathrm{H}$ 氧化反应的发展具有指 导意义.

环丙烷及其衍生物是一类用途广泛的分子，在有机 合成中有着广泛的应用. 由于其刚性的结构和固有的反 应活性，环丙烷可以成为合成复杂分子的关键成分. 2015 年, Skoulika 课题组 ${ }^{[169]}$ 报道了碘催化的 2,6-二甲基 喹啉、吡啶与苯甲醛和丙二腈缩合产物的非对映选择性 环丙基化反应(Scheme 73). 该反应中加入吡定, 在碘催 化下对 $\mathrm{C}-2$ 位上 $\mathrm{C}\left(\mathrm{sp}^{3}\right)-\mathrm{H}$ 进行活化, 得到中等产率.

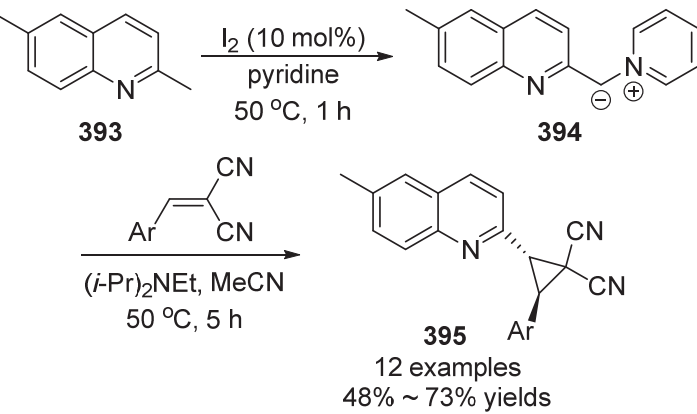

图式 73 碘催化非对映选择性环丙基化反应 Scheme 73 Iodine-catalyzed diastereoselective cyclopropanation

2016年, Itoh 课题组 ${ }^{[170]}$ 开发了一种新型的光诱导活 性亚甲基化合物与苯乙烯的分子间环丙烷化方法 (Scheme 74). 具有不同取代基团(烷基和吸电子基团)的 苯乙烯能产生相应的环丙烷 398, 产率中等到良好. 同 时, 作者提出了一种通过光诱导的均相 $\mathrm{C}-\mathrm{I}$ 键裂解生 成自由基中间体的一般反应机制，可进一步应用于各种 类型的反应. 在无过渡金属条件下得到相应的环丙烷产 物，实现了环丙烷衍生物的绿色化学合成.

作者提出了合理的反应机制. 首先, 碱辅助碘化底 物形成自由基前体 399. 然后光诱导同相 $\mathrm{C}-\mathrm{I}$ 键裂解生 成自由基中间体 400. 生成的碳自由基进攻烯烃得到中

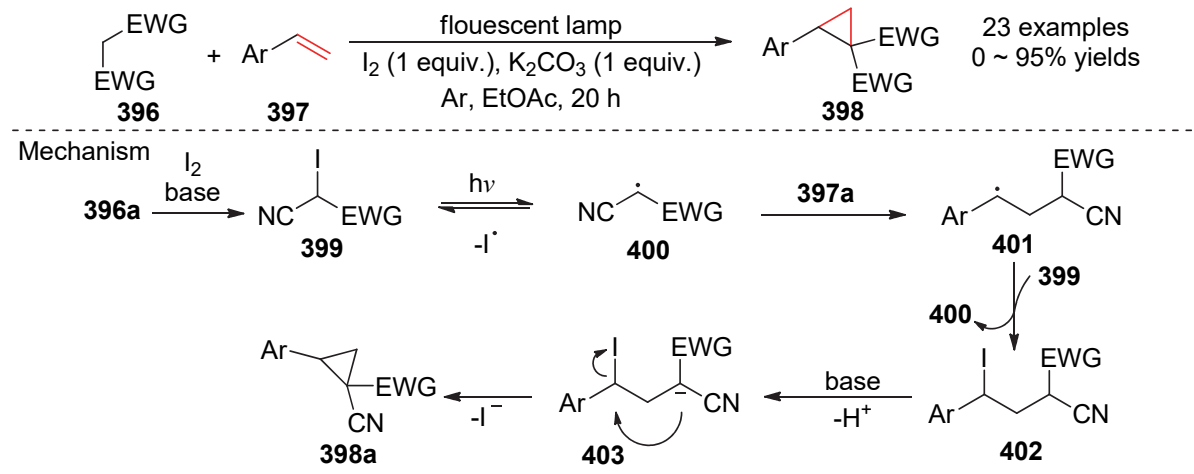

图式 74 碘和可见光催化苯乙烯分子间环丙化反应

Scheme 74 Iodine and visible light catalyzed intermolecular cyclopropanation of styrenes 
间体 401, 再从 399 中提取 I 原子, 转化为自由基 400 和 中间体 402. 最后, 中间体 402 通过 3-exo-四环化得到产 物环丙烷 398a.

2016 年, Adimurthy 课题组 ${ }^{[171]}$ 采用一种无金属、无 碱试剂、无氧化剂的方法, 在温和条件下, 通过碘催化 $\mathrm{C}-\mathrm{C}$ 键和 $\mathrm{C}-\mathrm{N}$ 键的偶联构建了吲哚嗪类化合物 405 和 406 (Scheme 75). 由 2-吡啶乙酸与炔或烯烃反应, 该 反应官能团兼容性好, 产率中等到良好.

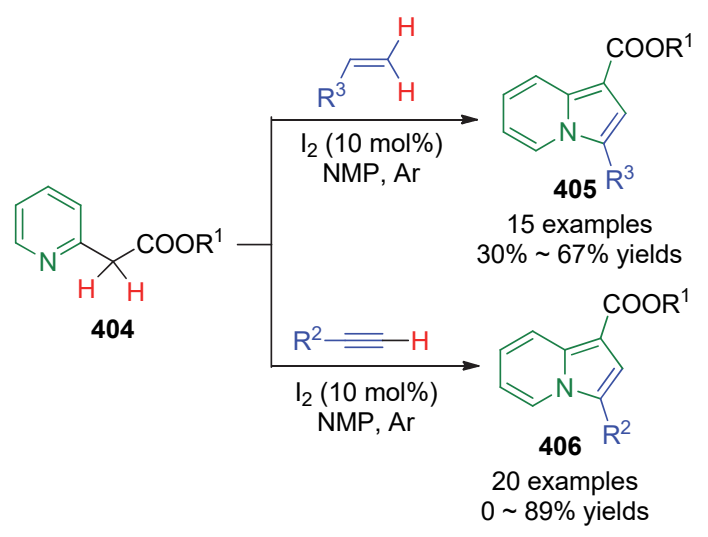

图式 75 碘催化氧化 $\mathrm{C}-\mathrm{C}$ 和 $\mathrm{C}-\mathrm{N}$ 键合成吲哚嗪类化合物 Scheme 75 Iodine-catalyzed synthesis of indolizines through oxidative $\mathrm{C}-\mathrm{C}$ and $\mathrm{C}-\mathrm{N}$ bond formations

2016 年, 严汝龙课题组 ${ }^{[172]}$ 开发了 2-烷基喹啉与碘 的卤化反应, 再通过与 $\mathrm{AgF}_{2}$ 进行交换得到氟代产物 (Scheme 76). 该方法提供了一种构建 $\mathrm{C}-\mathrm{I} / \mathrm{F}$ 键的简便 策略, 并且有着良好的官能团耐受性, 产率中等至良好. 控制实验证明该反应不涉及自由基过程.

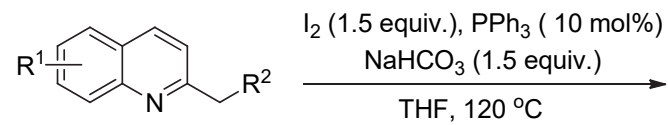

407

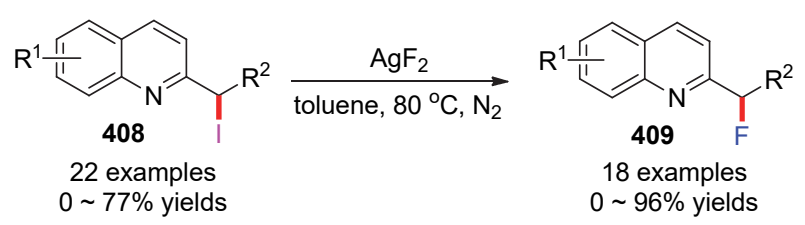

图式 76 碘取代的 2-烷基喹啉的卤代反应

Scheme 76 Halogenations of substituted 2-alkylquinoline with iodine

2017 年, 渠瑾课题组 ${ }^{[173]}$ 利用分子碘介导了吡咯 $\alpha-\mathrm{C}-\mathrm{H}$ 键氧化, 实现了分子内 $\mathrm{C}-\mathrm{O}$ 键的构建 (Scheme 77). 研究发现分子碘介导的二级 $\alpha-\mathrm{C}-\mathrm{H}$ 键比三级 $\alpha-$ $\mathrm{C}-\mathrm{H}$ 键更具有氧化优先性, 提高了先前报道方法的原 子经济性. 并且采用该方法合成了 $(2 S, 3 S, 5 R)$-1-甲基-5壬基-2-苄基-3-吡咯烷醇(Preussin)和对应的 C(3)异构体.

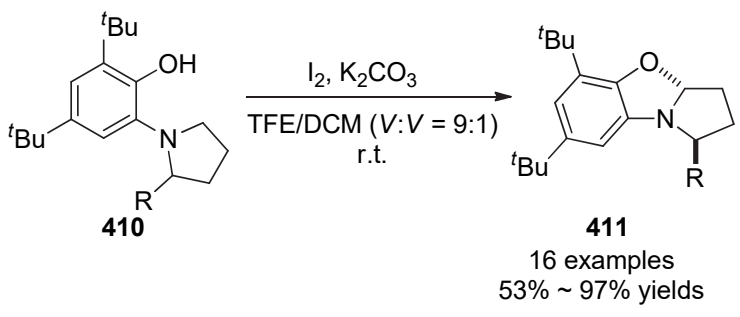

图式 77 分子碘介导的 $\alpha-\mathrm{C}-\mathrm{H}$ 氧化吡咯烷酮合成 $N, O$-乙酰 化合物

Scheme 77 Iodine-mediated $\alpha-\mathrm{C}-\mathrm{H}$ oxidation of pyrrolidines to $N, O$-acetals

2017 年，谭桂山课题组 ${ }^{[174]}$ 首次报道了碘介导的由 $N$-烷基哌嗪一锅合成 2-(哌嗪-1-)吡嗪衍生物 413 的反应 (Scheme 78). 这种转化为合成 2-(哌嗪-1-)吡嗪衍生物提 供了一条直接、简便的途径，并且 $N$-烷基哌嗪类化合物 为唯一原料. 作者提出了一种合理的反应机理. 以底物 412a 为例, 反应开始由底物得到 $N$-碘铵中间体 414. 中 间体 414 消除两个 $\mathrm{HI}$ 分子, 得到了的亚胺阳离子中间体 415. 随后氨解转化为中间体 416. 实验说明, 仲胺在这 一步骤中比伯胺活性更好. 随后，中间体 416 进一步碘 化转化为新的碘铵中间体 417 , 再离去 $\mathrm{HI}$ 得到中间体 418. 最后中间体 418 水解得到目标产物 413a, 并消除 了苯甲醛分子.

2,3-二取代吲哚侧链的直接 $\mathrm{C}-\mathrm{H}$ 键功能化方法相 当有限. 2018 年, 刘培均课题组 ${ }^{[175]}$ 在氯胺盐存在下, 在 2,3-取代吲哚的 $2 \alpha$-位实现了一种新型的碘催化酰胺化 和亚胺化反应, 具有较高的区域选择性(Scheme 79).

不同底物, 在相同的催化条件下, 都有着较高的区 域选择性. 此外, 作者通过五步反应由 $2 \alpha$-酰胺化产物 制备了阿枯米灵生物碱的桥接四环骨架，有效证明这一 转化的合成价值. 作者提出的反应机理: 最初, 氯胺和 碘的相互作用得到活性 $N$-碘-氯苯磺酰胺 422, 随后激 活吲哚 419a, 得到亚胺中间体 423; 在 $2 \alpha$ 位置消除氢原 子转化为烯胺 424 , 氯胺对 424 进行 $\mathrm{S}_{\mathrm{N}} 2$ 取代得到氯胺 425, 然后与碘离子反应生成酰胺化产物 421a; 最后, 得到的氯碘氧化再生碘. 对于 2-甲基-3-取代吲哚类底 物, 中间 $2 \alpha$-胺化吲哚 $\mathbf{4 2 6}$ 继续与另一分子 $\mathbf{4 2 2}$ 反应, 该 分子产生最终的亚胺化产物 420a, 同时释放苯磺酰胺 和碘氯.

2020 年, 张继东课题组 ${ }^{[176]}$ 报道了一种直接合成杂 芳基取代 1,3,5-三嗪衍生物 430 的方法(Scheme 80). 该 方法在有氧条件下通过碘介导串联 $\mathrm{C}\left(\mathrm{sp}^{3}\right)-\mathrm{H}$ 氧化胺 化、缩合和脒环化得到目标产物. 甲基喹啉、吡啶和苯 并噻唑衍生物均能有效地与各种缕类化合物组合, 高效 地构建 $1,3,5$-三嗪衍生物. 


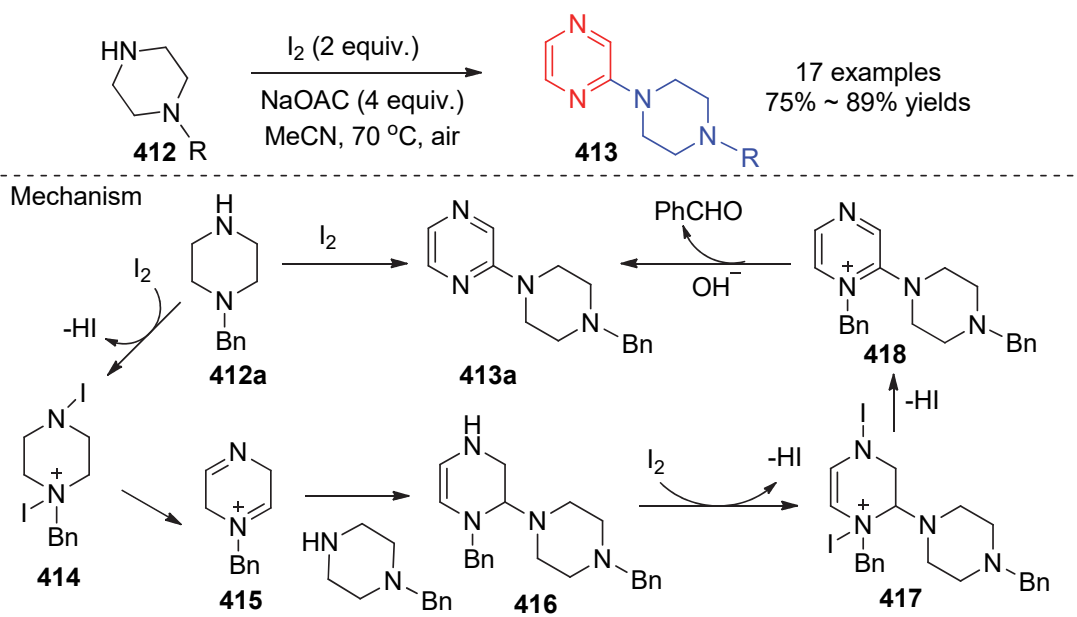

图式 78 碘介导由 $N$-烷基哌嗪一锅合成 2-(哌嗪-1-)吡嗪衍生物

Scheme 78 Iodine-mediated one-pot synthesis of 2-(piperazin-1-yl)pyrazine derivatives from $N$-alkyl piperazines

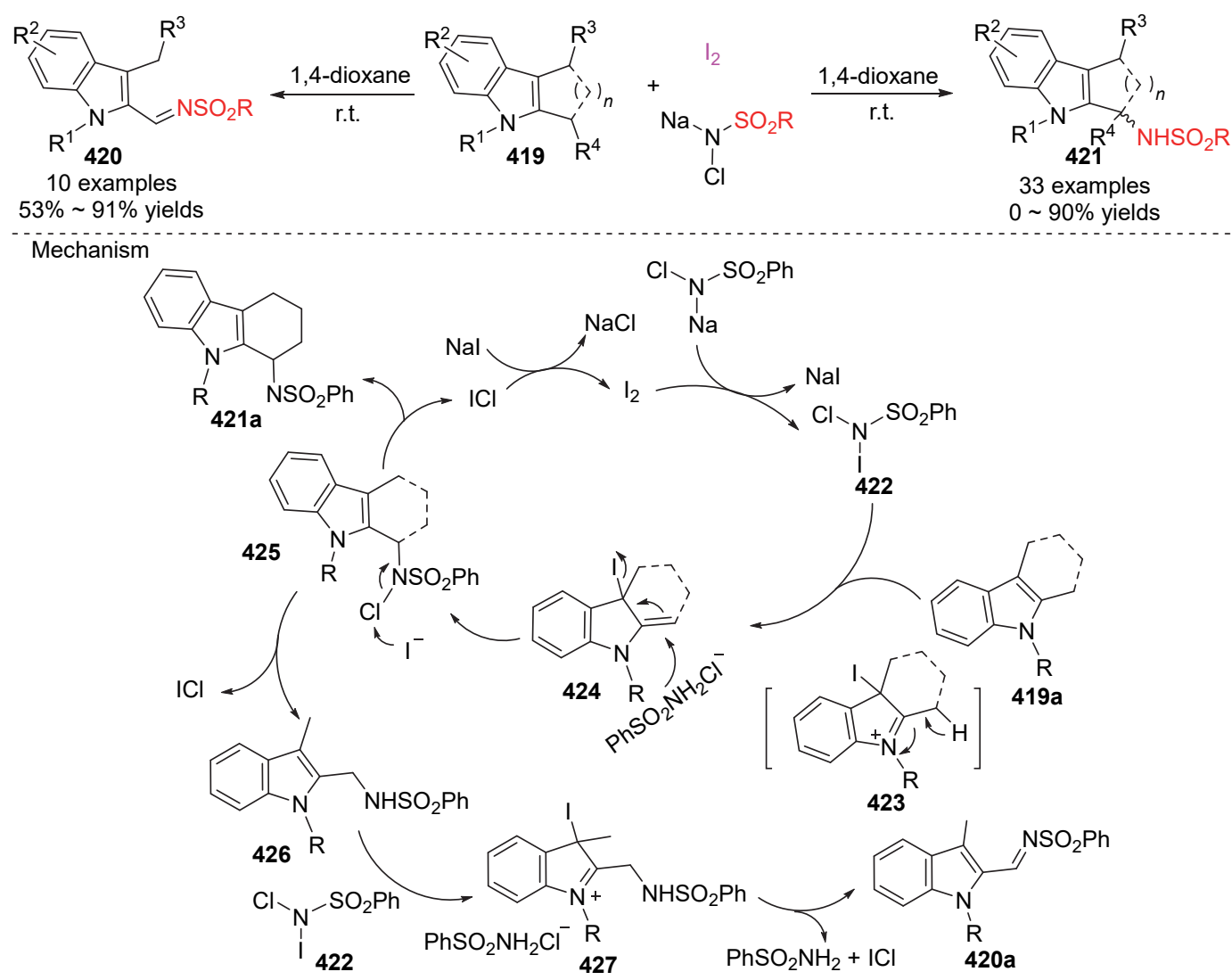

图式 79 碘催化 $2 \alpha$-位的 2,3-二取代吲哚与氯胺盐的 $\mathrm{C}-\mathrm{H}$ 酰胺化和亚胺化

Scheme 79 Iodine-catalyzed $\mathrm{C}-\mathrm{H}$ amidation and imination at the $2 \alpha$-position of 2,3-disubstituted indoles with chloramine salts

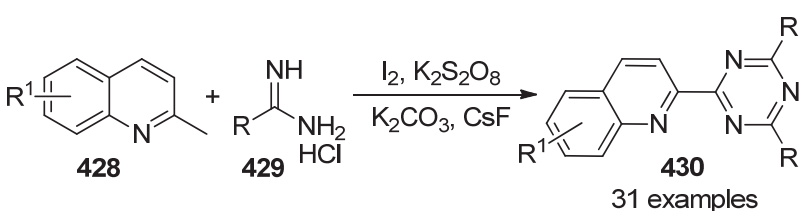

$0 \sim 92 \%$ yields

图式 $80 \mathrm{I}_{2} / \mathrm{K}_{2} \mathrm{~S}_{2} \mathrm{O}_{8}$ 介导 $1,3,5$-三嗪衍生物的合成

Scheme $80 \quad \mathrm{I}_{2} / \mathrm{K}_{2} \mathrm{~S}_{2} \mathrm{O}_{8}$-mediated synthesis of substituted 1,3,5-triazines
以上工作发展了不同体系下分子碘催化的 $\mathrm{C}\left(\mathrm{sp}^{3}\right)$ $\mathrm{H}$ 功能化, 有效说明了分子碘作为一种重要的试剂在 $\mathrm{C}\left(\mathrm{sp}^{3}\right)-\mathrm{H}$ 功能化反应的研究中有着不可取代的位置.

\section{3 总结与展望}

分子碘是廉价、稳定、易得、低毒的化学试剂, 通 常碘还能进行回收利用，大大降低了反应的污染和成 
本, 这也是分子碘作为催化剂的特别之处. 分子碘催化 的 $\mathrm{C}\left(\mathrm{sp}^{3}\right)-\mathrm{H}$ 功能化反应应用于各种含杂原子化合物的 合成, 实现了精准转化, 这其中包括许多具有生物活性 的复杂杂环化合物, 例如尼古丁衍生物 ${ }^{[45]}, \beta$-氨基醇生

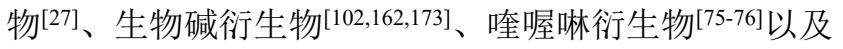
三唑衍生物 ${ }^{[74,114]}$ 等. 同时, 直接的 $\mathrm{C}\left(\mathrm{sp}^{3}\right)-\mathrm{H}$ 功能化还 可以对化合物进行结构修饰, 位点选择性地构建 $\mathrm{C}$ $\mathrm{O} / \mathrm{S} / \mathrm{N}$ 键等. 从反应机制角度而言, 一方面分子碘在体 系中形成 $\mathrm{C} / \mathrm{N} / \mathrm{S}$ - 键后, 进一步活化, 通过自由基传递 实现 $\mathrm{C}-\mathrm{H}$ 键功能化. 另一方面也能通过形成弱化学键 后通过离子形式进行活化. 反应类型多样, 包括多组分 串联反应、串联环化、迈克尔反应、交叉脱氢偶联反应、 芳构化和 HLF 反应等. 从反应体系角度而言, 使用碘作 为绿色催化剂, 加入温和氧化剂(高价碘、DMSO、过氧 化物、氧气), 能够简单、高效地实现 $\mathrm{C}\left(\mathrm{sp}^{3}\right)-\mathrm{H}$ 功能化 反应, 该类催化体系相比较传统的催化方法具有很大优 势. 同时, 含碘试剂可在氧化剂或电解池中原位生成分 子碘催化反应, 拓展了碘试剂在绿色有机转化中的应 用. 除此之外，过渡金属和分子碘协同催化的 $\mathrm{C}\left(\mathrm{sp}^{3}\right)-$ $\mathrm{H}$ 功能化反应作为一种新型的反应体系具有较高的反 应性能

近几年来, 虽然分子碘催化的 $\mathrm{C}\left(\mathrm{sp}^{3}\right)-\mathrm{H}$ 功能化反 应已经取得了长足的发展, 但是目前仍然存在着很大的 发展空间, 比如: (1)开发更加绿色高效的碘催化氧化体 系, 将碘试剂的用量进行定量化和最小化, 运用更科学 的检测手段对碘在反应过程中的转化进行捕捉, 将为深 入研究碘催化有机反应的机理提供有价值的帮助; (2)相 比较于芳基碘类化合物在不对称合成领域上的进步, 分 子碘催化不对称领域仍然空缺, 实现位点和对映选择性 地 $\mathrm{C}\left(\mathrm{sp}^{3}\right)-\mathrm{H}$ 键的精确转化具有巨大发展潜力. 分子碘 形成的自由基物种是可以实现的, 控制自由基实现不对 称合成将会实现该领域的重大突破.

\section{References}

[1] Togo, H.; Iida, S. Synlett 2006, 2006, 2159.

[2] Ren, Y. M.; Cai, C.; Yang, R. C. RSC Adv. 2013, 3, 7182.

[3] Chu, C. M.; Gao, S. J.; Sastry, M. N. V.; Yao, C. F. Tetrahedron Lett. 2005, 46, 4971.

[4] Yin, G. D.; Fan, L.; Ren, T. B.; Zheng, C. Y.; Tao, Q.; Wu, A. X.; She, N. F. Org. Biomol. Chem. 2012, 10, 8877.

[5] Wang, S. Y.; Ji, S. J.; Loh, T. P. Synlett 2003, 2003, 2377.

[6] Parvatkar, P. T.; Manetsch, R.; Banik, B. K. Chem.-Asian J. 2019, $14,6$.

[7] Mphahlele, M. J. Molecules 2009, 14, 5308.

[8] Gaikwad, S.; Kamble, D.; Lokhande, P. Tetrahedron Lett. 2018, 59, 2387.

[9] Humne, V.; Dangat, Y.; Vanka, K.; Lokhande, P. Org. Biomol. Chem. 2014, 12, 4832.

[10] Stateman, L. M.; Nakafuku, K. M.; Nagib, D. A. Synthesis 2018, $50,1569$.

[11] Zhao, Y. Y.; Wang, E. B.; Wang, Y. L. Chin. J. Org. Chem. 2017,
37, 866 (in Chinese).

(赵玉英, 王二兵, 王颖莉, 有机化学, 2017, 37, 866.)

[12] Shi, Z. J.; Wang, L. H.; Cui, X. L. Chin. J. Org. Chem. 2019, 39, 1596 (in Chinese).

(施兆江, 王连会, 崔秀灵, 有机化学, 2019, 39, 1596.)

[13] Xu, X. M.; Chen, D. M.; Wang, Z. L. Chin. J. Org. Chem. 2019, 39, 3338 (in Chinese)

(徐金明, 陈德茂, 王祖利, 有机化学, 2019, 39, 3338.)

[14] Du, X. P.; Zhang, X.; Hou, F.; Liu, X. J.; Wang, X. C.; Quan, Z. J. Chin. J. Org. Chem. 2020, 40, 1337 (in Chinese).

(杜兴鹏, 张胥, 候飞, 刘小军, 王喜存, 权正军, 有机化学, 2020, 40, 1337.)

[15] Yang, L. F.; Hui, R. J.; Shan, H. Y.; Gong, K. Chin. J. Org. Chem. 2017, 37, 3242 (in Chinese).

(杨丽烽, 惠人杰, 单恒悦, 巩凯, 有机化学, 2017, 37, 3242.)

[16] Blanksby, S. J.; Ellison, G. B. Acc. Chem. Res. 2003, 36, 255.

[17] Simões, J. A. M.; Beauchamp, J. L. Chem. Rev. 1990, 90, 629.

[18] Siegbahn, P. E. M. J. Phys. Chem. 1995, 99, 12723.

[19] Yeung, C. S.; Dong, V. M. Chem. Rev. 2011, 111, 1215.

[20] Beccalli, E. M.; Broggini, G.; Martinelli, M.; Sottocornola, S. Chem. Rev. 2007, 107, 5318.

[21] Hosseinian, A.; Ahmadi, S.; Nasab, F. A. H.; Mohammadi, R.; Vessally, E. Top. Curr. Chem. 2018, 376, 1.

[22] Li, C. J.; Li, Z. P. Pure Appl. Chem. 2006, 78, 935.

[23] Borpatra, P. J.; Deka, B.; Deb, M. L.; Baruah, P. K. Org. Chem. Front. 2019, 6, 3445.

[24] Chu, J. C. K.; Rovis, T. Angew. Chem., Int. Ed. 2017, 56, 2.

[25] Meng, G. Y.; Guo, T. J.; Ma, T. C.; Zhang, J.; Shen, Y. C.; Sharpless, K. B.; Dong, J. J. Nature 2019, 574, 86.

[26] Wu, X.; Gao, Q. H.; Geng, X.; Zhang, J. J.; Wu, Y. D.; Wu, A. X. Org. Lett. 2016, 18, 2507.

[27] Stateman, L. M.; Wappes, E. A.; Nakafuku, K. M.; Edwards, K. M.; Nagib, D. A. Chem. Sci. 2019, 10, 2693.

[28] Long, J. G.; Cao, X.; Zhu, L. Z.; Qiu, R. H.; Au, C. T.; Yin, S. F.; Iwasaki, T.; Kambe, N. Org. Lett. 2017, 19, 2793.

[29] Siddaraju, Y.; Prabhu, K. R. Org. Lett. 2016, 18, 6090.

[30] Liang, Y. F.; Li, X. Y.; Wang, X. Y.; Zou, M. C.; Tang, C. H.; Liang, Y. J.; Song, S.; Jiao, N. J. Am. Chem. Soc. 2016, 138, 12271.

[31] Reddy, P. N.; Reddy, B. V. S.; Padmaja, P. Curr. Org. Synth. 2018, 15,815 .

[32] Monga, A.; Bagchi, S.; Sharma, A. New J. Chem. 2018, 42, 1551.

[33] Tashrifi, Z.; Khanaposhtani, M. M.; Larijani, B.; Mahdavi, M. Adv. Synth. Catal. 2020, 362, 65.

[34] Sudo, Y.; Yamaguchi, E.; Itoh, A. Org. Lett. 2017, 19, 1610.

[35] Rong, H. J.; Yao, J. J.; Li, J. K.; Qu, J. J. Org. Chem. 2017, 82, 5557.

[36] Huang, H. Y.; Wu, H. R.; Wei, F.; Wang, D.; Liu, L. Org. Lett. 2015, 17, 3702.

[37] Qian, P.; Zha, Z. G.; Wang, Z. Y. ChemElectroChem 2020, 12, 2527.

[38] Yang, L.; Xu, G. H.; Ma, J. J.; Yang, Q.; Feng, A.; Cui, J. G. Chin. J. Org. Chem. 2020, 40, 28 (in Chinese).

(杨柳, 许国贺, 马晶军, 杨倩, 冯安, 崔景港, 有机化学, 2020, 40, 28.)

[39] Hofmann, A. W. Chem. Ber. 1883, 16, 558.

[40] Armas, P. D.; Carrau, R.; Concepción, J. I.; Francisco, C. G.; Hernández, R.; Suárez, E. Tetrahedron Lett. 1985, 26, 2493.

[41] Dorta, R. L.; Francisco, C. G.; Suárez, E. J. Chem. Soc., Chem. Commun. 1989, 1168.

[42] Francisco, C. G.; Herrera, A. J.; Kennedy, A. R.; Melián, D.; Suárez, E. Angew. Chem., Int. Ed. 2002, 41, 856.

[43] Paz, N. R.; Rodríguez-Sosa, D.; Valdés, H.; Marticorena, R.; Melián, D.; Copano, M. B.; González, C. C.; Herrera, A. J. Org. Lett. 2015, 17, 2370.

[44] Martínez, C.; Muñiz, K. Angew. Chem., Int. Ed. 2015, 54, 8287.

[45] Castillo, E. D.; Muñiz, K. Org. Lett. 2019, 21, 705.

[46] Barluenga, J.; González, J. M.; Campos, P. J.; Asensio, G. Angew. Chem., Int. Ed. 1985, 24, 319.

[47] Zhdankin, V. V.; Koposov, A. Y.; Yashin, N. V. Tetrahedron Lett. 
2002, 43, 5735.

[48] Carlsson, A. C. C.; Mehmeti, K.; Uhrbom, M.; Karim, A.; Bedin, M.; Puttreddy, R.; Kleinmaier, R.; Neverov, A. A.; Nekoueishahraki, B.; Gräfenstein, J.; Rissanen, K.; Erdélyi, M. J. Am. Chem. Soc. 2016, 138, 9853.

[49] Duhamel, T.; Martínez, M. D.; Sideri, I. K.; Muñiz, K. ACS Catal. 2019, 9, 7741 .

[50] Bosnidou, A. E.; Duhamel, T.; Muñiz, K. Eur. J. Org. Chem. 2020, 2020, 6361 .

[51] Bosnidou, A. E.; Muñiz, K. Angew. Chem., Int. Ed. 2019, 58, 7485.

[52] Zhang, D.; Wang, H.; Cheng, H. C.; Hernández, J. G.; Bolm, C. Adv. Synth. Catal. 2017, 359, 4274.

[53] Genovino, J.; Lütz, S.; Sames, D.; Touré, B. B. J. Am. Chem. Soc. 2013, 135, 12346

[54] Ripper, J. A.; Tiekink, E. R. T.; Scammells, P. J. Bioorg. Med. Chem. Lett. 2001, 11, 443.

[55] Lancefield, C. S.; Zhou, L.; Lébl, T.; Slawin, A. M. Z.; Westwood, N. J. Org. Lett. 2012, 14, 6166.

[56] Shu, X. Z.; Xia, X. F.; Yang, Y. F.; Ji, K. G.; Liu, X. Y.; Liang, Y. M. J. Org. Chem. 2009, 74, 7464.

[57] Zhu, Y.; Shao, L. D.; Deng, Z. T.; Bao, Y.; Shi, X.; Zhao, Q. S. J. Org. Chem. 2018, 83, 10166.

[58] Kanyiva, K. S.; Tane, M.; Shibata, T. J. Org. Chem. 2019, 84, 12773.

[59] Wappes, E. A.; Nakafuku, K. M.; Nagib, D. A. J. Am. Chem. Soc. 2017, 139, 10204

[60] Prusinowski, A. F.; Twumasi, R. K.; Wappes, E. A.; Nagib, D. A. J. Am. Chem. Soc. 2020, 142, 5429.

[61] Zhao, P.; Wu, X.; Geng, X.; Wang, C.; Zhou, Y.; Wu, Y. D.; Wu, A. X. J. Org. Chem. 2019, 84, 8322.

[62] Monga, A.; Bagchi, S.; Sharma, A. New J. Chem. 2018, 42, 1551.

[63] Gao, Q. H.; Liu, S.; Wu, X.; Zhang, J. J.; Wu, A. X. J. Org. Chem. 2015, 80, 5984.

[64] Gao, Q. H.; Liu, S.; Wu, X.; Wu, A. X. Org. Lett. 2014, 16, 4582.

[65] Wu, X.; Geng, X.; Zhao, P.; Zhang, J. J.; Wu, Y. D.; Wu, A. X. Chem. Commun. 2017, 53, 3438.

[66] Wu, X.; Geng, X.; Zhao, P.; Zhang, J. J.; Gong, X. X.; Wu, Y. D.; Wu, A. X. Org. Lett. 2017, 19, 1550.

[67] Wu, X.; Zhao, P.; Geng, X.; Zhang, J. J.; Gong, X. X.; Wu, Y. D.; Wu, A. X. Org. Lett. 2017, 19, 3319.

[68] Wu, X.; Geng, X.; Zhao, P.; Wu, Y. D.; Wu, A. X. Org. Lett. 2017, 19,4584 .

[69] Xue, W. J.; Gao, Q. H.; Wu, A. X. Tetrahedron Lett. 2015, 56, 7115.

[70] Liu, S.; Xi, H. L.; Zhang, J. J.; Wu, X.; Gao, Q. H.; Wu, A. X. Org. Biomol. Chem. 2015, 13, 8807.

[71] Wu, X.; Gao, Q. H.; Geng, X.; Zhang, J. J.; Wu, Y. D.; Wu, A. X. Org. Lett. 2016, 18, 2507.

[72] Qun, C.; Zhuang, S. Y.; Yang, M.; Peng, N.; Liu, Y.; Wu, A. X. Tetrahedron 2019, 75, 130756.

[73] Wang, C.; Geng, X.; Zhao, P.; Zhou, Y.; Wu, Y. D.; Wu, A. X. Org. Chem. Front. 2019, 6, 2534.

[74] Weng, W. Z.; Gao, Y. H.; Zhang, X.; Liu, Y. H.; Shen, Y. J.; Zhu, Y. P.; Sun, Y. Y.; Meng, Q. G.; Wu, A. X. Org. Biomol. Chem. 2019, 17, 2087.

[75] Zhang, Z. Y.; Xie, C. X.; Tan, X. C.; Song, G. L.; Wen, L. L.; Gao, H.; Ma, C. Org. Chem. Front. 2015, 2, 942.

[76] Xie, C. X.; Zhang, Z. Y.; Yang, B. C.; Song, G. L.; Gao, H.; Wen, L. L.; Ma, C. Tetrahedron 2015, 71, 1831.

[77] Satish, G.; Polu, A.; Ramar, T.; Ilangovan, A. J. Org. Chem. 2015, $80,5167$.

[78] Liang, Y. F.; Wu, K.; Song, S.; Li, X. Y.; Huang, X. Q.; Jiao, N. Org. Lett. 2015, 17, 876

[79] Liang, Y. F.; Li, X. Y.; Wang, X. Y.; Zou, M. C.; Tang, C. H.; Liang, Y. J.; Song, S.; Jiao, N. J. Am. Chem. Soc. 2016, 138, 12271.

[80] Liang, Y. F.; Song, S.; Ai, L. S.; Li, X. W.; Jiao, N. Green Chem. 2016, 18,6462

[81] Mupparapu, N.; Vishwakarma, R. A.; Ahmed, Q. N. Tetrahedron 2015, 71,3417
[82] Yang, L.; Shi, X.; Hu, B. Q.; Wang, L. X. Asian J. Org. Chem. 2016, 5, 494

[83] Sun, P. F.; Yang, D. S.; Wei, W.; Sun, X. J.; Zhang, W. H.; Zhang, H.; Wang, Y.; Wang, H. Tetrahedron 2017, 73, 2022.

[84] Siddaraju, Y.; Prabhu, K. R. Org. Lett. 2016, 18, 6090.

[85] Siddaraju, Y.; Prabhu, K. R. Org. Biomol. Chem. 2017, 15, 5191.

[86] Chen, S. H.; Li, Y.; Chen, J. Y.; Xu, X. H.; Su, L. B.; Tang, Z.; Au, C. T.; Qiu, R. H. Synlett 2016, 27, 2339.

[87] Xi, L. Y.; Zhang, R. Y.; Shi, L.; Chen, S. Y.; Yu, X. Q. Beilstein J. Org. Chem. 2016, 12, 1072.

[88] Xiong, M. T.; Gao, Z.; Liang, X.; Cai, P. F.; Zhu, H. P.; Pan, Y. J. Chem. Commun. 2018, 54, 9679.

[89] Barak, D. S.; Dighe, S. U.; Avasthi, I.; Batra, S. J. Org. Chem. 2018, 83, 3537.

[90] Rahim, A.; Shaik, S. P.; Baig, M. F.; Alarifi, A.; Kamal, A. Org Biomol. Chem. 2018, 16, 635.

[91] Mani, G. S.; Donthiboina, K.; Shankaraiah, N.; Kamal, A. New J. Chem. 2019, 43, 15999.

[92] Salihila, J.; Silva, L.; Pulgar, H. P. D.; Molina, A. Q.; González-Coloma, A.; Olmeda, A. S.; Moral, J. F. Q. D.; Barrero, A. F. J. Org. Chem. 2019, 84, 6886.

[93] Chen, H.; Liu, L.; Huang, T. Z.; Chen, J.; Chen, T. Q. Adv. Synth. Catal. 2020, 362, 3332.

[94] Liu, M.; Chen, T. Q.; Zhou, Y. B.; Yin, S. F. Catal. Sci. Technol. 2016, 6, 5792.

[95] Liu, M.; Chen, X.; Chen, T. Q.; Xu, Q.; Yin, S. F. Org. Biomol. Chem. 2017, 15, 9845.

[96] Chen, H.; Liu, L.; Huang, T. Z.; Jing, C.; Chen, T. Q. Org. Biomol. Chem. 2020, 16, 3332.

[97] Cao, Y.; Liu, L.; Huang, T.; Chen, T. Q. New J. Chem. 2020, 44, 8697.

[98] Jayram, J.; Xulu, B. A.; Jeena, V. Tetrahedron 2019, 75, 130617.

[99] Shang, Z. H.; Sun, J.; Guo, J. S.; Sun, Y. Y.; Weng, W. Z.; Zhang, Z. X.; Li, Z. J.; Zhu, Y. P. Tetrahedron 2020, 76, 130887.

[100] Grigoropoulou, G.; Clark, J. H.; Elings, J. A. Green Chem. 2003, 5 , 1.

[101] Faveri, G. D.; Ilyashenko, G.; Watkinson, M. Chem. Soc. Rev. 2011 $40,1722$.

[102] Tang, S.; Liu, K.; Long, Y.; Qi, X. T.; Lan, Y.; Lei, A. W. Chem. Commun. 2015, 51, 8769.

[103] Tang, S.; Liu, K.; Long, Y.; Gao, X. L.; Gao, M.; Lei, A. W. Org. Lett. 2015, 17, 2404.

[104] Cao, H.; Yuan, J. W.; Liu, C.; Hu, X. Q.; Lei, A. W. RSC Adv. 2015 $5,41493$.

[105] Samanta, S.; Donthiri, R. R.; Dindaa, M.; Adimurthy, S. RSC $A d v$. 2015, 5, 66718 .

[106] Vadagaonkar, K. S.; Kalmode, H. P.; Murugan, K.; Chaskar, A. C. RSC Adv. 2015, 5, 5580.

[107] Vadagaonkar, K. S.; Kalmode, H. P.; Prakash, S.; Chaskar, A. C. Synlett 2015, 26, 1677.

[108] Verma, A.; Patel, S.; Meenakshi; Kumar, A.; Yadav, A.; Kumar, S.; Jana, S.; Sharma, S.; Prasad, C. D.; Kumar, S. Chem. Commun. 2015, 51, 1371.

[109] Luo, W. K.; Shi, X.; Zhou, W.; Yang, L. Org. Lett. 2016, 18, 2036.

[110] Shi, X.; Zhang, F.; Luo, W. K.; Yang, L. Synlett 2017, 28, 494.

[111] Luo, W. K.; Xu, C. L.; Yang, L. Tetrahedron Lett. 2019, 60 151328

[112] Shantharjun, B.; Rajeswari, R.; Vani, D.; Unnava, R.; Sridhar, B.; Reddy, K. R. Asian J. Org. Chem. 2019, 8, 2162.

[113] Zhu, D.; Luo, W. K.; Yang, L.; Ma, D. Y. Org. Biomol. Chem. 2017, 15,7112 .

[114] Chen, Z. K.; Li, H. L.; Dong, W. P.; Miao, M. Z.; Ren, H. J. Org Lett. 2016, 18, 1334.

[115] Wei, W.; Cui, H. H.; Yang, D. S.; Liu, X. X.; He, C. L.; Dai, S. C.; Wang, H. Org. Chem. Front. 2017, 4, 26.

[116] Chen, K. L.; Gao, B.; Shang, Y. G.; Du, J. Y.; Gu, Q. L.; Wang, J. X. Org. Biomol. Chem. 2017, 15, 8770.

[117] Sun, K.; Lv, Y. H.; Chen, Y. H.; Zhou, T. T.; Xing, Y. Y.; Wang, X. 
Org. Biomol. Chem. 2017, 15, 4464.

[118] Deb, M. L.; Borpatra, P. J.; Saikia, P. J.; Baruah, P. K. Synlett 2017, $28,461$.

[119] Long, J. G.; Cao, X.; Zhu, L. Z.; Qiu, R. H.; Au, C. T.; Yin, S. F.; Iwasaki, T.; Kambe, N. Org. Lett. 2017, 19, 2793.

[120] Yaragorla, S.; Babu, V. P. Tetrahedron Lett. 2017, 58, 1879.

[121] Wang, J.; Zhang, F. D.; Tang, D.; Wu, P.; Zhang, X. G.; Chen, B. H. RSC Adv. 2017, 7, 24594.

[122] Wei, W. T.; Zhu, W. M.; Bao, W. H.; Chen, W. T.; Huang, Y. L.; Gao, L. H.; Xu, X. D.; Wang, Y. N.; Chen, G. P. ACS Sustainable Chem. Eng. 2018, 6, 5615.

[123] Chen, C.; Liu, W. B.; Zhou, P.; Liu, H. L. RSC Adv. 2017, 7, 20394.

[124] Duhamel, T.; Stein, C. J.; Martínez, C.; Reiher, M.; Muñiz, K. ACS Catal. 2018, 8, 3918.

[125] Becker, P.; Duhamel, T.; Stein, C. J.; Reiher, M.; Muñiz, K. Angew. Chem., Int. Ed. 2017, 56, 8004.

[126] Duhamel, T.; Muñiz, K. Chem. Commun. 2019, 55, 933.

[127] Wang, H. X.; Wei, T. Q.; Xu, P.; Wang, S. Y.; Ji, S. J. J. Org. Chem. 2018, 83, 13491.

[128] Liu, L.; Tan, C.; Fan, R.; Wang, Z. H.; Du, H. G.; Xu, K.; Tan, J. J. Org. Biomol. Chem. 2019, 17, 252.

[129] Valeur, E.; Bradley, M. Chem. Soc. Rev. 2009, 38, 606.

[130] El-Faham, A.; Albericio, F. Chem. Rev. 2011, 111, 6557.

[131] Li, J.; Lear, M. J.; Kawamoto, Y.; Umemiya, S.; Wong, A. R.; Kwon, E.; Sato, I.; Hayashi, Y. Angew. Chem., Int. Ed. 2015, 127, 13178.

[132] Huang, H. Y.; Wu, H. R.; Wei, F.; Wang, D.; Liu, L. Org. Lett. 2015, 17,3702 .

[133] Nguyen, T. B.; Ermolenko, L.; Retailleau, P.; Al-Mourabit, A. Org. Lett. 2016, 18, 2177.

[134] Sudo, Y.; Yamaguchi, E.; Itoh, A. Org. Lett. 2017, 19, 1610.

[135] Yang, J. Y.; Xie, D. T.; Zhou, H. Y.; Chen, S. W.; Huo, C. D.; Li, Z. Org. Chem. Front. 2018, 5, 1325.

[136] Tuo, X. L.; Chen, S. P.; Jiang, P. Y.; Ni, P. H.; Wang, X. D.; Deng, G. J. $R S C A d v$. 2020, 10,8348 .

[137] Lv, Y. H.; Sun, K.; Wang, T. T.; Li, G.; Pu, W. Y.; Chai, N. N.; Shen, H. H.; Wu, Y. T. RSC Adv. 2015, 7, 72142.

[138] Lv, Y. H.; Sun, K.; Wang, T. T.; Wu, Y. T.; Li, G.; Pu, W. Y.; Mao, S. K. Asian J. Org. Chem. 2016, 5, 325.

[139] Lv, Y. H.; Pu, W. Y.; Niu, J. J.; Wang, Q. Q.; Chen, Q. Tetrahedron Lett. 2018, 59, 1497.

[140] Zhou, Y.; Chen, J. W.; Elsayed, A. A.; Zhang, Z. G.; Bao, Z. B.; Yang, Q. W.; Yang, Y. W.; Ren, Q. L. Catal. Lett. 2019, 149, 574.

[141] Sridhar, A.; Selvaraj, M. ChemistrySelect 2019, 4, 1890.

[142] Zhang, J.; Zhao, X.; Liu, P.; Sun, P. P. J. Org. Chem. 2019, 84, 12596.

[143] Tan, C.; Liu, Y. G.; Liu, X. Y.; Jia, H. X.; Xu, K.; Huang, S. H.; Wang, W. J.; Tan, J. J. Org. Chem. Front. 2020, 7, 780.

[144] Castanedo, G.; Liu, Y. Z.; Crawford, J. J.; Braun, M. G. J. Org. Chem. 2016, $81,8617$.

[145] Wang, P.; Gao, X. L.; Huang, P. F.; Lei, A. W. ChemCatChem 2020, $1,27$.

[146] Hu, X.; Nie, L.; Zhang, G. T.; Lei, A. W. Angew. Chem., Int. Ed. 2020, $59,15238$.

[147] Tang, S.; Wang, S. Y.; Liu, Y. C.; Cong, H. J.; Lei, A. W. Angew.
Chem., Int. Ed. 2018, 57, 4737.

[148] Liu, K.; Song, C. L.; Wu, J. R.; Deng, Y. Q.; Tang, S.; Lei, A. W. Green Chem. 2019, 21, 765 .

[149] Liang, S.; Zeng, C. C.; Tian, H. Y.; Sun, B. G.; Luo, X. G.; Ren, F. Z. J. Org. Chem. 2016, 81, 11565.

[150] Liang, S.; Zeng, C. C.; Tian, H. Y.; Sun, B. G.; Luo, X. G.; Ren, F. Z. Adv. Synth. Catal. 2018, 360, 1444.

[151] Qian, P.; Yan, Z.; Zhou, Z. H.; Hu, K. F.; Wang, J. W.; Li, Z. B.; Zha, Z. G.; Wang, Z. Y. Org. Lett. 2018, 20, 6359.

[152] Qian, P.; Zhou, Z. H.; Hu, K. F.; Wang, J. W.; Li, Z. B.; Zha, Z. G.; Wang, Z. Y. Org. Lett. 2019, 21, 6403.

[153] Wang, J. W.; Qian, P.; Hu, K. F.; Zha, Z. G.; Wang, Z. Y. ChemElectroChem 2019, 16, 4292 .

[154] Rafiee, M.; Wang, F.; Hruszkewycz, D. P.; Stahl, S. S. J. Am. Chem. Soc. 2017, 140, 22

[155] Wang, H. Q.; Zhang, J. J.; Tan, J. J.; Xin, L. L.; Li, Y. P.; Zhang, S.; Xu, K. Org. Lett. 2018, 20, 2505.

[156] Mohan, D. C.; Ravi, C.; Pappula, V.; Adimurthy, S. J. Org. Chem. 2015, 80, 6846.

[157] Zhao, Z. G.; Wang, T.; Yuan, L.; Ji, X. W.; Zhao, J. F. RSC $A d v$ 2015, 5, 75386.

[158] Gao, Q. H.; He, S.; Wu, X.; Zhang, J. J.; Bai, S. P.; Wu, Y. D.; Wu, A. X. Org. Chem. Front. 2018, 5, 765.

[159] Iwahama, T.; Syojyo, K.; Sakaguchi, S.; Ishii, Y. Org. Process Res. Dev. 1998, 2, 255.

[160] Wu, X.; Zhao, P.; Geng, X.; Wang, C.; Wu, Y. D.; Wu, A. X. Org. Lett. 2018, 20, 688.

[161] Geng, X.; Wang, C.; Huang, C.; Bao, Y.; Zhao, P.; Zhou, Y.; Wu, Y D.; Feng, L. L.; Wu, A. X. Org. Lett. 2020, 22, 140.

[162] Wu, X.; Zhang, J. J.; Liu, S.; Gao, Q. H.; Wu, A. X. Adv. Synth. Catal. 2016, 358, 218.

[163] Yi, X. L.; Xi, C. J. Tetrahedron 2017, 73, 1311.

[164] Ujwaldev, S. M.; Rohit, K. R.; Harry, N. A.; Anilkumar, G. Tetrahedron Lett. 2019, 13, 150950.

[165] Sangeetha, S.; Sekar, G. Org. Lett. 2018, 21, 75.

[166] Sangeetha, S.; Sekar, G. Chem Commun. 2020, 56, 10906.

[167] Chen, L. S.; Zhang, L. B.; Tian, Y.; Li, J. H.; Liu, Y. Q. Eur. J. Org. Chem. 2020, 2020, 5523.

[168] Zhang, H. W.; Muñiz, K. ACS Catal. 2017, 7, 4122.

[169] Yavari, I.; Hosseinpour, R.; Skoulika, S. Synlett 2015, 26, 380

[170] Usami, K.; Nagasawa, Y.; Yamaguchi, E.; Tada, N.; Itoh, A. Org. Lett. 2016, 18, 8 .

[171] Reddy, N. N. K.; Mohan, D. C.; Adimurthy, S. Tetrahedron Lett. 2016, 57, 1074.

[172] Pang, X. B.; Xiang, L. K.; Ma, J. X.; Yang, X. D.; Yan, R. L. RSC $A d v$. 2016, 6, 111713.

[173] Rong, H. J.; Yao, J. J.; Li, J. K.; Qu, J. J. Org. Chem. 2017, 82, 5557.

[174] Liu, R. H.; Wang, Y. K.; Weng, Y. M.; Yao, C. P.; Zhang, Y.; Zhu, G. Z.; He, X. A.; Xu, K. P.; Tan, G. S. Synlett 2017, 28, 1083.

[175] Liu, X. Z.; Zhou, Y. X.; Yang, Z. Q.; Li, Q.; Zhao, L.; Liu, P. J. J. Org. Chem. 2018, 83, 4665.

[176] Zhang, J.; Zheng, T. T.; Zhang, J. D. Eur. J. Org. Chem. 2020, 2020, 860 . 